\title{
Phosphinidene-Bridged Binuclear Complexes
}

M. Esther García, ${ }^{a}$ Daniel García-Vivó, ${ }^{a}$ Alberto Ramos, ${ }^{\mathrm{b}}$ Miguel A. Ruiz ${ }^{\mathrm{a}, *}$

${ }^{a}$ Departamento de Química Orgánica e Inorgánica/IUQOEM, Universidad de Oviedo, C/ Julián

Clavería, 8, 33071 Oviedo (Spain).

${ }^{\mathrm{b}}$ Departamento de Química Inorgánica, Orgánica y Bioquímica, Instituto Regional de Investigación Científica Aplicada, Universidad de Castilla-La Mancha, Campus Universitario, E13071 Ciudad Real (Spain).

\begin{abstract}
This article contains a comprehensive review of the work carried out within the last three decades on the synthesis, structural studies and reactivity of the binuclear complexes of transition and lanthanide elements bearing bridging phosphinidene (PR) ligands. The latter are grouped into three different classes according to their geometry and electronic distribution: pyramidal, symmetric planar trigonal and asymmetric planar trigonal. Different reactivity patterns can be then outlined for each of these classes of metal complexes, which differ in many ways from those characterizing the extensively studied chemical behaviour of mononuclear phosphinidene complexes.
\end{abstract}

\section{Keywords}

Transition metal complexes

Phosphinidene complexes

Binuclear complexes

Synthesis

Reactivity

Structure and bonding

\section{Contents}

1. Introduction

2. Phosphinidene bonding conventions

3. Synthetic methods 
3.1. Salt metathesis

3.1.1. Reactions with dihalophosphines

3.1.2. Reactions with metallophosphines

3.1.3. Reactions with anionic phosphinidene complexes

3.1.4. Related processes

3.2. Deprotonation of phosphanyl (PHR) ligands

3.3. Dehydrohalogenation

3.4. Elimination of $\mathrm{H}_{2}$ or $\mathrm{RH}$

3.5. Cleavage of $\mathrm{P}-\mathrm{H}$ bonds at unsaturated metal complexes

3.6. From other phosphinidene complexes

3.7. From dihalophosphine or halophosphanyl complexes

3.8. From "naked" phosphorus complexes

3.9. Other methods

4. Structure and bonding

4.1. Pyramidal phosphinidene complexes

4.2. Symmetric trigonal planar phosphinidene complexes

4.3. Asymmetric trigonal planar phosphinidene complexes

5. Reactivity

5.1. Pyramidal phosphinidene complexes

5.1.1. Reactions with simple electrophiles

5.1.2. Reactions with molecules containing $\mathrm{E}-\mathrm{H}$ bonds

5.1.3. Reactions with unsaturated organic molecules

5.1.3.1. Reactions with molecules containing $\mathrm{C}-\mathrm{C}$ multiple bonds

5.1.3.2. Reactions with molecules containing $\mathrm{N}-\mathrm{N}$ multiple bonds

5.1.4. Oxidation reactions with group 16 elements and related processes

5.1.5. Addition of metal fragments

5.1.6. Thermolysis and photolysis

5.1.7. Reactivity of the transient diradical $\left[\mathrm{Fe}_{2}\left(\mu-\mathrm{PN}^{i} \mathrm{Pr}_{2}\right)_{2}(\mathrm{CO})_{6}\right]$

5.2. Symmetric trigonal planar phosphinidene complexes

5.2.1. Reactions with simple nucleophiles

5.2.2. Reactions with molecules containing $\mathrm{E}-\mathrm{H}$ bonds $(\mathrm{E}=\mathrm{B}, \mathrm{P})$

5.2.3. Reactions with unsaturated organic molecules

5.2.3.1. Reactions with molecules containing $\mathrm{C}-\mathrm{C}$ multiple bonds 
5.2.3.2. Reactions with molecules containing $\mathrm{C}-\mathrm{N}$ multiple bonds

5.2.3.3. Reactions with molecules containing $\mathrm{N}-\mathrm{N}$ multiple bonds

5.2.3.4. Reactions with molecules containing $\mathrm{C}-\mathrm{E}$ multiple bonds $(\mathrm{E}=\mathrm{O}, \mathrm{S}$,

P)

5.2.4. Reactions with other p-block elements and compounds

5.2.5. Addition of metal fragments

5.2.6. Thermolysis and photolysis

5.3. Asymmetric trigonal planar phosphinidene complexes

5.3.1. Reactions with simple neutral ligands

5.3.2. Reactions with electrophiles

5.3.3. Reactions with unsaturated organic molecules

5.3.4. Reactions with other p-block elements and compounds

5.3.5. Addition of metal fragments

5.3.6. Thermolysis and photolysis

\section{Introduction}

The chemistry of transition-metal phosphinidene complexes (PR; phosphanylidenes according to IUPAC recommended nomenclature) has emerged during the last decades as an active area of research within the organometallic field, this being in part due to its direct analogy with the ubiquitous carbene complexes [1]. This relationship holds particularly well for mononuclear compounds with bent phosphinidene ligands, which can be roughly divided in two groups, displaying either electrophilic or nucleophilic behaviour reminiscent of that observed for Fischer or Schrock carbenes, respectively. In turn, these analogies can be traced back, in a simplified manner, to two different extreme descriptions of the $\mathrm{M}-\mathrm{P}$ bond in these compounds, as single dative or double bond, respectively (A and $\mathbf{B}$ in Chart 1). Then, it is not surprising that these compounds show an extraordinary reactivity derived from the combined presence of multiple $\mathrm{M}-\mathrm{P}$ bonding, a phosphorus lone pair and a low lying $\mathrm{P}$ centred LUMO. Such a chemical versatility makes these compounds to act as valuable synthons for the preparation of diverse organophosphorus derivatives or novel metal complexes, and their chemistry has been the focus of several excellent reviews [2]. 


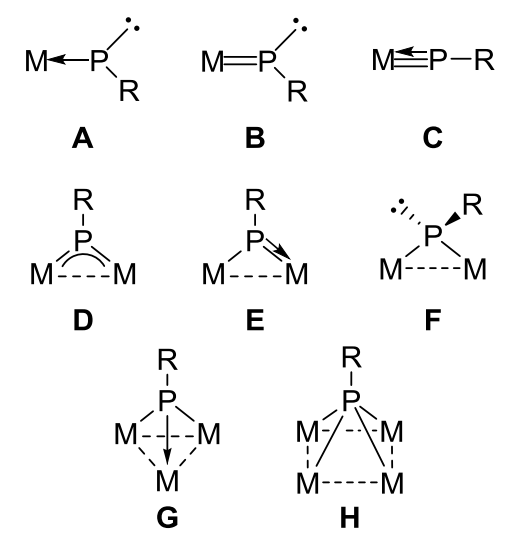

Chart 1. Coordination modes of the phosphinidene ligand.

In contrast to the "carbene-like" chemistry, the presence of a lone electron pair at the phosphorus atom of phosphinidene complexes opens up the possibility for these ligands to act as four-electron donors, thus enabling them to bind efficiently up to four metal atoms with a wide variety of coordination modes ( $\mathbf{D}-\mathbf{H}$, Chart 1). Obviously, the nature of the M-P bonds changes dramatically among the different coordination modes so does the corresponding reactivity. In particular, the M-P bonds are essentially single for ligands bound to three or four metals (modes $\mathbf{G}$ and $\mathbf{H}$ ), a situation for which little reactivity can be expected. Indeed, $\mu_{3}$ - or $\mu_{4}$-PR groups are good supporting ligands in clusters, efficient to maintain their nuclearity in the course of reactions, although a limited number of examples exists in which an alteration of the M-P bond occurs for these compounds. In contrast, binuclear compounds retain either M-P bond multiplicity (types $\mathbf{D}$ or $\mathbf{E}$ ) or a chemically active phosphorus lone pair (type $\mathbf{F}$ ), therefore high reactivity can be anticipated for these systems. Indeed, after the pioneering work carried out in the late seventies and early eighties (mainly centred on type $\mathbf{D}$ complexes and reviewed by Huttner in 1986) [3], the chemistry of binuclear phosphinidene complexes has expanded exponentially to include complexes of almost every transition-metal element. More recently, even some rare-earth elements have been added to the panoply of phosphinidene complexes, in spite of the less favoured M-P interactions in these cases (hard-soft combinations). Recent work from several research groups has highlighted the great versatility of all these compounds, which proved to be quite reactive towards an immense variety of organic molecules, transition metal complexes and $p$-block compounds. Expectedly, the chemical reactivity of these molecules is substantially influenced by the coordination mode attained by the phosphinidene ligand, with the pyramidal complexes (type F) exhibiting a marked nucleophilicity at the phosphorus position, while that of the symmetric and asymmetric trigonal planar complexes (types $\mathbf{D}$ and $\mathbf{E}$ ) is more unpredictable, especially for systems also having $\mathbf{M}-\mathbf{M}$ multiple bonds. 
The main goal of this contribution is to review comprehensively the last decades of work (from 1986 to mid 2016) on binuclear complexes having bridging phosphinidene ligands. We will discuss the most common routes used for their synthesis, the main structural parameters associated to the three coordination modes known to date (D-F), and the reactivity studies carried out on these complexes, with particular attention to the processes in which the phosphinidene group is directly involved, and not a mere spectator. Thus, we aim to provide a global vision of the state-of-the-art in the chemistry of these versatile complexes, thus setting a concise reference which will be of use for further progress in the field to follow in the near future. Finally, we must note that some minor parts of the work covered by this review have appeared scattered over different earlier contributions [4a, b, 2b, $4 \mathrm{c}-\mathrm{f}]$.

\section{Phosphinidene bonding conventions}

Before we move on to the description of the synthetic methodologies used for the preparation of binuclear phosphinidene complexes, it seems reasonable to provide a classification of the different bonding modes of these ligands when bridging two metal atoms as well as the different schemes used to represent the distinct bonding situations.

Conceptually, the simplest possible coordination mode of a $\mu_{2}$-phosphinidene ligand would follow from the double metallation of a phosphine molecule, then retaining a $s p^{3}$ hybridisation of the $\mathrm{P}$ atom and hence a pyramidal geometry, with a P-based lone electron pair (F in Chart 1). This arrangement implies that the phosphinidene ligand acts as a twoelectron donor, hence two single $\mathrm{M}-\mathrm{P}$ bonds are to be expected following from two $\sigma$-type interactions between half-filled $s p^{3}$ orbitals of the $\mathrm{P}$ atom and the corresponding half-filled metal-based orbitals of proper symmetry. As discussed later on, the number of complexes displaying this coordination mode is remarkably limited, and its chemistry is typically dictated by the high nucleophilicity of the $\mathrm{P}$ atom derived from the presence of the lone electron pair at this site.

On the other hand, the phosphinidene ligand can also act as a four-electron donor, thanks to the participation of the P-based lone electron pair in $\pi$-bonding with the dimetal centre. In fact, the vast majority of $\mu_{2}$-phosphinidene complexes known to date display a trigonal planar geometry around the $\mathrm{P}$ atom, indicative of $\mathrm{M}-\mathrm{P} \pi$-bonding. However, two different 
types of complexes have been reported with trigonal $\mathrm{P}$ environments, namely, the symmetric and asymmetric ones ( $\mathbf{D}$ and $\mathbf{E}$ in Chart 1). The main factor at the origin of these two coordination modes is the presence of two metal fragments with identical or different electron counts. In the former case, the M-P bonding generally follows from two $\sigma$-type interactions and a $\pi$-type three-centre two-electron interaction that can be represented through two canonical forms (I and $\boldsymbol{I I}$ in Chart 2) or by a delocalised diagram (III in Chart 2 ). The latter will be the representation used in the following sections for the symmetrically bridged complexes. As for the asymmetric coordination, most examples known to date contain a phosphinidene ligand bridging 15- and 17-electron metal fragments. Although DFT calculations carried out for some of these complexes (to be discussed later on) proved that in most cases there is a measurable delocalisation of the $\pi$-bonding electrons over the whole $\mathrm{M}-\mathrm{P}-\mathrm{M}$ skeleton, yet the dominant contribution to the ground-state structure seems to be better represented by canonical form $\boldsymbol{I V}$, the one emphasizing localisation of the $\mathrm{M}-\mathrm{P} \pi$ bonding with the 15-electron metal fragment, and this is the representation we will use in the next pages for compounds of this category. In such a localised description, bonding with the 15-electron metal fragment would be comparable to the metal-phosphorus interaction expected for a terminal three-electron donor phosphanyl ligand $\left(-\mathrm{PR}_{2}\right)$, and a single bond interaction will connect the phosphorus atom to the 17 -electron metal fragment. It is important to note that, for both trigonal coordination modes ( $\mathbf{D}$ and $\mathbf{E}$ ), the corresponding ${ }^{31} \mathrm{P}$ NMR chemical shifts are typically quite high. This behaviour has been explained by assuming that the small HOMO-LUMO gap in these molecules (in turn derived from the presence of $\mathrm{M}-\mathrm{P} \pi$-bonding) allows for a significant admixture of excited states into the ground-state electronic configuration, eventually resulting in an enhancement of the paramagnetic contribution to the ${ }^{31} \mathrm{P}$ chemical shift [5].
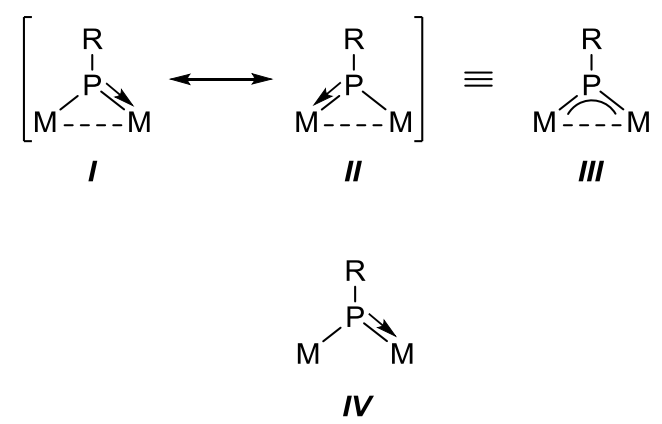

Chart 2. Canonical forms representing $\mathrm{M}-\mathrm{P}$ bonding in symmetric (top) and asymmetric (bottom) trigonal planar phosphinidene-bridged complexes. 


\section{Synthetic methods}

\subsection{Salt metathesis}

Doubtless, the most common way to access binuclear complexes with bridging phosphinidene ligands is based on salt metathesis strategies. Conceptually, this methodology can be accomplished at least in three possible ways (Scheme 1): (1) reaction of a metallate with the desired dihalophosphine (typically a dichlorophosphine), (2) reaction of a halide complex with a metallated phosphine, and (3) reaction of an anionic mononuclear phosphinidene complex with a halide complex. As shown below, examples of these three methods are known, as also are some variants in which the salt metathesis step is followed by further reactions which finally generate the phosphinidene complex (i.e. methane elimination, silyl group redistribution, etc.) (4).

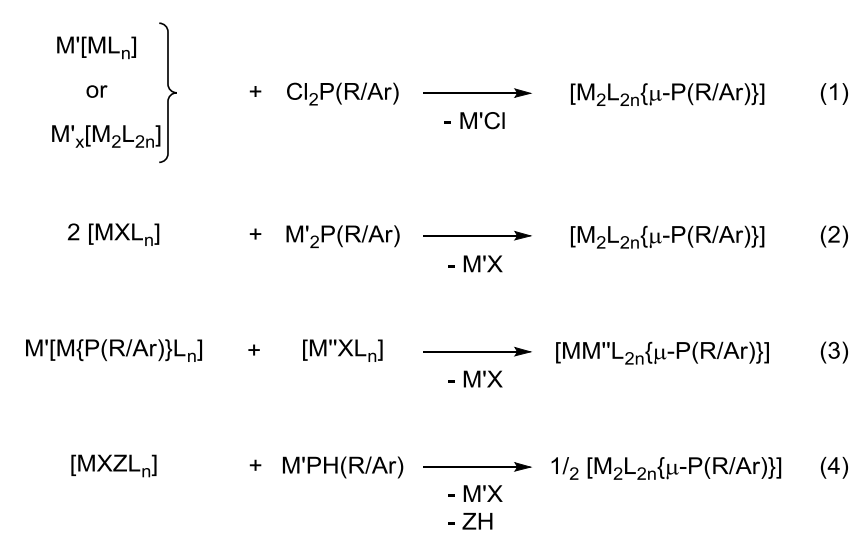

\section{Scheme 1}

\subsubsection{Reactions with dihalophosphines}

The reaction of a two-fold excess of a transition-metal anionic complex with the corresponding dihalophosphine is conceptually one of the easiest ways to access binuclear complexes with bridging phosphinidenes. In practice, this methodology has been widely used for the preparation of different homonuclear phosphinidene complexes, especially those derived from readily available transition-metal carbonylates. 
Thus, the group of Cowley used this methodology for the preparation of different V [6], Co [7], Mo $[8,7 \mathrm{~b}]$ and $\mathrm{W}[7 \mathrm{~b}]$ complexes (Scheme 2 and entries 1-5 in Table 1) bearing phosphinidene ligands with sterically demanding substituents such as Mes* $\left(\mathrm{Mes}^{*}=2,4,6-{ }^{t} \mathrm{Bu}_{3} \mathrm{C}_{6} \mathrm{H}_{2}\right)$ or TMP $(\mathrm{TMP}=$ 2,2,6,6-tetramethylpiperidyl). However, the generality of this method was limited. For instance, the reaction of $\mathrm{K}\left[\mathrm{Co}(\mathrm{CO})_{4}\right]$ with halophosphines having smaller substituents such as $\mathrm{Ph}, \mathrm{NEt}_{2}$ or $\mathrm{CH}\left(\mathrm{SiMe}_{3}\right)_{2}$ failed to produce binuclear phosphinidenes, eventually yielding compounds of higher nuclearity in reactions likely involving the intermediate formation of binuclear phosphinidenes. Not only the steric hindrance of the phosphorus substituent is important, but also the metal centre, as this methodology also failed to produce binuclear iron phosphinidenes when using the anion $\left[\mathrm{Fe}_{2}(\mathrm{CO})_{8}\right]^{2-}[7 \mathrm{a}]$, even for the more favourable Mes*-substituted halophosphine. A second drawback of all these reactions is that the phosphinidene complexes are typically isolated in moderate to low yields, mainly because of competitive reactions, including different redox processes, to give distinct by-products such as phosphinidene clusters, diphosphenes $\mathrm{R}-\mathrm{P}=\mathrm{P}-\mathrm{R}$, diphosphines $\mathrm{R}(\mathrm{H}) \mathrm{P}-\mathrm{P}(\mathrm{H}) \mathrm{R}$ or halophosphanyl complexes $\left[\mathrm{L}_{\mathrm{n}} \mathrm{M}\{=\mathrm{P}(\mathrm{R}) \mathrm{Cl}\}\right]$. The structural characterisation of the new phosphinidene complexes included in most cases an X-ray diffraction analysis, which confirmed the symmetric trigonal planar disposition of the $\mathrm{P}$ atom in these compounds, also anticipated from the highly deshielded ${ }^{31} \mathrm{P}$ NMR resonances observed for these species (range of $\delta_{\mathrm{P}}=687-593 \mathrm{ppm}$ ).

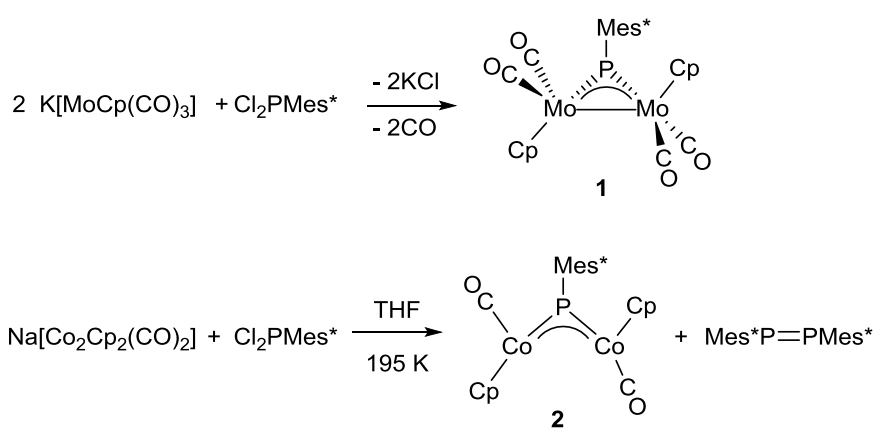

\section{Scheme 2}

Jutzi and Kroos also used this route for the preparation of $\mathrm{Cp}^{*}$-substituted phosphinidenes of the group 6 metals, $\left[\mathrm{M}_{2}(\mu-\mathrm{PCp} *)(\mathrm{CO})_{10}\right]\left(\mathrm{M}=\mathrm{Cr}(\mathbf{3})\right.$, $\mathrm{Mo}(\mathbf{4})$ and $\left.\mathrm{W}(\mathbf{5}) ; \mathrm{Cp}^{*}=\mathrm{C}_{5} \mathrm{Me}_{5}\right)$ (Scheme 3, entries 7-10 in Table 1), characterised by dramatically deshielded ${ }^{31} \mathrm{P}$ NMR resonances (range of $\delta_{\mathrm{P}}=1331-1074 \mathrm{ppm}$ ) [9]. Although all these complexes were obtained only in moderate yields, the chemical reactivity of the ditungsten compound has been thoroughly studied by the group of Scheer, which also reported its solid-state structure in 
1998 [10]. Power and co-workers had previously prepared related dichromium complexes $\left[\mathrm{Cr}_{2}(\mu-\mathrm{PR})(\mathrm{CO})_{10}\right]$ by reacting $\mathrm{Na}_{2}\left[\mathrm{Cr}(\mathrm{CO})_{5}\right]$ with $\mathrm{Cl}_{2} \mathrm{PR}\left(\mathrm{R}=4-\mathrm{Me}-2,6-{ }^{t} \mathrm{Bu}_{2} \mathrm{C}_{6} \mathrm{H}_{2} \mathrm{O}\right.$, $\left.\mathrm{N}\left(\mathrm{SiMe}_{3}\right)_{2}, \mathrm{Mes} ; \mathrm{Mes}=2,4,6-\mathrm{Me}_{3} \mathrm{C}_{6} \mathrm{H}_{2}\right)$ [11]. In the reaction with the $\mathrm{N}\left(\mathrm{SiMe}_{3}\right)_{2}$-substituted phosphine an additional phosphinidene product was the trinuclear complex $\left[\mathrm{Cr}_{3}\{\mu-\right.$ $\left.\left.\mathrm{PN}\left(\mathrm{SiMe}_{3}\right)_{2}\right\}_{2}(\mathrm{CO})_{14}\right]$, this containing a central $\mathrm{Cr}(\mathrm{CO})_{4}$ fragment bearing two phosphinidene ligands. However, as in most examples mentioned so far, low isolated yields of all these phosphinidene complexes were invariably obtained as a consequence of the formation of several side-products (i.e. diphosphene complexes). More recently, an attempted preparation of related $\mathrm{Mn}$ complexes using the carbonylate $\left[\mathrm{Mn}(\mathrm{CO})_{5}\right]^{-}$led instead to a mixture of the phosphanyl-bridged anions $\left[\mathrm{Mn}_{2}\left(\mu-\mathrm{PC}_{11} \mathrm{H}_{14} \mathrm{O}\right)(\mathrm{CO})_{8}\right]^{-}$and $\left[\mathrm{Mn}_{2}\left(\mu-\mathrm{PHCp}^{*}\right)(\mathrm{CO})_{8}\right]^{-}$, both of them formed after reduction of the sought binuclear phosphinidene complex $\left[\mathrm{Mn}_{2}\left(\mu-\mathrm{PCp}^{*}\right)(\mathrm{CO})_{10}\right]$ by excess $\left[\mathrm{Mn}(\mathrm{CO})_{5}\right]^{-}$present in the reaction mixture [12].

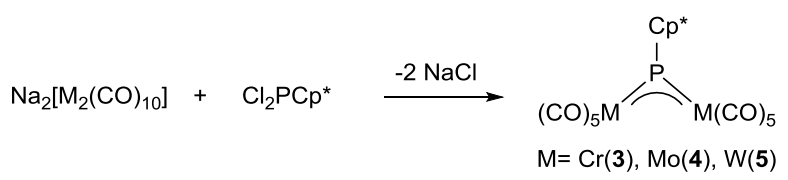

\section{Scheme 3}

The reaction of phosphorus trihalides with metal anions can lead to the formation of halophosphinidenes in favourable cases. Thus, reaction of the anion $\left[\mathrm{W}_{2}(\mathrm{CO})_{10}\right]^{2-}$ with $\mathrm{PCl}_{3}$ yielded the chlorophosphinidene complex 6 as the main product (Scheme 4) [13]. However, this reaction also gave significant amounts of other two organometallic products, including an unprecedented dichlorodiphosphene complex 7. Unfortunately, compound $\mathbf{6}$ could not be isolated from the reaction mixture and its characterisation was only facilitated by its strongly deshielded ${ }^{31} \mathrm{P}$ resonance $\left(\delta_{\mathrm{P}}=\right.$ $868 \mathrm{ppm}$ ), indicative of a trigonal planar disposition of the phosphinidene ligand, as also supported by high-level theoretical calculations. In any case, this compound would be analogous to the bromophosphinidenes of formula $\left[\mathrm{M}_{2}(\mu-\mathrm{PBr})(\mathrm{CO})_{10}\right](\mathrm{M}=\mathrm{Cr}, \mathrm{W})$ obtained previously by Huttner et al. in the stoichiometric reaction of $\mathrm{PBr}_{3}$ with the corresponding dinuclear anions [14]. However, the outcome of the latter reaction was highly dependent on the particular experimental conditions, leading to the formation of the diphosphorus compound $\left[\mathrm{W}_{4}\left(\mu-\eta^{2}: \eta^{2}: \kappa^{1}: \kappa^{1}-\mathrm{P}_{2}\right)(\mathrm{CO})_{19}\right]$ when a slight excess of $\mathrm{PBr}_{3}$ was used instead (1:1.5 ratio) [15]. 


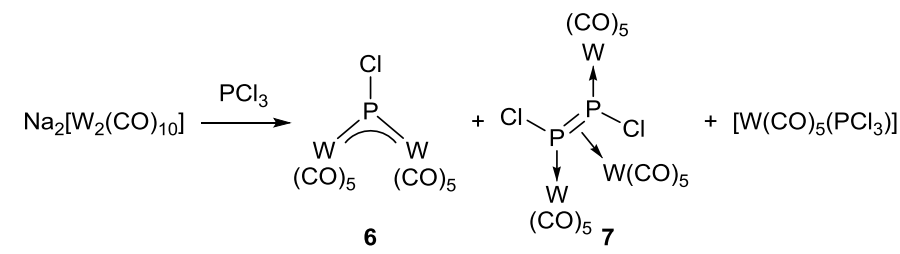

\section{Scheme 4}

Finally, the group of Carty has recently used this strategy for the preparation of several Mn and Co complexes with TMP- or $\mathrm{N}^{i} \mathrm{Pr}_{2}$-substituted phosphinidenes (Scheme 5). Thus, reaction of $\mathrm{K}\left[\mathrm{Co}(\mathrm{CO})_{4}\right]$ with $\mathrm{Cl}_{2} \mathrm{PR}\left(\mathrm{R}=\mathrm{TMP}, \mathrm{N}^{i} \mathrm{Pr}_{2}\right)$ at low temperature led to the unstable phosphinidene complexes $\left[\mathrm{Co}_{2}(\mu-\mathrm{PR})(\mathrm{CO})_{6}\right]\left(\mathrm{R}=\mathrm{TMP}[16], \mathrm{N}^{i} \operatorname{Pr}_{2}\right.$ [17]), which at room temperature evolved rapidly by $\mathrm{CO}$ loss to generate different clusters. Fortunately, more stable derivatives of formula $\left[\mathrm{Co}_{2}(\mu-\mathrm{PR})\left(\mu-\kappa^{1}: \kappa^{1}-\mathrm{dppm}\right)(\mathrm{CO})_{6}\right]\left(\mathrm{R}=\mathrm{TMP}(\mathbf{8 a})[16], \mathrm{N}^{i} \mathrm{Pr}_{2}(\mathbf{8 b})[18] ; \mathrm{dppm}=\mathrm{Ph}_{2} \mathrm{PCH}_{2} \mathrm{PPh}_{2}\right)$ were prepared when these reactions were carried out in the presence of the dppm ligand. In contrast, the related Mn compounds $\left[\mathrm{Mn}_{2}(\mu-\mathrm{PR})(\mathrm{CO})_{8}\right]\left(\mathrm{R}=\mathrm{TMP}(\mathbf{9 a})\right.$ [19], $\mathrm{N}^{i} \operatorname{Pr}_{2}(\mathbf{9 b})$ [18]), prepared from the reaction of $\mathrm{K}\left[\mathrm{Mn}(\mathrm{CO})_{5}\right]$ with $\mathrm{Cl}_{2} \mathrm{PR}$, were much more stable than their cobalt analogues, remaining unchanged even after several days in THF solution. All these phosphinidene complexes display symmetrically bridging phosphinidene ligands with a trigonal planar disposition around the $\mathrm{P}$ atom, as corroborated by an X-ray study for the $\mathrm{PN}^{i} \mathrm{Pr}_{2}$-bridged $\mathrm{Mn}$ complex, and accordingly they give rise to highly deshielded ${ }^{31} \mathrm{P}$ resonances ( $c a .600 \mathrm{ppm}$ for Co compounds and $c a .730 \mathrm{ppm}$ for $\mathrm{Mn}$ complexes).

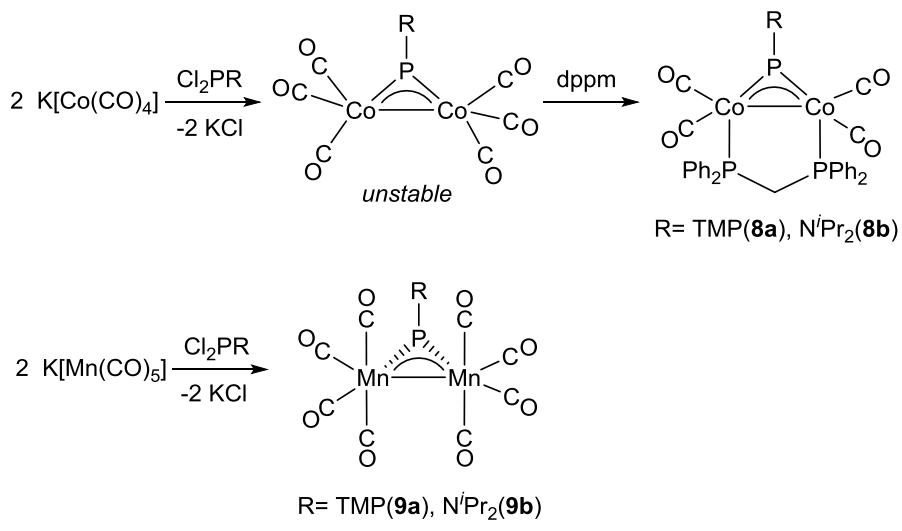

\section{Scheme 5}

Table 1. Synthesis of binuclear phosphinidene complexes through salt metathesis method 1. 


\begin{tabular}{|c|c|c|c|c|}
\hline & Anion & $\mathrm{Cl}_{2} \mathrm{PR}$ & $\begin{array}{l}\text { Yield } \\
(\%)\end{array}$ & Ref. \\
\hline 1 & $\mathrm{Na}_{2}\left[\mathrm{VCp}(\mathrm{CO})_{3}\right]$ & Mes* & 30 & {$[6]$} \\
\hline 2 & $\mathrm{~K}\left[\mathrm{Co}(\mathrm{CO})_{4}\right]$ & Mes* & 57 & {$[7 \mathrm{~B}]$} \\
\hline 3 & $\mathrm{~K}\left[\mathrm{MoCp}(\mathrm{CO})_{3}\right]$ & Mes* & 17 & [7B] \\
\hline 4 & $\mathrm{~K}\left[\mathrm{MoCp}(\mathrm{CO})_{3}\right]$ & TMP & 30 & {$[7 \mathrm{~B}]$} \\
\hline 5 & $\mathrm{~K}\left[\mathrm{WCp}(\mathrm{CO})_{3}\right]$ & TMP & 44 & {$[7 \mathrm{~B}]$} \\
\hline 6 & $\mathrm{Na}\left[\mathrm{Co}_{2} \mathrm{Cp}_{2}(\mathrm{CO})_{2}\right]$ & Mes* & 45 & {$[7 \mathrm{~A}]$} \\
\hline 7 & $\mathrm{Na}_{2}\left[\mathrm{M}_{2}(\mathrm{CO})_{10}\right]$ & & & \\
\hline 8 & $\mathrm{M}=\mathrm{Cr}$ & $\mathrm{Cp}^{*}$ & 25 & [9] \\
\hline 9 & $\mathrm{M}=\mathrm{Mo}$ & $\mathrm{Cp}^{*}$ & - & [9] \\
\hline 10 & $\mathrm{M}=\mathrm{W}$ & $\mathrm{Cp}^{*}$ & 31 & [9] \\
\hline 11 & $\mathrm{M}=\mathrm{W}$ & $\mathrm{Cl}$ & - & [13] \\
\hline 12 & $\mathrm{Na}_{2}\left[\mathrm{Cr}(\mathrm{CO})_{5}\right]$ & Mes & 18 & [11] \\
\hline 13 & $\mathrm{Na}_{2}\left[\mathrm{Cr}(\mathrm{CO})_{5}\right]$ & $\mathrm{N}\left(\mathrm{SiMe}_{3}\right)$ & 45 & [11] \\
\hline 14 & $\mathrm{Na}_{2}\left[\mathrm{Cr}(\mathrm{CO})_{5}\right]$ & $\begin{array}{l}4-\mathrm{Me}-2,6- \\
{ }^{t} \mathrm{Bu}_{2} \mathrm{C}_{6} \mathrm{H}_{2}\end{array}$ & - & [11] \\
\hline 15 & $\mathrm{~K}\left[\mathrm{Co}(\mathrm{CO})_{4}\right]$ & TMP & 53 & [16] \\
\hline 16 & $\mathrm{~K}\left[\mathrm{Co}(\mathrm{CO})_{4}\right]^{a}$ & TMP & 70 & {$[16]$} \\
\hline 17 & $\mathrm{~K}\left[\mathrm{Mn}(\mathrm{CO})_{5}\right]$ & $\mathrm{N}^{i} \mathrm{Pr}_{2}$ & 47 & [18] \\
\hline 18 & $\mathrm{~K}\left[\mathrm{Co}(\mathrm{CO})_{4}\right]^{a}$ & $\mathrm{~N}^{i} \mathrm{Pr}_{2}$ & 50 & [18] \\
\hline 19 & $\mathrm{~K}\left[\mathrm{Mn}(\mathrm{CO})_{5}\right]$ & TMP & 53 & [19] \\
\hline
\end{tabular}

\subsubsection{Reactions with metallophosphines}

The preceding synthetic methodology is not suitable for the preparation of complexes based on early or high-valent transition metals, mainly because of difficulties associated with the preparation of suitable anionic complexes for these metals. As an alternative approach, a limited number of reports deal with the preparation of binuclear phosphinidene complexes by reacting lithiated phosphines with the corresponding halocomplexes. Thus, Stephan and co-workers demonstrated that the reaction of $\mathrm{Li}_{2}[\mathrm{PR}]$ with $\left[\mathrm{ZrCl}_{2} \mathrm{Cp}_{2}\right]$ leads to the formation of paramagnetic binuclear bis(phosphinidene) complexes of formula $\left[\mathrm{Zr}_{2} \mathrm{Cp}_{4}(\mu-\mathrm{PR})_{2}\right]^{2-}(\mathbf{1 0})$ (Scheme 6) [20]. This formulation was sustained by a crystallographic study on the phenyl derivative which, interestingly, contains as counter cation $\left[\mathrm{Li}_{2}\left(\mathrm{~N}_{2}\right)(\mathrm{THF})_{6}\right]^{2+}$, formed when the reaction was carried out under $\mathrm{N}_{2}$ atmosphere [20a]. However, the formulation of these compounds as dianionic $\mathrm{Zr}$ (III)/ $\mathrm{Zr}$ (III) complexes was brought into question in a subsequent report by Shilov, which characterised crystallographically the compound $\left[\mathrm{Zr}_{2} \mathrm{Cp}_{4}(\mu-\mathrm{PPh})_{2}\right]\left[\mathrm{Li}_{2}(\mu-\mathrm{Cl})(\mathrm{THF})_{6}\right]$ [21], therefore containing a $\mathrm{Zr}(\mathrm{III}) / \mathrm{Zr}(\mathrm{IV})$ pair. However, such a formulation appears to be inconsistent with the observation of a half-field transition in the EPR spectrum of Stephan's compound [4d]. A further point of interest in these compounds is the pseudo pyramidal disposition around the $\mathrm{P}$ atoms in these compounds $\left(\sum \mathrm{X}-\mathrm{P}-\mathrm{Y}\right.$ $\approx 354^{\circ}$ ), in contrast with the trigonal planar geometry observed in the related complex $\left[\mathrm{Zr}_{2} \mathrm{Cl}_{2} \mathrm{Cp}_{4}(\mu\right.$-PMes)] [22]. 


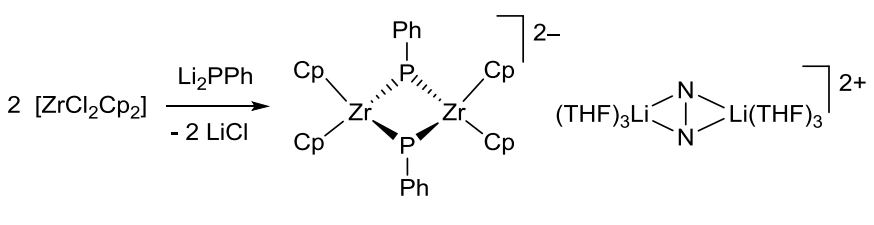

10

\section{Scheme 6}

\subsubsection{Reactions with anionic phosphinidene complexes}

The reaction of a mononuclear anionic phosphinidene with a halocomplex is ideally a simple way to access either homonuclear or heteronuclear complexes bridged by phosphinidene ligands. In practice, however, the preparation of sufficiently stable anionic phosphinidene complexes poses a severe limitation to this approach. In fact, this method has only been used by the group of Malisch [23], which reacted the anion [WCp(PMes*)(CO) $\left.{ }_{2}\right]^{-}$(prepared in situ) with either $\left[\mathrm{WBrCp}(\mathrm{CO})_{3}\right]$ or $\left[\mathrm{FeCpI}(\mathrm{CO})_{2}\right]$, to give selectively the corresponding dinuclear complexes 11 and 13 with an asymmetric phosphinidene ligand connecting 15and 17-electron metal fragments (Scheme 7) [23]. Removal of a CO ligand in these complexes then could be performed easily under photochemical conditions to generate the corresponding “closed" complexes 12 and 14 having a metal-metal bond and symmetric phosphinidene ligands. This structural change was accompanied by a dramatic deshielding of some $300 \mathrm{ppm}$ in the corresponding ${ }^{31} \mathrm{P}$ NMR resonances.
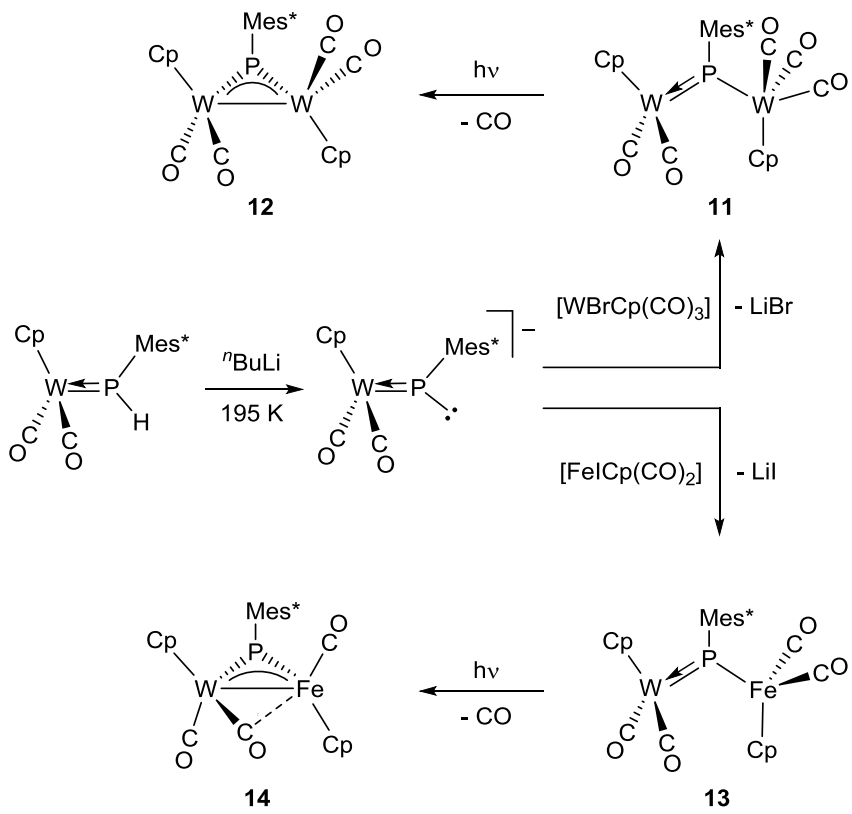


\section{Scheme 7}

\subsubsection{Related processes}

In a number of cases the salt metathesis step is followed by further rearrangement or elimination of suitable groups of the species initially generated, to eventually yield a binuclear phosphinidene complex.

This is the case of the reactions of $\left[\mathrm{ZrCl}_{2} \mathrm{Cp}_{2}\right]$ with some lithiated diphosphanes of formula $\mathrm{Li}\left[\left(\mathrm{SiMe}_{3}\right) \mathrm{P}-\mathrm{PR}_{2}\right]$ studied by Pikies and co-workers, in which the initial salt metathesis step is followed by a silyl group redistribution to give new phosphanylphosphinidene complexes along with $\mathrm{R}_{2} \mathrm{P}-\mathrm{P}\left(\mathrm{SiMe}_{3}\right)_{2}$. The outcome of these reactions was quite sensitive to the substituents at the lithiated diphosphane. Thus, for the ${ }^{t} \mathrm{Bu}$-substituted diphosphane only one of the chloride ligands was replaced, generating the phosphinidene complex 15 , in which the $\mathrm{P}-\mathrm{P}{ }^{t} \mathrm{Bu}_{2}$ ligand is coordinated in a side-on mode and the P atom displays a non-planar geometry (Scheme 8) [24]. In contrast, the bis(phosphinidene) complex 16 was obtained instead when using the $\mathrm{NEt}_{2}$-substituted reagent; moreover, other products were obtained in these reactions when changing the solvent [25]. The influence of the metal in these reactions was also notable, since analogous reactions with $\left[\mathrm{HfCl}_{2} \mathrm{Cp}_{2}\right]$ failed to yield any phosphinidene complex [25], while reaction of $\left[\mathrm{WCl}_{2} \mathrm{Cp}_{2}\right]$ with $\mathrm{Li}\left[\left(\mathrm{SiMe}_{3}\right) \mathrm{P}-\mathrm{P}^{i} \mathrm{Pr}_{2}\right]$ yielded the cyclopentadienylidene-phosphinidene complex $\left[\mathrm{W}_{2} \mathrm{Cp}_{2}\left(\mu-\kappa^{1}: \kappa^{1}, \eta^{5}-\right.\right.$ $\left.\mathrm{PC}_{5} \mathrm{H}_{4}\right)_{2}$ ], but only in extremely low yield [26].

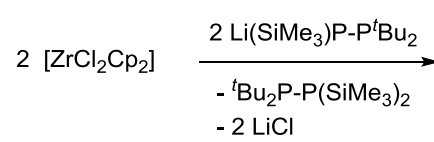
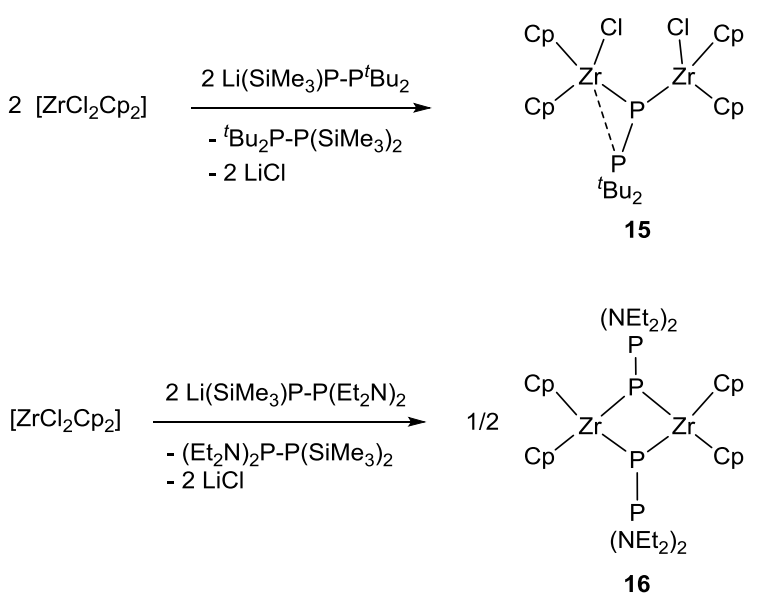

\section{Scheme 8}


A similar silyl redistribution process following the salt metathesis step has been invoked by Chen and co-workers to explain the formation of the neodymium bis(phosphinidene) complex $(17)$ in the reaction of $\left[\mathrm{NdI}_{3}(\mathrm{THF})_{3.5}\right]$ with $\mathrm{K}\left[\mathrm{P}\left(\mathrm{SiMe}_{3}\right)(\mathrm{DIPP})\right](\mathrm{DIPP}=2,6-$ ${ }^{i} \mathrm{Pr}_{2} \mathrm{C}_{6} \mathrm{H}_{3}$; Scheme 9) [27]. This paramagnetic compound could be characterised in the solid state and exhibits two phosphinidene ligands with an almost perfectly trigonal planar geometry around the $\mathrm{P}$ atoms. Interestingly, the presence of terminal iodide ligands opened up the possibility to further modify this compound through salt elimination processes, as exemplified by the reactions with potassium hydrotris(pyrazolyl)borates or $\mathrm{KCp}$ * (Scheme 9) [28].

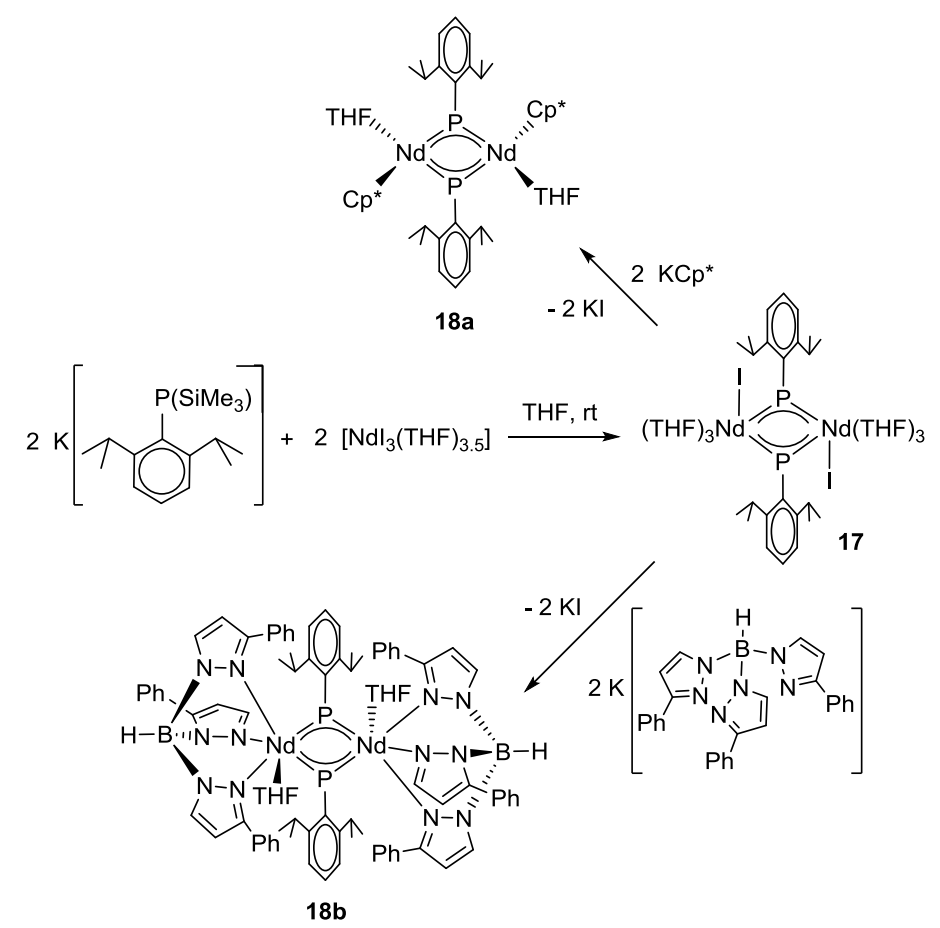

\section{Scheme 9}

Although initially designed for the preparation of mononuclear complexes with terminal phosphinidenes, the reaction of scandium complexes bearing methyl and chloride ligands with metallated primary phosphines has been shown to produce binuclear bis(phosphinidene) complexes in high yields by the groups of Mindiola and Chen independently (Scheme 10) [29]. In both cases the initial step seems to be the formation of a scandium phosphanyl complex retaining the Me group, which then would evolve rapidly by methane elimination to generate unstable mononuclear phosphinidene complexes, not observed, which then dimerise to give the final binuclear products. In fact, a mononuclear phosphinidene complex could be isolated as the corresponding $\mathrm{LiBr}$ adduct when the reaction was carried out using the extremely bulky reagent $\mathrm{Li}[\mathrm{PH}(\mathrm{Xyl})](\mathrm{Xyl}=2,6-$ 
$\mathrm{MesC}_{6} \mathrm{H}_{3}$ ) [29b]. In any case, these complexes display symmetrically coordinated phosphinidene ligands with trigonal planar environments around the $\mathrm{P}$ atoms indicative of a delocalisation of the $\mathrm{P}$ lone pairs over the central four-membered rings.

2
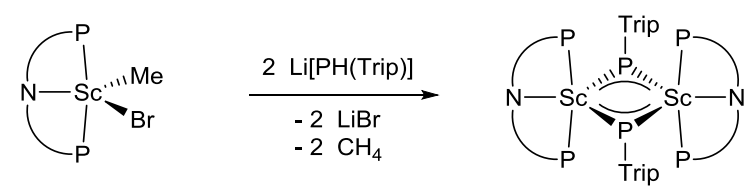

19
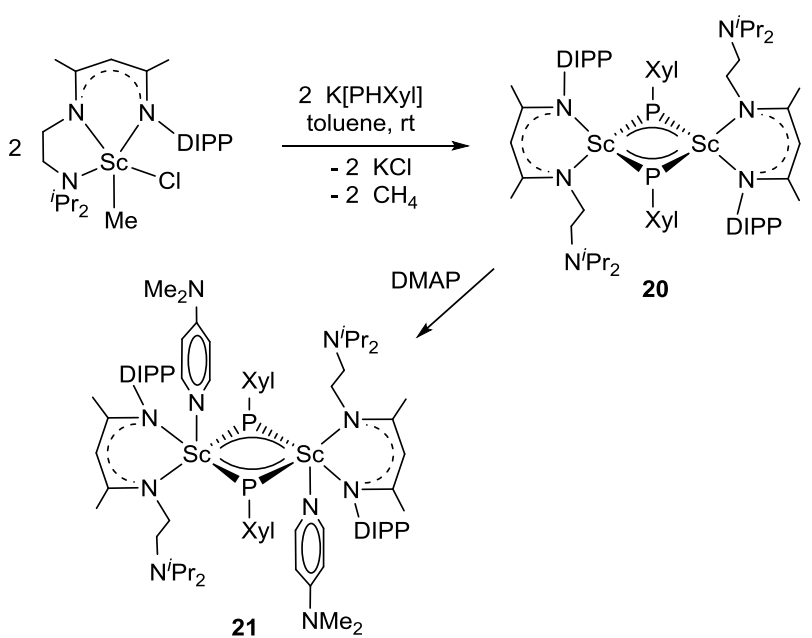

\section{Scheme 10}

A final example of this approach was reported by Hey-Hawkins and co-workers, who prepared several ditantalum bis(phosphinidene) complexes in high yield (73-86\%) by the low temperature reaction of $\left[\mathrm{TaCl}_{4} \mathrm{~L}\right]\left(\mathrm{L}=\eta^{5}-\mathrm{Cp}^{*}, \eta^{5}-\mathrm{Cp} ; \mathrm{Cp}^{\prime}=\mathrm{C}_{5} \mathrm{H}_{4} \mathrm{Me}\right)$ with a two-fold excess of lithium phosphanides Li[PHR] (Scheme 11) [30]. We note that the role of the lithium reagent in these reactions is multiple, since it acts as reducing agent, base and substitution reagent. All these new compounds display short Ta-Ta distances compatible with the formulation of metal-metal single bonds and trigonal planar dispositions around the $\mathrm{P}$ atoms, and accordingly give rise to strongly deshielded ${ }^{31} \mathrm{P}$ NMR resonances ( $\delta_{\mathrm{P}}$ range $\left.390-482 \mathrm{ppm}\right)$.

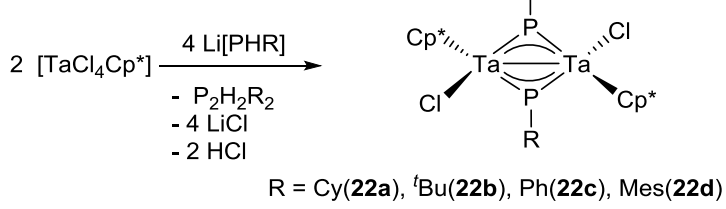

\section{Scheme 11}




\subsection{Deprotonation of phosphanyl (PHR) ligands}

Removal of a proton from a bridging PHR phosphanyl ligand is conceptually the easiest way to generate a bridging phosphinidene group, and indeed this approach has been used in a number of cases for the preparation of phosphinidene complexes, particularly for those with pyramidally-bound ligands (F in Chart 1). Most of the reported examples, however, involve deprotonation of neutral complexes and hence the generation of anionic phosphinidene derivatives, for which limited structural information is available due to difficulties associated with its isolation. In fact, in most cases the formation of an anionic phosphinidene complex is inferred mainly from trapping experiments with suitable electrophiles. The situation improves significantly for cationic phosphanyl complexes, which after deprotonation yield neutral phosphinidene complexes, usually more stable and susceptible of full characterisation.

An early example of this approach is given by the reaction of the triosmium hydrido cluster $\left[\mathrm{Os}_{3}(\mu-\mathrm{H})(\mu-\mathrm{PHPh})(\mathrm{CO})_{10}\right]$ with the strong base DBU (1,8-diazabicyclo[5.4.0]undec-7-ene) to generate the corresponding anionic phosphinidene complex 23 (Scheme 12) [31], a chemistry which was later re-investigated by Deeming and co-workers [32]. Unfortunately, this compound could be characterised only by infrared (IR) and ${ }^{31} \mathrm{P}$ NMR spectroscopy, and its formulation as a phosphinidene complex was only supported by reactivity studies which proved the incorporation of several electrophiles at the $\mathrm{P}$ site [32].

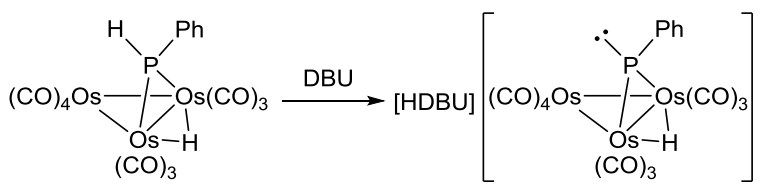

23

\section{Scheme 12}

This strategy was also used for group 4 metal complexes by Stephan and co-workers, who reported the deprotonation of the dimers $\left[\mathrm{Zr}_{2} \mathrm{Cp}_{4}(\mu-\mathrm{PHR})_{2}\right](\mathrm{R}=\mathrm{Ph}$ and $\mathrm{Cy})$ with excess $\mathrm{KH}$ to give the dianionic bis(phosphinidene) complexes of type 10 [20b]. These paramagnetic anions were characterised by EPR, and their formulation as phosphinidene complexes was fully supported by trapping experiments with acids or methylating reagents. Interestingly, 
the heterometallic phosphanyl complex $\left[\mathrm{MoZrCp}(\mu-\mathrm{PHCy})\left(\mu-\kappa^{1}: \eta^{2}-\mathrm{CO}\right)(\mathrm{CO})\right]$ could be also deprotonated with $\mathrm{KH}$ to give the corresponding phosphinidene-bridged derivative [20b].

Several papers by the groups of Haupt [33], Scheer [34], Whitmire [35], Glueck [36] and Mays [37] also dealt with deprotonation of PHR-bridged dinuclear complexes which, as judged from trapping experiments with halocomplexes or other electrophiles, led to the formation of intermediate anionic phosphinidene complexes. However, most of these intermediates were poorly characterised and unstable species for which even their solution structures could not be defined clearly. A particularly complex situation was found when the starting phosphanyl complex also bears bridging hydride ligands, a circumstance enabling deprotonation to competitively occur at either the P or M sites. In fact, equilibrium between the two possible deprotonation products takes places in some cases.

An example of stable anionic phosphinidene complexes prepared by the deprotonation route was recently reported by Layfield and co-workers, who isolated the $\left[\mathrm{Li}(\mathrm{THF})_{4}\right]^{+}$salts of complexes 24 and 25 (Scheme 13), which exhibit interesting magnetic properties and were characterised through an X-ray study [38].

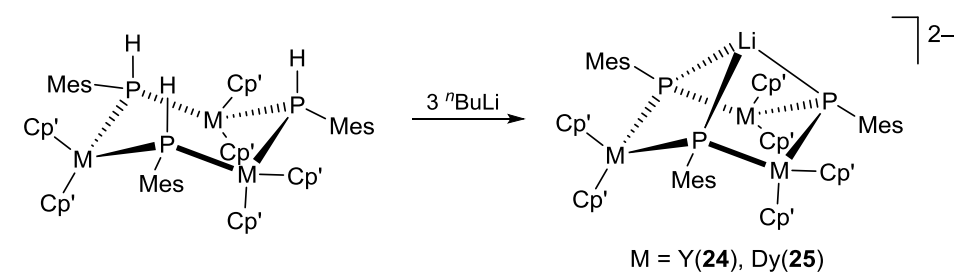

\section{Scheme 13}

As noted above, deprotonation of cationic complexes usually yields more stable phosphinidene complexes. Malisch and Hirth deprotonated the heterometallic complexes $\left[\mathrm{FeWCp}_{2}(\mu \text {-PHMes })(\mathrm{CO})_{4} \mathrm{~L}\right]^{+}\left(\mathrm{L}=\mathrm{CO}, \mathrm{PMe}_{3}\right)$ with DBU, which eventually yielded the phosphinidene complex 28 after additional loss of ligand L (Scheme 14) [39]. This product displays an asymmetrically coordinated trigonal phosphinidene ligand $\left(\delta_{\mathrm{P}}=353 \mathrm{ppm}\right)$ which formally bridges 15- and 17-electron metal fragments. Low-temperature experiments also allowed to identify the intermediate species preceding the loss of the L group, characterised by strongly shielded ${ }^{31} \mathrm{P}$ resonances $\left(\delta_{\mathrm{P}}\right.$ ca. $\left.-140 \mathrm{ppm}\right)$, for which a pyramidal (2-electron donor) coordination mode of the phosphinidene ligand was proposed. In a similar vein, 
Lorenz and co-workers obtained the unstable diiron phosphinidene $\mathbf{2 9}$ upon deprotonation of the corresponding $\mathrm{PHPh}$-bridged cationic complex with $\mathrm{KO}^{t} \mathrm{Bu}$. This elusive species could be trapped upon reaction with alkyl halides or other electrophiles [40].
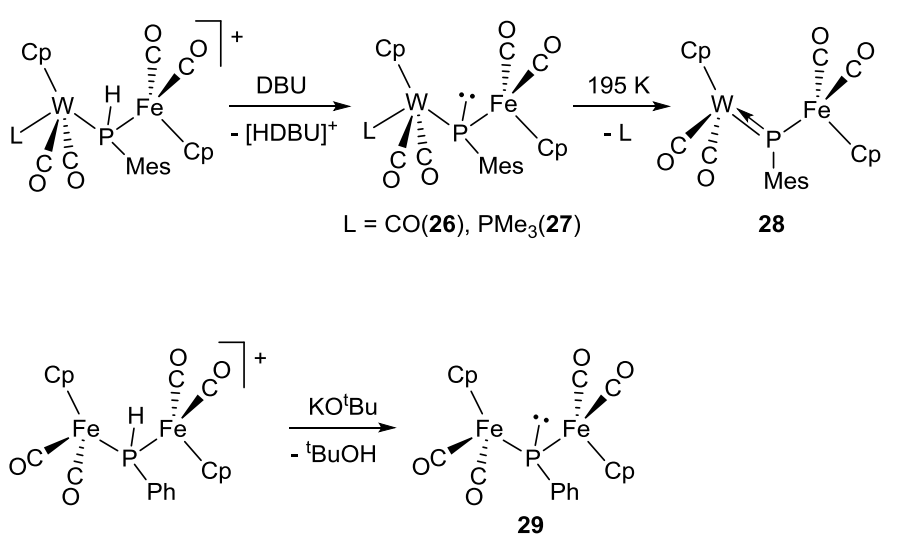

\section{Scheme 14}

Glueck and Kourkine prepared the neutral diplatinum complex 30 upon deprotonation of the dicationic complex $\left[\mathrm{Pt}_{2}(\mu \text {-PHMes })_{2}(\text { dppe })_{2}\right]^{2+}\left(\mathrm{dppe}=\mathrm{Ph}_{2} \mathrm{PCH}_{2} \mathrm{CH}_{2} \mathrm{PPh}_{2}\right)$ with a two-fold excess of ${ }^{n} \mathrm{BuLi}$ (Scheme 15) [41]. The singly-deprotonated compound 31 was also accessible either by using 1 equivalent of base or, alternatively, by addition of $\mathrm{HBF}_{4}$ to $\mathbf{3 0}$. Unfortunately, none of these compounds could be studied by X-ray crystallography, yet the available NMR data of the neutral complex suggest that it contains pyramidal phosphinidene ligands $\left(\delta_{\mathrm{P}}=-57 \mathrm{ppm}\right)$, a proposal also supported by the nucleophilic behaviour of this compound, which resembles that of a tertiary phosphine.

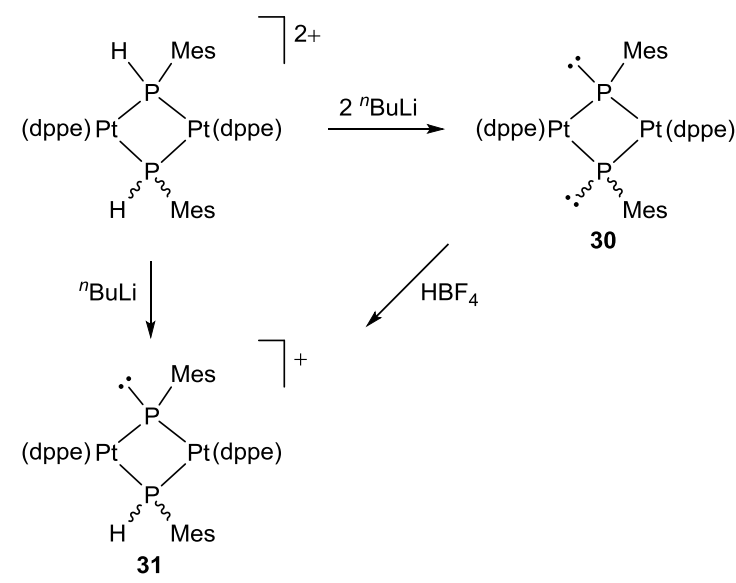

\section{Scheme 15}


More recently, this methodology has been used by Ruiz and co-workers for the synthesis of metal-metal bound diiron phosphinidene complexes starting from the readily available cations $\left[\mathrm{Fe}_{2} \mathrm{Cp}_{2}(\mu-\mathrm{PHR})(\mu-\mathrm{CO})(\mathrm{CO})_{2}\right]^{+}$. The latter complexes are prepared in turn through one- or two-electron oxidation of $\left[\mathrm{Fe}_{2} \mathrm{Cp}_{2}(\mu-\mathrm{CO})_{2}(\mathrm{CO})\left(\mathrm{PH}_{2} \mathrm{R}\right)\right]$, and are easily deprotonated with $\mathrm{KOH}$ or other strong bases to generate the phosphinidene-bridged complexes $\left[\mathrm{Fe}_{2} \mathrm{Cp}_{2}(\mu-\mathrm{PR})(\mu-\mathrm{CO})(\mathrm{CO})_{2}\right][\mathrm{R}=\mathrm{Cy}(\mathbf{3 2 a}), \mathrm{Ph}(\mathbf{3 2 b}), \mathrm{Mes}(\mathbf{3 2 c})$, and Mes $*(32 \mathrm{~d})]\left(\delta_{\mathrm{P}}\right.$ range 495-593 ppm) (Scheme 16) [42]. Remarkably, all these compounds display strongly pyramidalised phosphinidene ligands, as revealed by crystallographic studies on the $\mathrm{PPh}$ and PMes* complexes.

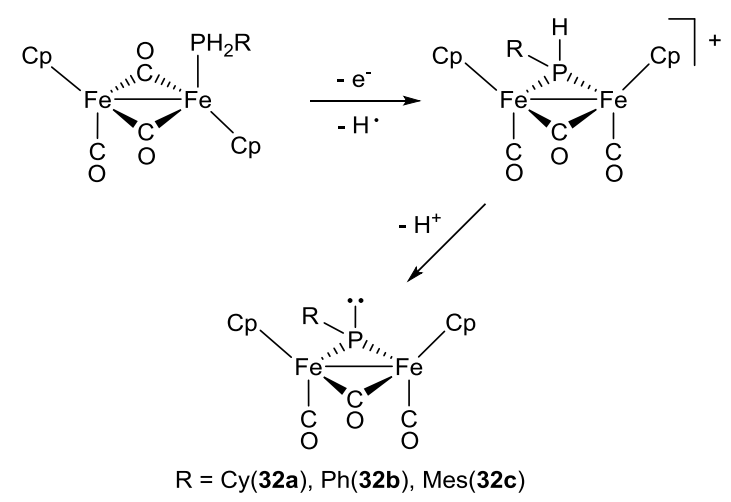

\section{Scheme 16}

\subsection{Dehydrohalogenation}

Double dehydrohalogenation induced by base is an useful approach for the preparation of mononuclear phosphinidene complexes [2b]; it is thus not surprising that in some cases this approach also allows for the synthesis of dinuclear complexes bearing bridging phosphinidene ligands.

Lammertsma and co-workers reported the dehydrohalogenation of the mononuclear iridium complexes $\left[\mathrm{IrCl}_{2} \mathrm{Cp} *\left(\mathrm{PH}_{2} \mathrm{Ar}\right)\right](\mathrm{Ar}=\mathrm{Mes}, \mathrm{Mes} *)$ using the strong phosphazene base BTPP (tert-butylimino-tri(pyrrolidino)phosphorane) (Scheme 17) [43]. The outcome of these reactions, however, was critically dependent on several experimental factors such as the substituent size, temperature and stoichiometry. Thus, for the bulky $\mathrm{PH}_{2} \mathrm{Mes}^{*}$ phosphine, addition of a two-fold excess of BTPP at room temperature gave the mononuclear phosphinidene [ $\left.\mathrm{IrCp}^{*}\left(\mathrm{PMes}^{*}\right)\left(\mathrm{PH}_{2} \mathrm{Mes}^{*}\right)\right]$, while the addition of 1.5 equivalent of base at lower temperature ( $c a .200 \mathrm{~K}$ ) yielded instead the dinuclear phosphinidene/phosphanyl 
complex $\left[\operatorname{Ir}_{2} \mathrm{ClCp}_{2}{ }_{2}\left(\mu-\mathrm{PHMes}^{*}\right)(\mu\right.$-PMes*)]. The latter is an unstable compound which evolves upon addition of further base or on raising the reaction temperature to generate the phosphinidene complex 33, following from a selective $\mathrm{C}-\mathrm{H}$ bond activation in a putative bis(phosphinidene) intermediate $\left[\operatorname{Ir}_{2} \mathrm{Cp}^{*}{ }_{2}\left(\mu-\mathrm{PMes}^{*}\right)_{2}\right]$ [43]. In contrast, no phosphinidene complexes could be identified for the Mes-substituted complex, and a double $\mathrm{C}-\mathrm{H}$ activation product was isolated instead, this suggesting in situ generation of the corresponding bis(phosphinidene) complex which, however, could be neither detected.
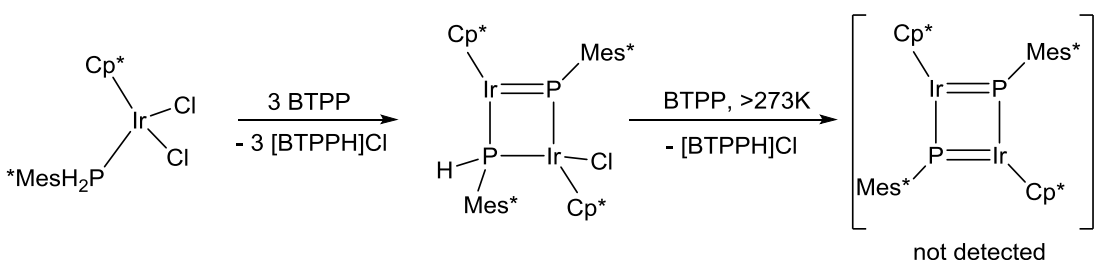

$\mathrm{CH}$ activation

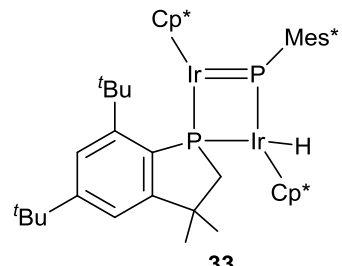<smiles>CP(N)(Cl)(Cl)[Ge]</smiles>
$\underset{-2 \text { [BTPPH }] \mathrm{Cl}}{\stackrel{2 \text { BTPP, } 200 \mathrm{~K}}{\longrightarrow}}$

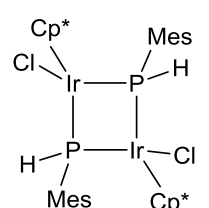

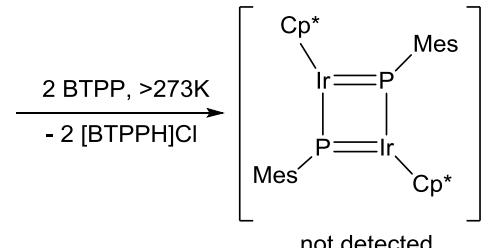

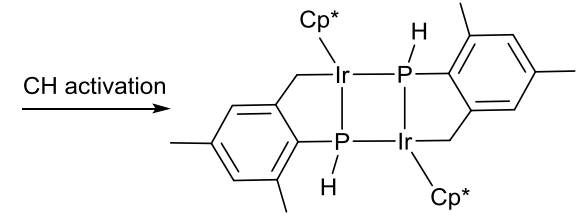

\section{Scheme 17}

A more complex example was provided by Hey-Hawkins and co-workers in the reaction of the tantalum(V) complex $\left[\mathrm{TaCl}_{4} \mathrm{Cp}\right.$ ' $\left(\mathrm{PH}_{2}\right.$ Trip)] (Trip $=2,4,6-{ }^{i} \mathrm{Pr}_{3} \mathrm{C}_{6} \mathrm{H}_{2}$ ) with DBU (in a 1:2 or 1:3 ratio), to give the tantalum(IV) phosphinidene complex 34 in ca. 55\% yield (Scheme 18) [44]. The DBU has a double role in this reaction, acting first as a base and then as reducing agent. The coordination environment around the $\mathrm{P}$ atom in the resulting phosphinidene complex is trigonal planar, accordingly displaying a relatively deshielded ${ }^{31} \mathrm{P}$ NMR resonance $\left(\delta_{\mathrm{P}}=391 \mathrm{ppm}\right)$.
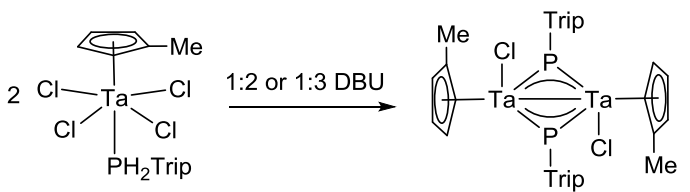

34

\section{Scheme 18}

\subsection{Elimination of $\mathrm{H}_{2}$ or $\mathrm{R}-\mathrm{H}$}


The reaction of suitable alkyl or hydrido complexes with primary phosphines also is a versatile synthetic route for the preparation of binuclear phosphinidene complexes. Thus, the reaction of [ $\mathrm{ZrClCp} \mathrm{p}_{2} \mathrm{H}$ ] with $\mathrm{PH}_{2}\left(\mathrm{SiPh}_{3}\right)$ in a 2:1 ratio led to the phosphinidene complex 35 in $c a$. $45 \%$ yield (Scheme 19) with concomitant elimination of $\mathrm{H}_{2}$ [2j]. In contrast, an analogous reaction with $\mathrm{PH}_{2} \mathrm{Mes}$ gave as main product the phosphinidene complex 36, a compound also accessible by an alternative route (see Section 3.5). The latter reaction, however, was not selective, and the phosphinidene complex was accompanied by variable amounts of the mononuclear phosphanyl complex $\left[\mathrm{ZrClCp}_{2}(\mathrm{PHMes})\right]$ and other products. In fact, independent experiments proved that the latter complex was an intermediate in the overall process, it further reacting with $\left[\mathrm{ZrClCp}_{2} \mathrm{H}\right]$ to give the phosphinidene product quantitatively. Increasing the size of the P substituent was also detrimental, as the reaction with $\mathrm{H}_{2}$ PMes* led instead to the formation of a trinuclear cluster bearing a $\mu_{3}-\mathrm{P}$ ligand [2j]. We finally note that the geometry around the $\mathrm{P}$ atoms in both phosphinidene complexes is trigonal planar, with the $\mathrm{Zr}-\mathrm{P}$ bonds being slightly shorter in the $\mathrm{SiPh}_{3}$ derivative, perhaps reflecting a higher degree of $\pi(\mathrm{ZrP})$ bonding in this compound.

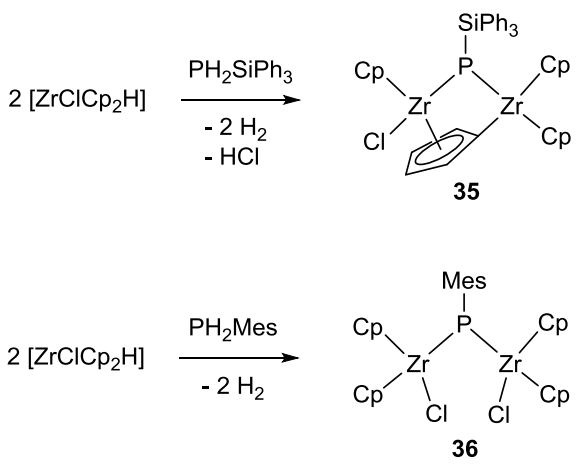

\section{Scheme 19}

In a similar study, the methyl complex $\left[\mathrm{ZrCp}_{2} \mathrm{Me}_{2}\right]$ was reacted with $\mathrm{PH}_{2} \mathrm{Mes}$ [45]. The stoichiometric reaction in refluxing toluene led to the formation of the phosphanyl phosphinidene complex 37 in $c a .70 \%$ yield, following from elimination of methane and C$\mathrm{H}$ activation of one of the $\mathrm{Cp}$ rings (Scheme 20). In contrast, when this reaction was carried out using a two-fold excess of the metallic complex, the isolated product was instead the methyl phosphinidene complex 38 ( $c a .82 \%$ yield). Both phosphinidene complexes displayed strongly deshielded ${ }^{31} \mathrm{P}$ resonances and planar dispositions around the $\mathrm{P}$ atoms, as revealed by the corresponding X-ray analyses. 


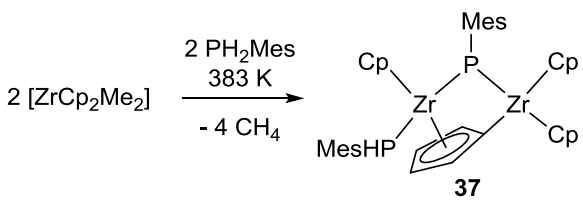

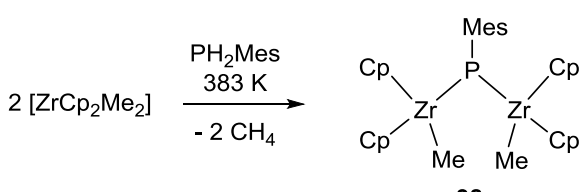

38

\section{Scheme 20}

This methodology has been also applied to some binuclear complexes bearing bridging hydride ligands. Thus, a series of tantalum phosphinidene complexes of formula $\left[\mathrm{Ta}_{2}\left({ }^{R} \mathrm{NPN}\right)_{2}(\mu-\mathrm{PR})(\mu-\mathrm{H})_{2}\right]\left(\mathrm{R}=\mathrm{Cy}, \mathrm{Ad} ;\right.$ and $^{R} \mathrm{NPN}=\mathrm{R}^{\prime} \mathrm{P}\left(\mathrm{CH}_{2} \mathrm{SiMe}_{2} \mathrm{NPh}\right)_{2}$ and $\left.\mathrm{R}^{\prime}=\mathrm{Cy}, \mathrm{Ph}\right)$ $(39,40)$ can be prepared in very high yield by the reaction of the tetrahydrido complex $\left[\mathrm{Ta}_{2}\left({ }^{R} \mathrm{NPN}\right)_{2}(\mu-\mathrm{H})_{4}\right]$ with primary phosphines $\mathrm{PH}_{2} \mathrm{R}$, following from $\mathrm{H}_{2}$ elimination (Scheme 21) [46]. Only the adamantly-substituted phosphinidene complex could be characterised through a crystallographic study, which confirmed the planar disposition around the $\mathrm{P}$ atom; yet, the formulation of all these products as phosphinidene complexes is fully supported by their quite deshielded ${ }^{31} \mathrm{P}$ resonances $\left(\delta_{\mathrm{P}}\right.$ range $\left.474-436 \mathrm{ppm}\right)$ [46].

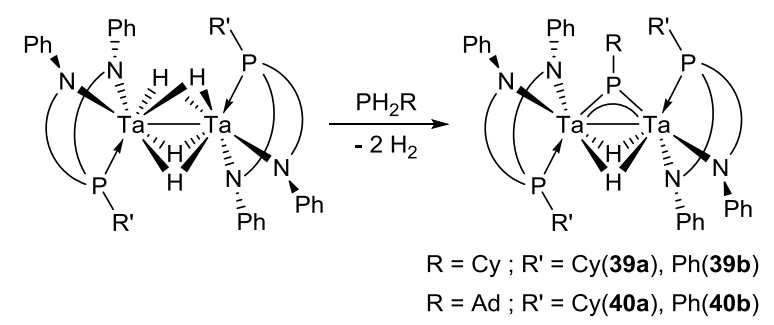

\section{Scheme 21}

More recently this methodology allowed the preparation of the first lanthanide complex with a phosphinidene ligand. This was accomplished by reacting the dialkyl lutetium complex $\left[\mathrm{Lu}\left(\mathrm{CH}_{2} \mathrm{SiMe}_{3}\right)_{2}(\mathrm{PNP})\right]\left(\mathrm{PNP}=\left\{2-\left({ }^{i} \mathrm{Pr}_{2} \mathrm{P}\right)-4-\mathrm{MeC}_{6} \mathrm{H}_{3}\right\}_{2} \mathrm{~N}\right)$ with $\mathrm{PH}_{2} \mathrm{Mes}$, this yielding the bis(phosphinidene) complex 41 in $52 \%$ yield (Scheme 22) [47]. Interestingly, the central $\mathrm{Lu}_{2} \mathrm{P}_{2}$ core of this compound displays a slight asymmetry, with one long and one short Lu-P bonds for each metal atom, while retaining a nearly planar disposition for the $\mathrm{P}$ atoms $\left(\sum \mathrm{X}-\mathrm{P}-\mathrm{Y} \approx 357^{\circ}\right)$ and a deshielded ${ }^{31} \mathrm{P}$ resonance $\left(\delta_{\mathrm{P}}=187 \mathrm{ppm}\right)$. According to the authors, this compound would be better described as an asymmetric dimer of the mononuclear phosphinidene complex [Lu(PNP)(PMes)]. 

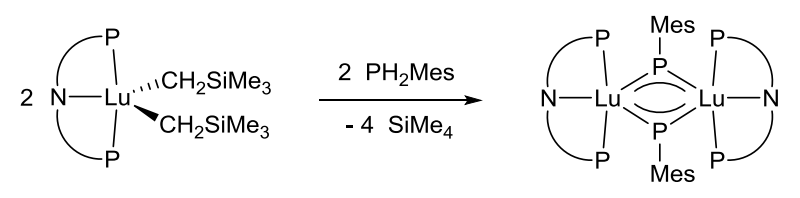

41

\section{Scheme 22}

Another example of this approach was reported by Chen and co-workers, but in this case it involves the reaction of a dialkyl complex with a phosphanyl (PHR) complex, rather than a primary phosphine. Thus, reaction between the scandium complexes $\left[\mathrm{ScLMe}_{2}\right](\mathrm{L}=$ $\mathrm{MeC}(\mathrm{NDIPP}) \mathrm{CHC}(\mathrm{NDIPP}) \mathrm{Me})$ and [ScLMe$\{\mathrm{PH}(\mathrm{DIPP})\}]$ under moderate heating (333 K) led to the formation of the methylidene phosphinidene complex 42, isolated in $c a$. 77\% yield (Scheme 23) [48]. This compound displays a remarkable chemical reactivity which, however, is mainly centred at the methylene group. Its crystal structure revealed that the phosphinidene ligand bridges symmetrically the metal atoms with a planar environment around the $\mathrm{P}$ atom. Surprisingly, its ${ }^{31} \mathrm{P}$ resonance $\left(\delta_{\mathrm{P}}=84 \mathrm{ppm}\right)$ appears significantly upfield from those of related complexes such as $\mathbf{2 0}$ $\left(\delta_{\mathrm{P}}=184 \mathrm{ppm}\right)$, for not obvious reason [29a].

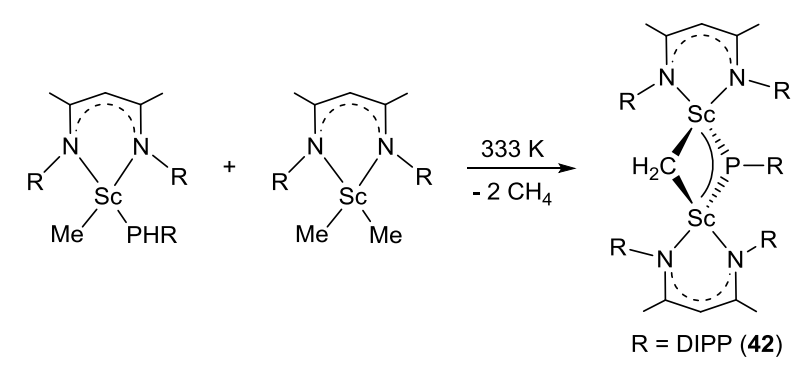

\section{Scheme 23}

Quite recently (2015) this methodology was extended to synthesise a thorium phosphinidene complex. Thus, the methyl complex [ThCp $\left.{ }_{2}{ }_{2} \mathrm{Me}_{2}\right]$ was reacted with $\mathrm{PH}_{2}$ Trip (Trip = 2,4,6- ${ }^{i} \mathrm{Pr}_{3} \mathrm{C}_{6} \mathrm{H}_{2}$ ) to give either the phosphanyl complex $\left[\mathrm{ThCp}_{2}{ }_{2}(\mathrm{PHTrip})_{2}\right]$ or the phosphinidene $43\left(\delta_{\mathrm{P}}=162 \mathrm{ppm}\right)$ (Scheme 24), depending on reaction conditions [49]. The phosphinidene complex was favoured when a two-fold excess of the metal precursor was used, and follows from activation of two $\mathrm{P}-\mathrm{H}$ bonds of the phosphine molecule as well as two $\mathrm{C}-\mathrm{H}$ bonds from the lateral aryl ring, with concomitant formation of Th-P and Th-C bonds. Interestingly, although the geometry around the $\mathrm{P}$ atom is almost perfectly planar, the geometry is not trigonal but rather T-shaped like, with an almost linear Th-P-Th angle $\left(174^{\circ}\right)$. Surprisingly, there seems to be negligible Th-P multiple bonding in this complex, according to DFT calculations. 


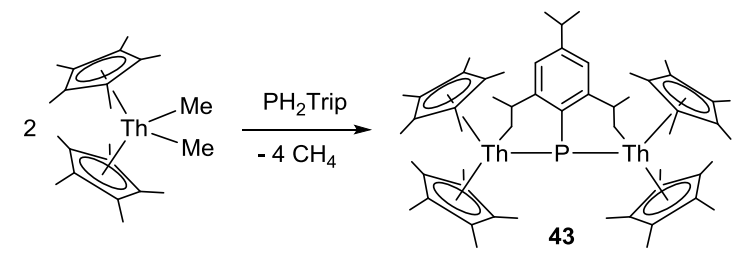

Scheme 24

\subsection{Cleavage of $\mathbf{P}-\mathrm{H}$ bonds at unsaturated metal complexes}

The insertion of in situ generated electron-deficient and coordinatively unsaturated metal fragments into the $\mathrm{P}-\mathrm{H}$ bonds of phosphines has also been used for the preparation of phosphinidene complexes.

The reaction of $\left[\mathrm{ZrCl}_{2} \mathrm{Cp}_{2}\right]$ with $\mathrm{Mg}$ in the presence of one equivalent of $\mathrm{PH}_{2} \mathrm{Mes}$ gave the phosphinidene complex 36 (Scheme 25) [22], a compound which can also be prepared by other routes (see Section 3.4). Here compound 36 seems to follow from reaction of the mononuclear complex $\left[\mathrm{ZrCp}_{2}(\mathrm{PMes})\right]$, generated after $\mathrm{H}_{2}$ loss in the initial insertion product $\left[\mathrm{ZrCp}_{2} \mathrm{H}(\mathrm{PHMes})\right]$, with the starting reagent $\left[\mathrm{ZrCl}_{2} \mathrm{Cp}_{2}\right]$. The same group also studied the reactions of in situ generated zirconocene $\left[\mathrm{ZrCp}_{2}\right]$ (prepared by the reaction of $\left[\mathrm{ZrCl}_{2} \mathrm{Cp}_{2}\right]$ with excess ${ }^{n} \mathrm{BuLi}$ ) with different phosphines such as $\mathrm{PH}_{2} \mathrm{Ph}, \mathrm{PH}_{2} \mathrm{Cy}, \mathrm{PH}_{2} \mathrm{Mes}$ and $\mathrm{PH}_{2} \mathrm{SiPh}_{3}$ [20b]. The outcome of these reactions depended critically on the electronic and steric nature of the phosphorus substituent, and in most cases led to the formation of phosphanyl complexes, but for the $\mathrm{SiPh}_{3}$ derivative the phosphinidene complex 44 could be isolated, albeit in very low yield $(<2 \%)$ (Scheme 25$)$. This compound represents a rare example of a mixed-valence $\mathrm{Zr}(\mathrm{III}) / \mathrm{Zr}(\mathrm{IV})$ complex with bridging phosphanyl and phosphinidene ligands in the same molecule. In the solid state, both groups could be easily differentiated by the coordination geometry around the $\mathrm{P}$ atoms, pyramidal for the phosphanyl group $\left(\sum \mathrm{X}-\mathrm{P}-\mathrm{Y} \approx 339^{\circ}\right)$ and almost perfectly planar for the phosphinidene $\left(\sum \mathrm{X}-\mathrm{P}-\mathrm{Y} \approx 352^{\circ}\right)$. Different $\mathrm{Zr}-\mathrm{P}$ bond lengths were also observed for these groups, with those involving the phosphinidene ligand being some $0.03 \AA$ A shorter. 

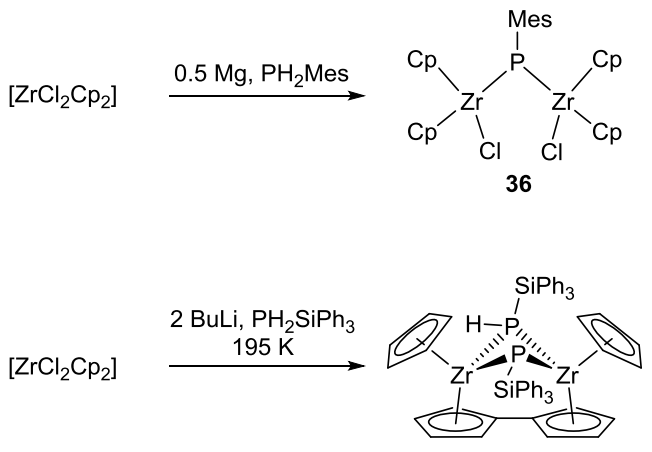

44

\section{Scheme 25}

In a related way, the reaction of the alkene complex $\left[\mathrm{Fe}(\mathrm{NacNac})\left(\eta^{2}-\mathrm{CH}_{2} \mathrm{CPh}_{2}\right)\right](\mathrm{NacNac}=$ $\left.\mathrm{HC}\left\{\mathrm{CMeNC}_{6} \mathrm{H}_{3}\left({ }^{i} \mathrm{Pr}\right)_{2}\right\}_{2}\right)$ with $\mathrm{PH}_{2} \mathrm{Ph}$ proceeds with elimination of alkene and $\mathrm{H}_{2}$, resulting in the formation of the paramagnetic bis(phosphinidene) complex 45 (Scheme 26) [50]. Surprisingly, this compound could also be obtained in the direct reaction of $\left[\mathrm{Fe}_{2}(\mu-\mathrm{Cl})_{2}(\mathrm{NacNac})_{2}\right]$ with $\mathrm{PHPh}_{2}$ and $\mathrm{Na} / \mathrm{K}$ alloy, now proceeding through benzene loss. Both the central $\mathrm{Fe}_{2} \mathrm{P}_{2}$ core of the molecule and the geometry about the bridging $\mathrm{P}$ atoms are almost planar $\left(\sum \mathrm{X}-\mathrm{P}-\mathrm{Y} \approx 356.2^{\circ}\right)$.

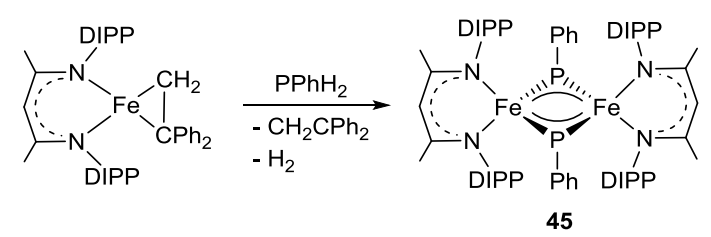

Scheme 26

\subsection{From other phosphinidene complexes}

The use of a phosphinidene complex as source of new phosphinidene derivatives has been used in a limited number of cases. Within this methodology we can differentiate between those processes involving a transfer of the phosphinidene group and those in which the starting compound is modified in some way so as to generate a new binuclear complex. Concerning the latter type, here we will only discuss those processes in which an effective modification in the coordination mode of the PR group has taken place.

The development of a high-yield route for the preparation of $\mathbf{1}$ (see Section 3.9) [51], a compound first obtained in low yield by the group of Cowley (see Table 1) [7b], allowed Ruiz and co-workers to develop a systematic study of its chemistry. This complex actually is an exceptionally versatile 
entrance point to other phosphinidene complexes. In particular, depending on the experimental conditions (wavelength, solvent, temperature and reaction time), the photolysis of this compound can yield one or several of the following products: the hydrido complex $\mathbf{4 6}$, the triply-bonded phosphinidene complex $47\left(\delta_{\mathrm{P}}=532 \mathrm{ppm}\right)$, its isomer $48\left(\delta_{\mathrm{P}}=510 \mathrm{ppm}\right)$ with no metal-metal bond and a ten-electron donor phosphinidene ligand, and the tricarbonyl 49a $\left(\delta_{\mathrm{P}}=476 \mathrm{ppm}\right)$ (Scheme 27) [52]. Fortunately, judicious choice of the reaction conditions allowed the almost selective preparation of each of these products.

The phosphinidene complex $\mathbf{4 8}$ can also be used as precursor of several new phosphinidenes. Thus, its reaction with simple donors such as $\mathrm{CO}$ or $\mathrm{CN}^{t} \mathrm{Bu}$ leads to a partial ring-slippage $\left(\eta^{6} \rightarrow \eta^{4}\right)$ of the aryl group of the phosphinidene, due to the preferential coordination of the donor molecule to the metallocene fragment (Scheme 27) [52a]. Its phosphinidene ligand can also be tautomerised to the cyclopentadienylidene-phosphinidene derivative $51\left(\delta_{\mathrm{P}}=519 \mathrm{ppm}\right)$, a complex displaying itself a rich chemistry [52a]. Initially, this tautomerisation was carried out via acid catalysis, but more recent experiments (2015) proved that it is better accomplished in a two-step procedure first involving full protonation of the parent compound with $\mathrm{HPF}_{6}$, and then deprotonation of the resulting cationic phosphido complex using $\mathrm{KH}$ [53]. In contrast to the reactivity of its parent compound, addition of simple donors (L) to the cyclopentadienylidene-phosphinidene complex does not occur at the metallocene site, likely due to the reluctance of the $\mathrm{C}_{5}$ rings to change their hapticity, but at the dicarbonyl fragment, then inducing a pyramidalisation of the phosphinidene ligand which increases substantially the nucleophilicity of the P atom [53]. In fact, the putative pyramidal phosphinidene complexes of formula $\mathbf{5 2}$ could be spectroscopically characterised only when the donors used were tertiary phosphines $\left(\delta_{\mathrm{P}}=122 \mathrm{ppm}\right.$ for $\left.\mathrm{L}=\mathrm{PMe}_{3}\right)$. For other donor molecules, such as CO or CNR, its formation could be only inferred by the evolution of these putative compounds [54], or by rapid trapping reactions with alkynes or alkenes [55]. To conclude, it is worth noting the great coordination versatility exhibited by the arylphosphinidene ligand in these compounds, which adapts its binding mode to the particular demands of the metal centres by switching between coordination modes $\mathbf{D}, \mathbf{E}$ and $\mathbf{F}$, and by involving (or not) $\pi$ coordination of its aryl ring. 


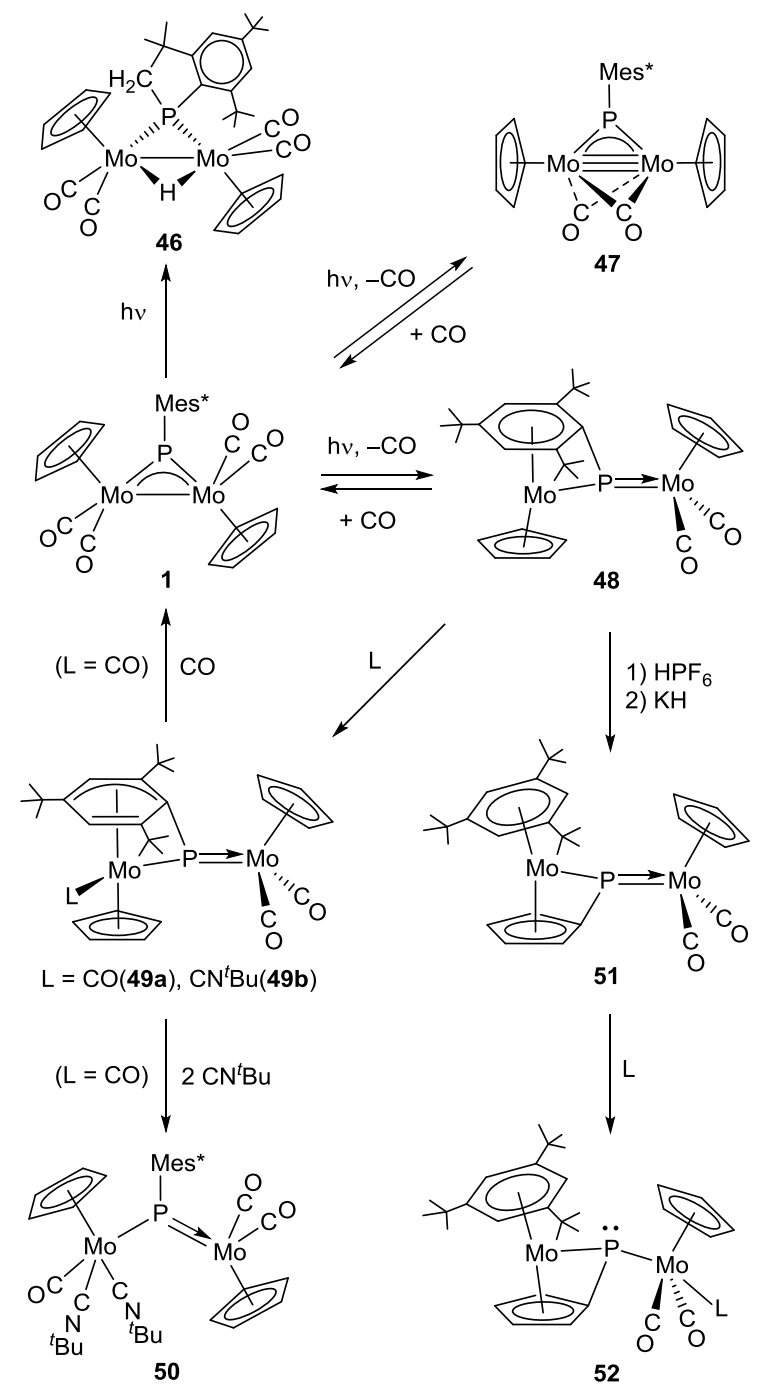

\section{Scheme 27}

Phosphinidene ligand transfer has been used by Tilley and Waterman for the preparation of $\mathrm{Pt}$ phosphinidenes. Thus, moderate heating of the hafnium phosphanyl complex $[\mathrm{HfCpCp} *(\mathrm{PHPh})(\mathrm{Me})]$ with one equivalent of $\left[\mathrm{PtCl}_{2}(\mathrm{dippe})\right]($ dippe $=1,2-$ bis(diisopropylphosphino)ethane) gave the dinuclear bis(phosphinidene) $\mathbf{5 3}$ (59\% yield), along with $\left[\mathrm{HfCpCp} * \mathrm{Cl}_{2}\right]$ (Scheme 28) [56]. The low chemical shift of the ${ }^{31} \mathrm{P}$ resonance for the phosphinidene ligand in this compound $\left(\delta_{\mathrm{P}}=-52 \mathrm{ppm}\right)$ was taken as an indication for lack of M-P $\pi$-bonding, whereby a pyramidal geometry around the phosphorus atom was assumed. Indeed, this was fully corroborated by a crystallographic study of the related complex $\mathbf{5 4}\left(\delta_{\mathrm{P}}=-39 \mathrm{ppm}\right)$, prepared in $54 \%$ yield by the reaction of $\mathbf{5 3}$ with $\left[\mathrm{Pt}_{2}(\mathrm{H})_{2}(\mathrm{dippe})_{2}\right]$. The solid-state structure of this compound confirmed the pyramidal coordination of the phosphinidene ligand $\left(\sum \mathrm{X}-\mathrm{P}-\mathrm{Y} \approx 290^{\circ}\right)$, which displays bond lengths to platinum ( $a v .2 .30 \AA$ ) comparable to those involving the diphosphine ligand, then consistent with the formulation of $\mathrm{Pt}-\mathrm{P}$ single bonds. 

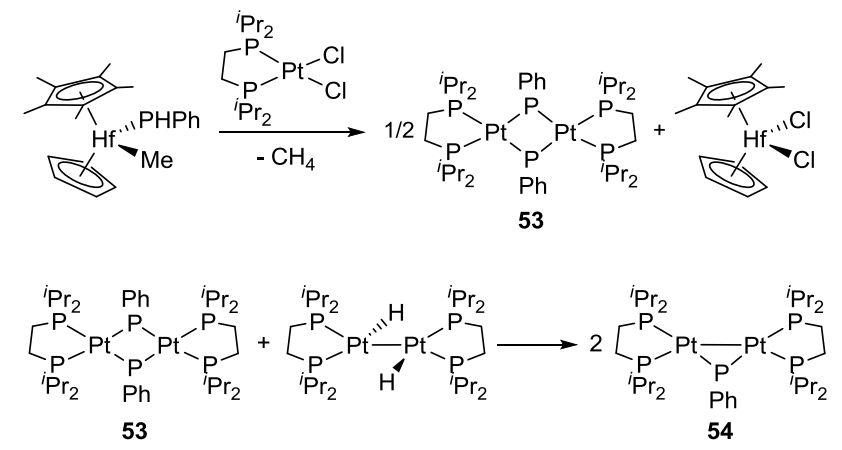

\section{Scheme 28}

The reaction of the phosphinidene complex 5 towards aniline and 1,4-benzodinitrile yielded two new phosphinidene complexes after formation of new P-N bonds (Scheme 29) [57]. In the first reaction, $\mathrm{HCp}^{*}$ is eliminated to give the aminophosphinidene complex $\mathbf{5 5}$, while the second reaction involves nitrile insertion into the $\mathrm{P}-\mathrm{Cp}^{*}$ bond to eventually yield the tetranuclear complex 56. The coordination of the phosphinidene ligand in these complexes is trigonal planar, as corroborated by X-ray analysis. Compound $\mathbf{5 6}$ displays relatively short $\mathrm{P}-\mathrm{N}$ bonds of ca. $1.59 \AA$, a figure indicative of significant $\pi$ interaction with the $\mathrm{P}$ atom, which accounts for its relatively low ${ }^{31} \mathrm{P}$ chemical shift $\left(\delta_{\mathrm{P}}=548 \mathrm{ppm}\right.$, to be compared with $1076 \mathrm{ppm}$ for $\left.\mathbf{5}\right)$. In contrast, the $\mathrm{P}-\mathrm{N}$ length of 1.655(3) A for $\mathbf{5 5}$ is closer to a single bond figure, and its chemical shift is accordingly higher $\left(\delta_{\mathrm{P}}\right.$ $=729 \mathrm{ppm})$.

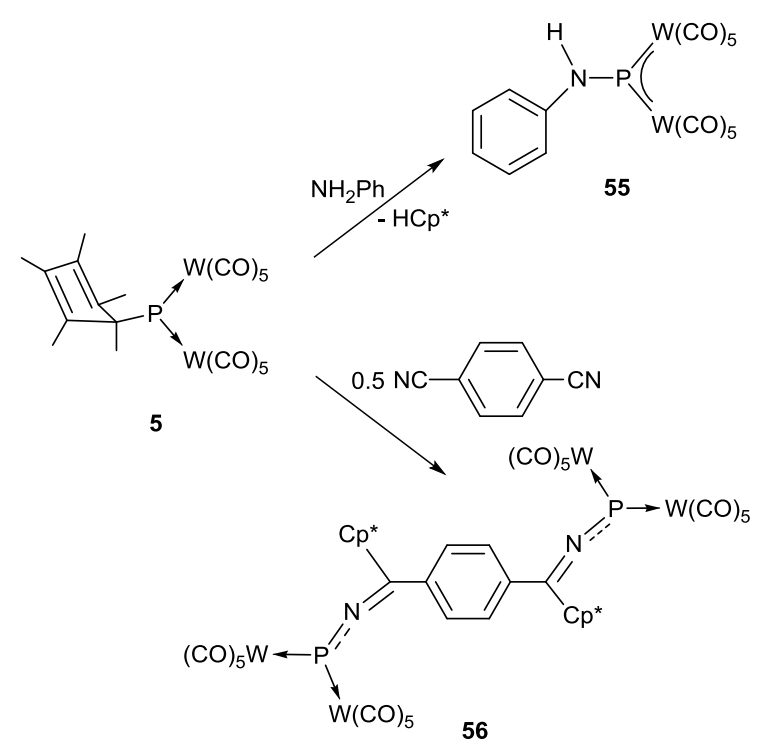

\section{Scheme 29}




\subsection{From dihalophosphine or halophosphanyl complexes}

Reduction of the complex $\left[\mathrm{M}\left(\mathrm{PBr}_{2} \mathrm{Ment}\right)(\mathrm{CO})_{5}\right](\mathrm{M}=\mathrm{Cr}, \mathrm{W}$; Ment = menthyl $)$ with magnesium gives the diphosphene complexes $\left[\mathrm{M}_{2}\{\mu-\mathrm{P}(\mathrm{Ment})=\mathrm{P}(\mathrm{Ment})\}(\mathrm{CO})_{10}\right]$ as main products, along with the phosphinidenes $\left[\mathrm{M}_{2}\{\mu-\mathrm{P}(\mathrm{Ment})\}(\mathrm{CO})_{10}\right]$, which are structurally related to compounds 3 and 5 (see Squeme 3) [58]. The latter compounds could be obtained with improved yields when the same reactions were carried out in the presence of $\left[\mathrm{M}(\mathrm{CO})_{5}(\mathrm{THF})\right](\mathrm{M}=\mathrm{Cr}, \mathrm{W})$. The coordination of the phosphinidene ligands in these complexes is trigonal planar, as corroborated by $\mathrm{X}$-ray analysis of the $\mathrm{Cr}$ compound.

Carty and co-workers studied the reactions of different chlorophosphanyl complexes $\left[\operatorname{MoL}\left\{\mathrm{P}(\mathrm{Cl}) \mathrm{NR}_{2}\right\}(\mathrm{CO})_{\mathrm{n}}\right]\left(\mathrm{n}=2, \mathrm{~L}=\mathrm{Cp}, \mathrm{NR}_{2}=\mathrm{TMP} ; \mathrm{n}=3, \mathrm{~L}=\mathrm{Cp}^{*}, \mathrm{NR}_{2}=\mathrm{N}^{i} \mathrm{Pr}_{2}\right)$ with different carbonyl complexes such as $\left[\mathrm{Co}_{2}(\mathrm{CO})_{8}\right],\left[\mathrm{Mn}_{2}(\mathrm{CO})_{10}\right],\left[\mathrm{Mo}_{2} \mathrm{Cp}_{2}(\mathrm{CO})_{6}\right]$ and $\left[\mathrm{Ru}_{3}(\mathrm{CO})_{12}\right]$ as a new route to polynuclear complexes containing bridging aminophosphinidene ligands (Scheme 30) [59]. These reactions seem to involve the abstraction of the chlorine atom by 17 -electron metal fragments generated upon $\mathrm{M}-\mathrm{M}$ homolysis of the parent carbonyls, and in most cases yielded the corresponding $\mathrm{PNR}_{2}$-bridged binuclear complexes 57-59, except for $\left[\mathrm{Ru}_{3}(\mathrm{CO})_{12}\right]$, which led instead to trimetallic or higher nuclearity compounds containing $\mu_{3}$ - or $\mu_{4}-\mathrm{PNR}_{2}$ ligands. All the new binuclear phosphinidene complexes were fully characterised by multinuclear NMR (range of $\delta_{\mathrm{P}}=$ $654-578 \mathrm{ppm}$ ) and X-ray diffraction, which revealed a trigonal planar environment at phosphorus compatible with delocalisation of a $\pi$ bonding electron pair over the central $\mathrm{M}_{2} \mathrm{P}$ core.

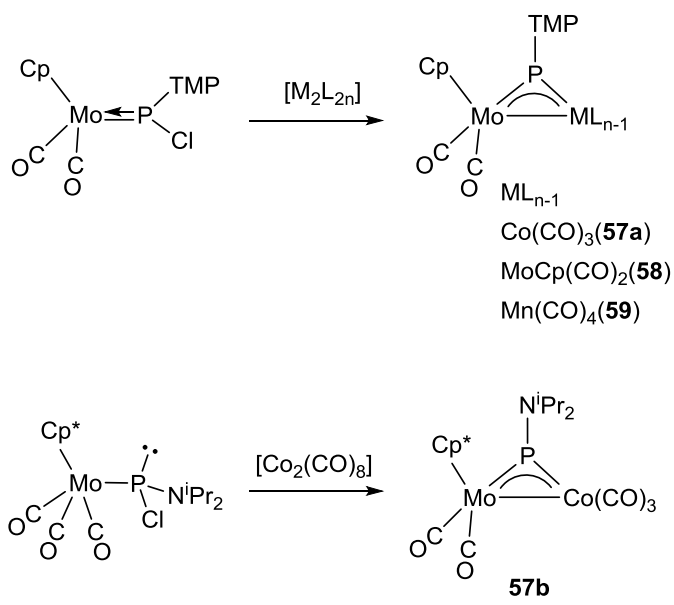

\section{Scheme 30}

\subsection{From "naked" phosphorus complexes}


In a limited number of cases, complexes containing "naked" phosphorus [60] atoms have been used as starting materials for the synthesis of binuclear phosphinidene complexes. An early example of this approach is found in the reaction of the diphosphorus compound $\left[\operatorname{Re}_{4} \mathrm{Cp}_{4}{ }_{4}\left(\mu_{4}-\kappa^{1}: \kappa^{1}: \kappa^{1}: \kappa^{1}-\mathrm{P}_{2}\right)(\mathrm{CO})_{8}\right]$ with an aqueous solution of $\mathrm{HCl}$ to give the hydroxiphosphinidene complex 60 in moderate yields (44\%) (Scheme 31) [61]. The P atom at the central $\mathrm{Re}_{2} \mathrm{PO}$ framework of this molecule displays a trigonal planar environment, this expectedly resulting in a strongly deshielded ${ }^{31} \mathrm{P}$ NMR resonance $\left(\delta_{\mathrm{P}}=595 \mathrm{ppm}\right)$.

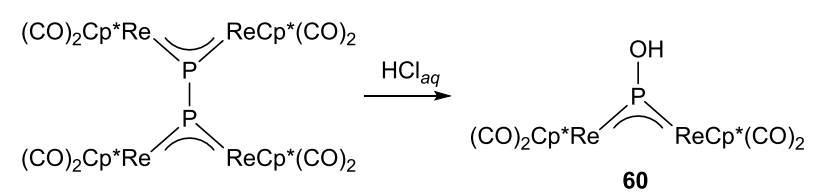

\section{Scheme 31}

An interesting triple-decker sandwich complex bearing a bridging $\mu-\mathrm{PH}$ phosphinidene ligand, $\left[\left\{\mathrm{Cr}_{2} \mathrm{Cp}_{2}(\mu-\mathrm{PH})(\mathrm{CO})_{4}\right\}\left\{\mathrm{Cr}_{2} \mathrm{Cp}_{2}\left(\mu-\eta^{1}: \eta^{1}: \eta^{5}: \eta^{5}-\mathrm{P}_{5}\right)\right\}\right][62]$, was formed in the reaction of the diphosphorus complex $\left[\mathrm{Cr}_{2} \mathrm{Cp}_{2}\left(\mu-\eta^{2}: \eta^{2}-\mathrm{P}_{2}\right)(\mathrm{CO})_{4}\right]$ with $\mathrm{LiBHEt}_{3}$ at $195 \mathrm{~K}$. Unfortunately, this compound was obtained in very low yield as the reaction also gives two other products bearing $\mu$ $\mathrm{PH}_{2}$ ligands. Moreover, the paramagnetic nature of the complex precluded full characterisation by NMR spectroscopy.

In a related study, the reactions of the cationic phosphido-bridged complex $\mathbf{6 1}$ with different sources of hydride ions were analyzed, this leading to some surprising results (Scheme 32) [63]. Thus, reaction with $\mathrm{KH}$ led to deprotonation of a $\mathrm{C}-\mathrm{H}$ bond at the metallocene $\mathrm{Cp}$ ring, to give the cyclopentadienylidene-phosphinidene derivative 51, a compound also accessible from other sources (see Section 3.6). Instead, reaction with $\mathrm{Li}\left[\mathrm{BHEt}_{3}\right]$ led to the formation of the phosphinidene complex 62, a complex for which the presence of a trigonal PH bridge was firmly denoted by the appearance of a quite deshielded ${ }^{31} \mathrm{P}$ resonance $\left(\delta_{\mathrm{P}}=513 \mathrm{ppm}\right)$ with relatively reduced (for a onebond connection) $\mathrm{P}-\mathrm{H}$ coupling $(179 \mathrm{~Hz})$. A third outcome for these reactions was still possible when using a sterically demanding source of hydride, $\mathrm{K}\left[\mathrm{BH}^{s} \mathrm{Bu}_{3}\right]$, then leading to the formation of the cyclopentadiene complex $\left[\left[\mathrm{Mo}_{2} \mathrm{Cp}(\mu-\mathrm{P})(\mathrm{CO})_{2}\left(\eta^{6}-\mathrm{HMes}^{*}\right)\left(\eta^{4}-\mathrm{C}_{5} \mathrm{H}_{6}\right)\right]\right.$, a molecule following from attack of the hydride to a carbon atom of a $\mathrm{Cp}$ ring in the metallocene fragment. This compound, however, was stable only below ca. $253 \mathrm{~K}$, otherwise rearranging into the PH-bridged complex. 


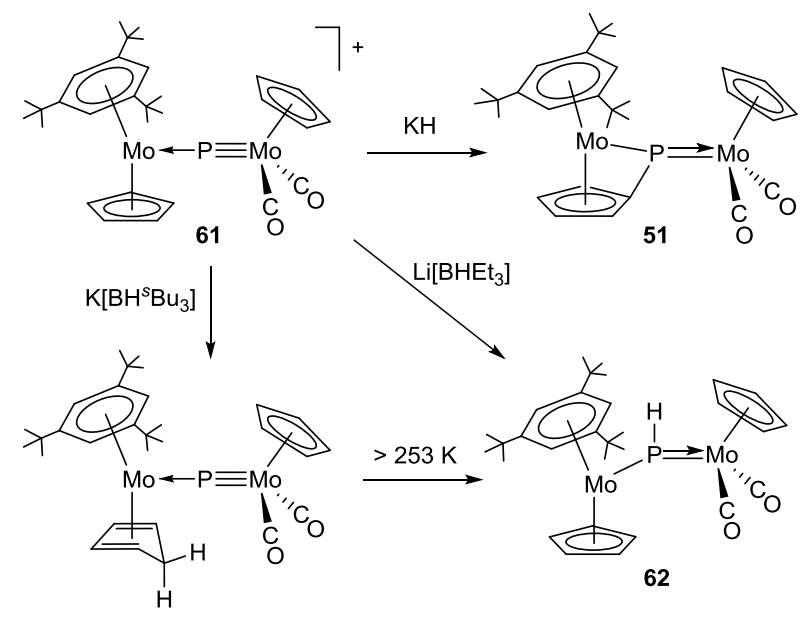

\section{Scheme 32}

\subsection{Other methods}

In this section we will summarise some preparative procedures for binuclear phosphinidene complexes which cannot be included in any of the preceding methodologies. For instance, Hermann and co-workers reported the formation of the phosphinidene $\mathbf{6 3}$ via the photochemical dehydrogenation of the phosphane complex $\left[\mathrm{MnCp} *(\mathrm{CO})_{2}\left(\mathrm{PH}_{3}\right)\right]$ (Scheme 33) [64]. Unfortunately, this complex was not thoroughly characterised at the time and its formulation relied on its similarities with related complexes prepared earlier by the group of Huttner [65].

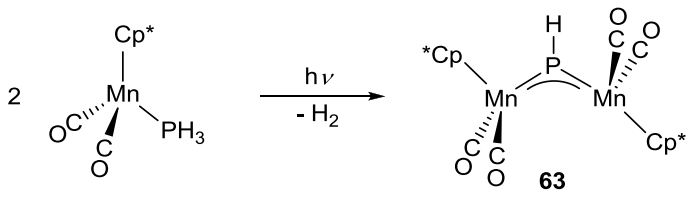

\section{Scheme 33}

Dehydrohalogenation of $\left[\mathrm{WClL}\left(\mathrm{PH}_{2} \mathrm{Mes}\right)(\mathrm{CO})_{2}\right](\mathrm{L}=\mathrm{Cp}, \mathrm{Cp} *)$ with DBU gave unexpectedly the binuclear phosphinidene complexes 64 (Scheme 34) [66]. The latter seems to follow from a dimerisation of the expected phosphanyl complex via addition of the $\mathrm{P}-\mathrm{H}$ bond of one molecule to the $\mathrm{W}-\mathrm{P}$ double bond of a second one. These molecules display an asymmetric planar coordination of the phosphinidene, as verified by a crystallographic study on the $\mathrm{Cp}$ complex. However, the $\mathrm{Cp}^{*}$ complex remained stable only at low temperature, otherwise evolving spontaneously by $\mathrm{PH}_{2} \mathrm{Mes}$ loss to give the corresponding symmetric phosphinidene complex $65\left(\delta_{\mathrm{P}}=589 \mathrm{ppm}\right)$. 


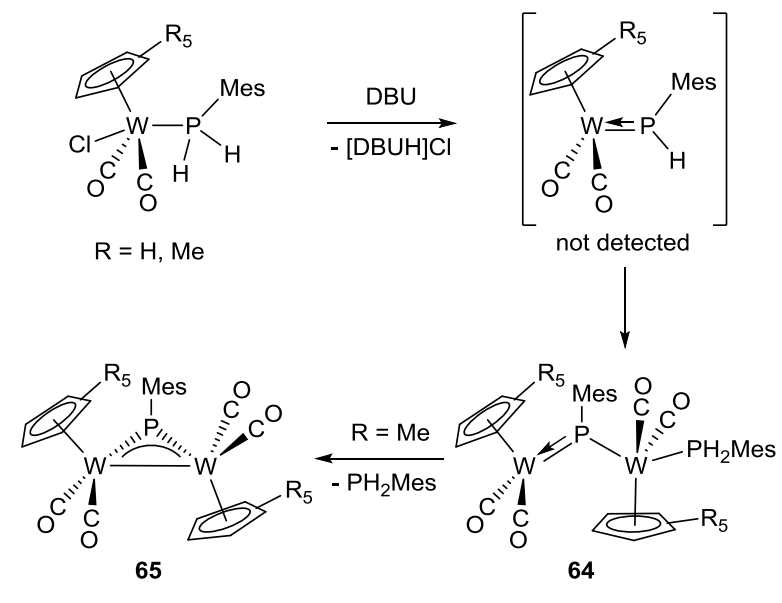

\section{Scheme 34}

The heterometallic phosphinidene complex $\mathbf{6 6}$ is formed by the thermally induced $\mathrm{P}-\mathrm{C}$ bond cleavage and $\mathrm{Cp}^{*}$ migration to iron of the phosphanyl complex $\left[\mathrm{FeMn}\left\{\mu-\mathrm{PCp} *\left(\mathrm{OMes}^{*}\right)\right\}(\mathrm{CO})_{8}\right]$, a species in turn prepared by the reaction of $\left[\mathrm{Mn}\left\{\mathrm{PCp} *\left(\mathrm{OMes}^{*}\right)\right\}(\mathrm{CO})_{4}\right]$ with $\left[\mathrm{Fe}_{2}(\mathrm{CO})_{9}\right]$ (Scheme 35) [67]. The MnFePO core of the molecule is almost perfectly planar, although the phosphinidene ligand is quite asymmetrically coordinated, retaining a relatively short Mn-P bond length $(2.13 \AA)$ compatible with a double bond formulation, while the Fe-P length of $2.26 \AA$ falls within the typical range of single bonds.

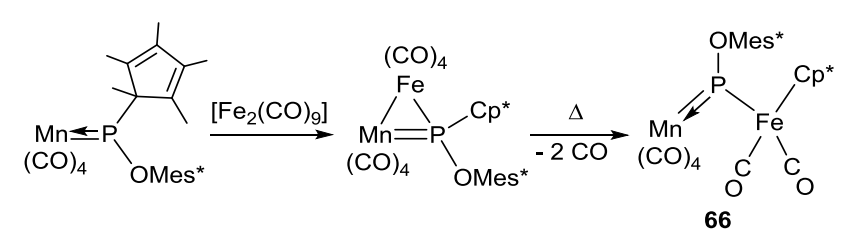

\section{Scheme 35}

Cyclophosphanes can also be used as sources for phosphinidene ligands. Ang and coworkers studied the reactions of $\left(\mathrm{F}_{3} \mathrm{CP}\right)_{4}$ and $\left(\mathrm{F}_{3} \mathrm{CP}\right)_{5}$ towards several osmium and ruthenium clusters, obtaining a wide variety of polynuclear complexes containing phosphinidene or phosphanyl ligands derived from these reagents [68]. The only product containing a $\mu_{2}$-phosphinidene ligand was the ruthenium cluster $\left[\mathrm{Ru}_{4}(\mu-\mathrm{H})_{2}\left(\mu-\mathrm{PCF}_{3}\right)\left(\mu_{3^{-}}\right.\right.$ $\left.\mathrm{PCF}_{3}\right)_{2}(\mathrm{CO})_{12}$, a compound obtained in very low yield $(8 \%)$ in the reaction of both cyclophosphanes with $\left[\mathrm{Ru}_{4}(\mu-\mathrm{H})_{2}(\mathrm{CO})_{12}\right]$. The main point of interest in this compound was the pyramidal coordination of the $\mu_{2}$-phosphinidene ligand in the crystal, which gives rise to a ${ }^{31} \mathrm{P}$ signal $\left(\delta_{\mathrm{P}}=223 \mathrm{ppm}\right)$ which falls between those expected for $\mu_{3}-\mathrm{PCF}_{3}$ and $\mu_{4}-\mathrm{PCF}_{3}$ phosphinidene ligands. 
As mentioned in Section 3.6, Ruiz and co-workers developed a high yield (95\%) two-step process to convert the phosphanyl complex $\left[\mathrm{Mo}_{2} \mathrm{Cp}_{2}(\mu-\mathrm{H})(\mu \text {-PHMes*)(CO) })_{4}\right]$ into the phosphinidene derivative $1\left(\delta_{\mathrm{P}}=686 \mathrm{ppm}\right)$ via the cationic phosphinidene hydrido complex $\left[\mathrm{Mo}_{2} \mathrm{Cp}_{2}(\mu-\mathrm{H})(\mu-\right.$ PMes $\left.*(\mathrm{CO})_{4}\right]^{+}\left(\delta_{\mathrm{P}}=725 \mathrm{ppm}\right)($ Scheme 36$)$ [51]. The initial step involves the protonation of the starting compound with strong acids (i.e. $\mathrm{HBF}_{4}$ ), this inducing $\mathrm{H}_{2}$ loss so as to generate an unsaturated cation, not detected, which then evolves rapidly by oxidative addition of the $\mathrm{P}-\mathrm{H}$ bond to give a phosphinidene- and hydrido-bridged cation. The latter cation can be then easily deprotonated even by weak bases such as $\mathrm{H}_{2} \mathrm{O}$ to give the neutral complex. Similar reactions were carried out for other related phosphanyl complexes bearing smaller substituents at the $\mathrm{P}$ atom $(\mathrm{Ph}$, Cy and Mes), but only phosphanyl-bridged cations were obtained, and no phosphinidene complexes were ever detected in these reactions [69].
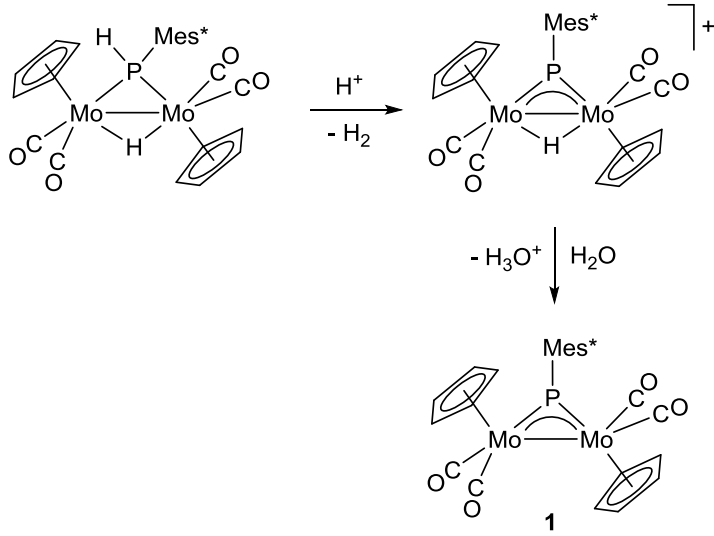

\section{Scheme 36}

In order to avoid the use of salt metathesis reactions for the preparation of $\mathrm{Zr}$ phosphinidene complexes, Driess and co-workers used a $\sigma$-bond metathesis approach starting with $\mathrm{Zr}$ amido complexes and $\mathrm{P}-\mathrm{H}$ acidic silylphosphanyl complexes. Thus, reaction of $\left[\mathrm{Zr}\left(\mathrm{NEt}_{2}\right)_{4}\right]$ with $\left[\mathrm{ZrCp}_{2}(\mathrm{PHR})_{2}\right]\left(\mathrm{R}=\mathrm{SiMe}_{2}\left(\mathrm{CMe}_{2}{ }^{i} \mathrm{Pr}\right)\right)$ gave the bis(phosphinidene $) 67\left(\delta_{\mathrm{P}}=288 \mathrm{ppm}\right)$ in almost quantitative yield (Scheme 37) [70]. In boiling xylene this compound undergoes an unconventional metathesis reaction to give the unsymmetrical complex $\mathbf{6 8}\left(\delta_{\mathrm{P}}=274 \mathrm{ppm}\right)$ in $28 \%$ yield. A crystallographic study of the latter complex revealed strongly pyramidal coordination geometry around the inequivalent $\mathrm{P}$ atoms $\left(a v . \sum \mathrm{X}-\mathrm{P}-\mathrm{Y} \approx 342^{\circ}\right)$. In a similar study, the related complexes 69 were prepared by catalytic dehydrogenation of the corresponding phosphanyl complexes $\left[\mathrm{Zr}_{2} \mathrm{Cp}_{4}(\mu\right.$ PHR $)_{2}$ ] (Scheme 37) [71]. 


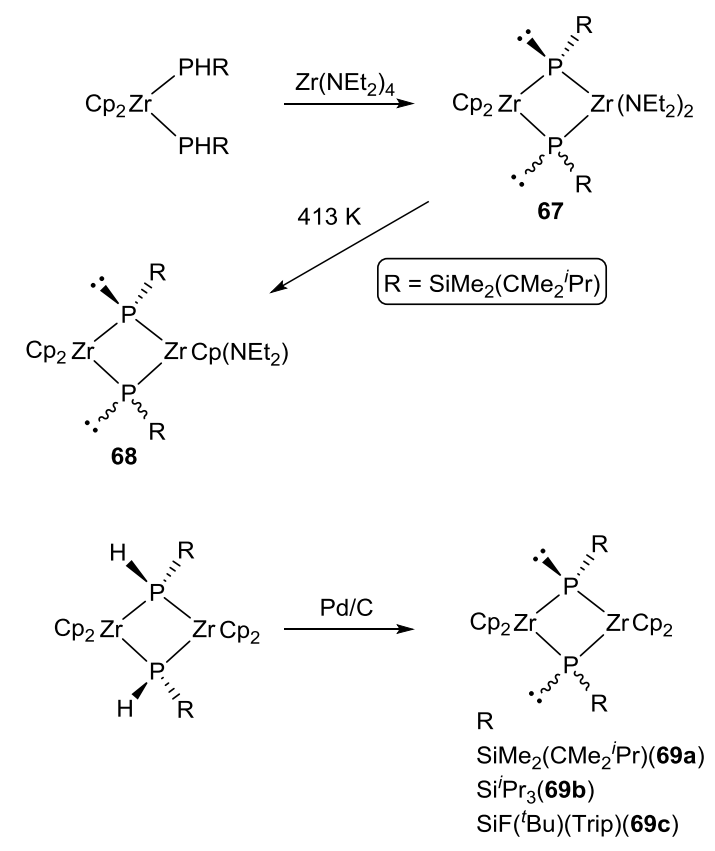

\section{Scheme 37}

The reaction of complex $\left[\mathrm{Nb}(\text { silox })_{3}\left(\mathrm{PMe}_{3}\right)\right]\left(\right.$ silox $\left.=\mathrm{OSi}^{t} \mathrm{Bu}_{3}\right)$ with a 1:1 mixture of $\mathrm{N}_{2}$ and $\mathrm{H}_{2}\left(p \mathrm{H}_{2} \sim p \mathrm{~N}_{2}=175\right.$ Torr $)$, in a NMR tube under ambient light, led to the precipitation of a brick-red insoluble solid (43\% yield) [72]. The product was then identified by an X-ray study as the phosphinidene complex $\left[\mathrm{Nb}_{2}(\operatorname{silox})_{6}(\mu-\mathrm{PH})\right]$. The presence of $\mathrm{a} \mathrm{Nb}^{\mathrm{V}} / \mathrm{Nb}^{\mathrm{III}}$ dimetallic unit forces an asymmetric coordination of the phosphinidene ligand, with the $\mathrm{P}$ atom being $c a$. $0.31 \AA$ closer to the $\mathrm{Nb}^{\mathrm{V}}$ centre, therefore the bonding in this compound is better described as $\mathrm{Nb}^{\mathrm{V}}=\mathrm{PH}-\mathrm{Nb}^{\mathrm{III}}$.

The diruthenium phosphinidene $\mathbf{7 0}$ has been prepared in high yield (77\%) upon reaction of $\left[\mathrm{Ru}_{2} \mathrm{Cp}_{2}{ }_{2}(\mu-\mathrm{NHPh})(\mu-\mathrm{PHPh})(\mu-\mathrm{CO})\right]$ with $\mathrm{CO}$ at atmospheric pressure (Scheme 38$)$ [73]. The loss of aniline in this process was fully corroborated by ${ }^{1} \mathrm{H}$ NMR (66\% yield). Although the crystal structure of this compound could not be determined, the authors proposed a pyramidal coordination of the phosphinidene ligand in this complex based on the similarity of its ${ }^{31} \mathrm{P}$ chemical shift $\left(\delta_{\mathrm{P}}=\right.$ $457 \mathrm{ppm})$ with that of the related iron complex 32b $\left(\delta_{\mathrm{P}}=498 \mathrm{ppm}\right)[42 \mathrm{c}]$.

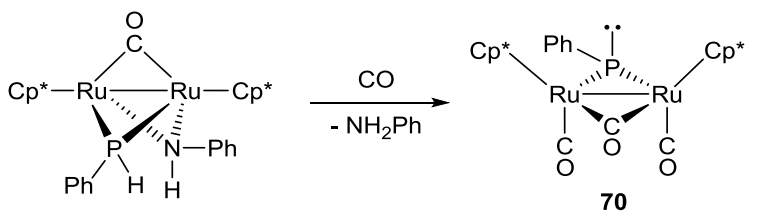

Scheme 38 
Ruiz and co-workers developed a method for the generation of heterometallic $\mu_{2}$-phosphinidene complexes via RP transmetallation using the phosphinidene sulphide complex $\left[\mathrm{Mo}_{2} \mathrm{Cp}_{2}\{\mu-\right.$ $\kappa_{P, S}^{2}: \kappa_{P}^{1}, \eta^{6}$-SPMes* $\}(C O)_{2}$ ] as precursor (Scheme 39) [74]. Reactions of the latter compound with several transition metal carbonyls, $\left[\mathrm{M}^{\prime}{ }_{\mathrm{x}}(\mathrm{CO})_{\mathrm{n}}\right]$, involved invariably the cleavage of $\mathrm{P}-\mathrm{S}$ and $\mathrm{Mo}-\mathrm{P}$ bonds with concomitant formation of a new M'-P multiple bond. However, the outcome of these reactions was greatly influenced by the metal carbonyl used. Thus, in the reaction with $\left[\mathrm{Co}_{2}(\mathrm{CO})_{8}\right]$ a fragment " $\left[\mathrm{MoCp}(\mathrm{S})(\mathrm{CO})_{2}\right]$ " was formally lost, then yielding the binuclear complex 71 as major product $\left(\delta_{\mathrm{P}}=628 \mathrm{ppm}\right)$. In contrast, the reaction with $\left[\mathrm{W}(\mathrm{CO})_{5}(\mathrm{THF})\right]$ or $\left[\mathrm{Fe}_{2}(\mathrm{CO})_{9}\right]$ led to tetranuclear clusters $\mathbf{7 2}$ and $\mathbf{7 3}$ respectively. In spite of the different structures, all the new complexes display an asymmetric trigonal planar geometry around the $\mathrm{P}$ atoms due to the presence of 15- and 17-electron metal fragments. It is remarkable that the coordination mode of the phosphinidene ligand in the Co/Mo heterometallic complex can be easily modified upon addition of simple donor ligands such as $\mathrm{CO}$ or $\mathrm{CN}^{\mathrm{t}} \mathrm{Bu}$, this involving full de-coordination of the aryl ring of the phosphinidene ligand to give $\left[\mathrm{CoMoCp}\left(\mu-\mathrm{PMes}^{*}\right)(\mathrm{CO})_{3}(\mathrm{~L})_{2}\right]\left(\mathrm{L}=\mathrm{CO}(\mathbf{5 7 c}), \mathrm{CN}^{\mathrm{t} B u} ; \delta_{\mathrm{P}} c a .653\right.$ ppm), a molecule now displaying a more conventional symmetric trigonal planar phosphinidene ligand [75]. This rearrangement is reminiscent of that in the related dimolybdenum complex $\mathbf{4 8}$ to give Cowley's complex 1 [52]. In contrast to the dimolybdenum substrate, however, the heterometallic complex 57c could not be decarbonylated photochemically to give back the asymmetric phosphinidene complex $\mathbf{7 1}$ or any isomer of it [75].
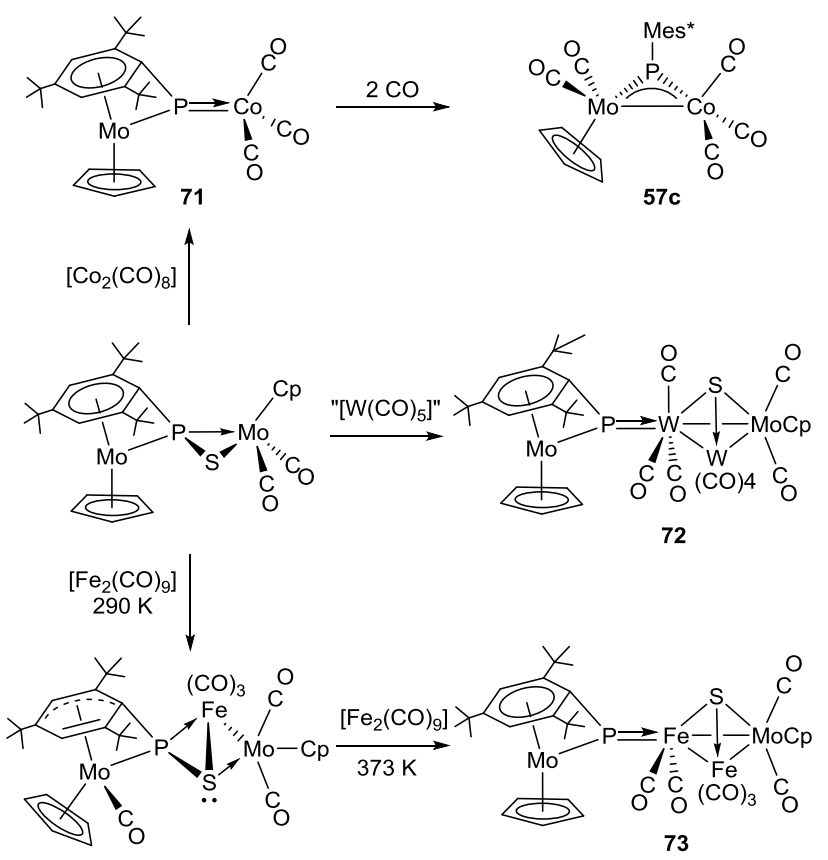


\section{Scheme 39}

The reaction of the three-coordinate amido complexes $\left[\left(\mathrm{IMe}_{4}\right) \mathrm{M}\left\{\mathrm{N}\left(\mathrm{SiMe}_{3}\right)_{2}\right\}_{2}\right](\mathrm{M}=\mathrm{Fe}$ or $\mathrm{Co}$; $\mathrm{IMe}_{4}=1,3,4,5$-tetramethylimidazolin-2-ylidene) with $\mathrm{PH}_{2} \mathrm{Mes}$ in the presence of excess carbene yields the dinuclear phosphinidene complexes 74 and 75 after amine elimination (Scheme 40) [76]. The structure of both complexes is centrosymmetric, with four-coordinate metal centres occupying distorted tetrahedral environments, and $\mathrm{P}$ atoms at the bridging phosphinidene ligands displaying pyramidal geometries, consistent with the moderate deshielding of the corresponding ${ }^{31} \mathrm{P} N \mathrm{NR}$ resonances $\left(\delta_{\mathrm{P}}=330(\mathbf{7 4})\right.$ and $\left.449 \mathrm{ppm}(\mathbf{7 5})\right)$.

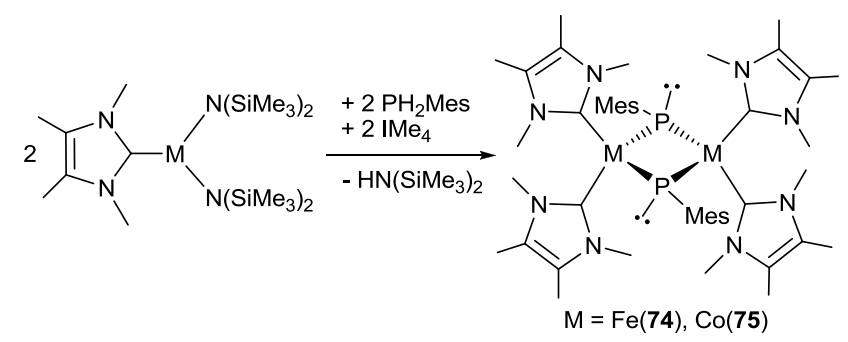

Scheme 40

\section{Structure and bonding}

As it can be appreciated from Table 2, some 70 crystal structures of $\mu_{2}$-phosphinidene complexes have been reported within the timeframe covered by this review. Around $75 \%$ of these complexes display a trigonal planar environment around the $\mathrm{P}$ atom of the phosphinidene ligand and, within this group of complexes, the symmetric coordination mode is clearly more abundant $(63 \%)$ than the asymmetric one (12\%). Given the relatively large number of structures reported, as well as the intrinsic differences of the three coordination modes, it seems appropriate to discuss separately each type. For the sake of brevity, we will focus our discussion only on the most relevant complexes, either for reasons of unusual structural and bonding features, or for aspects related to their chemistry.

\subsection{Pyramidal phosphinidene complexes}

As noted in Section 2, pyramidal phosphinidene complexes can be viewed as doubly metallated phosphines, hence two conventional M-P single bonds should be formulated, this leaving at the phosphinidene $\mathrm{P}$ atom a lone electron pair not involved in bonding with the 
metal atoms. This is nicely exemplified by the diiron complexes $\mathbf{3 2 b}$ and $\mathbf{3 2 d}$, which display M-P bond lengths around 2.25-2.30 $\AA$ [42b, c], figures which are slightly longer than those measured for related phosphanyl $\left(\mu-\mathrm{PR}_{2}\right)$ complexes, as expected from the different number of electrons provided by the $\mathrm{P}$ atoms in each case ( 1 vs. 1.5 per $\mathrm{M}-\mathrm{P}$ bond, respectively). However, this trend does not hold for the most numerous family of pyramidal phosphinidene complexes, which are those based on zirconium. In these compounds, the analysis of the bonding parameters is not so straightforward, as the corresponding $\mathrm{Zr}-\mathrm{P}$ lengths depend critically on the oxidation state of the metals and the overall charge of the complex, with both values being not clearly defined for all these complexes. Thus, $\mathrm{Zr}-\mathrm{P}$ bond lengths in the anionic complexes $\left[\mathrm{Zr}_{2} \mathrm{Cp}_{4}(\mu-\mathrm{PPh})_{2}\right]^{2-}$ (10) (av. $\left.2.57 \AA\right)$ [20a] and $\left[\mathrm{Zr}_{2} \mathrm{Cp}_{4}(\mu-\mathrm{PHPh})(\mu-\right.$ $\mathrm{PPh})]^{-}(a v .2 .57 \AA$ ) [20b], are shorter than the reference values for related $\mathrm{Zr}(\mathrm{III})$ neutral phosphanyl complexes $\left[\mathrm{Zr}_{2} \mathrm{Cp}_{4}(\mu-\mathrm{PHR})_{2}\right]$ (i.e. $2.64 \AA$ for $\mathrm{R}=\mathrm{Cy}$ ) [20b]. We must recall here that an alternative formulation has been suggested by Shilov and co-workers for these compounds, this involving the presence of mixed-valence $\mathrm{Zr}(\mathrm{III}) / \mathrm{Zr}(\mathrm{IV})$ centres which then renders all these compounds as monoanionic bis(phosphinidene) complexes [21]. A similar situation occurs in the complexes $\left[\mathrm{Zr}_{2} \mathrm{Cp}_{4}\left(\mu-\mathrm{PSiR}_{3}\right)_{2}\right][71]$ and $\left[\mathrm{Zr}_{2} \mathrm{Cp}_{3}\left(\mathrm{NEt}_{2}\right)\{\mu-\right.$ $\left.\mathrm{PSiMe}_{2}\left(\mathrm{CMe}_{2}{ }^{i} \mathrm{Pr}\right)\right\}_{2}$ ] [70], which display similar or slightly shorter $\mathrm{Zr}-\mathrm{P}$ bonds (2.60-2.64 and 2.52-2.62 $\AA$, respectively) than the related $\mathrm{Zr}$ (IV) bis(phosphanyl) complexes (2.65-2.70 $\AA$ A) [71]. Finally, the only crystallographically characterised Pt phosphinidene complex, $\left[\mathrm{Pt}_{2}(\text { dippe })_{2}(\mu-\mathrm{PPh})\right][56]$, contains a strongly pyramidalised $\mathrm{P}$ atom $\left(\sum \mathrm{X}-\mathrm{P}-\mathrm{Y}=290^{\circ}\right)$ with bonds to platinum ( $c a .2 .30 \AA$ ) being slightly shorter than those involving the diphosphine dippe ligand ( $a v .2 .38 \AA$ ), but otherwise compatible with a single-bond formulation.

\subsection{Symmetric trigonal planar phosphinidene complexes}

The vast majority of $\mu_{2}$-phosphinidine complexes characterised to date display a trigonal planar environment at the $\mathrm{P}$ atom which enables the participation of the $\mathrm{P}$ lone electron pair in $\mathrm{M}-\mathrm{P} \pi$-bonding, hence conferring multiple character to these bonds. In the case of the symmetric coordination, the $\mathrm{P}$ atom connects isoelectronic metal fragments and, ideally, the $\mathrm{P}-$ lone electron pair would be equally delocalised over the $\mathrm{M}-\mathrm{P}-\mathrm{M}$ skeleton thus conforming to a three-centre two-electron $\pi$ bonding interaction, with this resulting in two similar and relatively short $\mathrm{M}-\mathrm{P}$ bonds [3]. 
Several dinuclear scandium complexes have been structurally characterised [48, 29]. All these complexes have Sc-P bond lengths in the range 2.41-2.60 $\AA$, values which are significantly shorter than those measured for single dative bonds, such as those involving the framework phosphine ligands in complex 19 (2.83 Å) [29b]. Similarly short M-P bond lengths, indicative of the presence of significant multiple bonding, were also measured for several homo- or heterometallic V (ca. $2.25 \AA$ ) [6], Mn (ca. $2.15 \AA$ ) [19, 59], Co (ca. 2.08

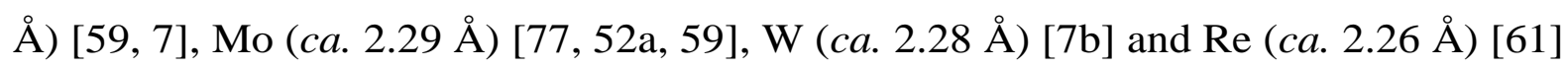
phosphinidene complexes. Nevertheless, some outsiders have been identified with slightly longer distances, such as the $c i s$ and trans isomers of $\left[\mathrm{Mo}_{2} \mathrm{Cp}_{2}\left(\mu-\mathrm{PMes}^{*}\right)\left(\mu-\kappa^{1}: \eta^{2}-\right.\right.$ $\left.\left.\mathrm{CN}^{t} \mathrm{Bu}\right)(\mathrm{CO})_{2}\right]$ (range 2.29-2.38) [77], and complexes of type $\left[\mathrm{W}_{2}(\mu-\mathrm{PR})(\mathrm{CO})_{10}\right](2.42-2.45$ $\AA$ ) $[10,57,78]$. These M-P lengths are longer than expected surely because of steric effects, but in any case they are still below the reference values for single dative bonds (e.g. $2.51 \AA$ in $\left.\left[\mathrm{M}(\mathrm{CO})_{5}\left(\mathrm{PMe}_{3}\right)\right], \mathrm{M}=\mathrm{Mo}[79], \mathrm{W}[80]\right)$.

Significant structural data are also available for an extensive family of dinuclear tantalum complexes reported by the groups of Hey-Hawkins [30, 44] and Fryzuk [46]. All these complexes display trigonal planar geometry around the $\mathrm{P}$ atoms, with relatively short $\mathrm{Ta}-\mathrm{P}$ lengths ( $a v .2 .36 \AA$ ) which are well below those of bridging phosphanyl ligands (e.g. $\left[\mathrm{Ta}_{2} \mathrm{Cp}_{2}{ }_{2}\left(\mu-\mathrm{PPh}_{2}\right)_{2}\left(\mathrm{PPh}_{2}\right)_{2}\right], a v$. Ta-P $\left.2.47 \AA\right)$ [44], or the ancillary phosphine ligands present in Fryzuk's complex (av. $2.63 \AA$ ), therefore indicative of the presence of significant $\pi$ bonding contribution to the Ta-P bond.

The diiron complex 45 behaves differently, since it displays relatively long $\mathrm{Fe}-\mathrm{P}$ bonds ( $c a$. $2.45 \AA$ ) [50]. In fact, these figures are significantly longer than those measured for the trigonal planar phosphinidene complex $\left[\mathrm{Fe}_{2}\left\{\mu-\mathrm{P}\left(\mathrm{OC}_{6} \mathrm{H}_{2}\left({ }^{t} \mathrm{Bu}\right)_{2} \mathrm{Me}\right\}_{2}(\mathrm{CO})_{6}\right](2.20\right.$ and $2.11 \AA)$ [81], and even longer than those in the diiron carbonyl complexes with pyramidal phosphinidene ligands of type 32 (2.25-2.30 ̊) [42b, c]. In a similar way, several $\mathrm{Zr}$ phosphinidene complexes with trigonal planar environments around the $\mathrm{P}$ atom also display $\mathrm{Zr}-\mathrm{P}$ bond lengths (2.55-2.64 $\AA$ ) which are remarkably similar to those of related $\mathrm{Zr}$ complexes with pyramidal phosphinidene ligands (2.53-2.64 $\AA$ ). Then, it is tempting to conclude that, in spite of the trigonal planar disposition around the $\mathrm{P}$ atoms in all these complexes, the $\pi$-component in the corresponding $\mathrm{M}-\mathrm{P}$ bonds is relatively weak, so the metal-phosphorus interaction might be better described in $\sigma$-only terms, as done for the mononuclear electrophilic complexes of type A. More work will be needed in order to better 
clarify the $\mathrm{M}-\mathrm{P}-\mathrm{M}$ bonding in these unusual trigonal complexes and the chemical consequences, if any, of it.

As for rare-earth elements, five binuclear phosphinidene complexes have been reported. The first lanthanide phosphinidene complex to be reported was the lutetium dimer 41, displaying an asymmetric $\mathrm{Lu}_{2} \mathrm{P}_{2}$ core with two short and two long $\mathrm{Lu}-\mathrm{P}$ bonds, with an average difference between them of nearly $0.06 \AA$ [47]. The short bonds in this complex are shorter than the reference Lu-P bond distances reported for lutetium phosphanyl complexes (av. 2.80 $\mathrm{A}$ ) [82]. This situation led the authors to conclude that this complex would be better described as an asymmetric dimer of the terminal phosphinidene $\left[\mathrm{Lu}\left\{\left(\mathrm{C}_{6} \mathrm{H}_{3}\left({ }^{i} \mathrm{Pr}_{2} \mathrm{P}\right) \mathrm{Me}\right)_{2} \mathrm{~N}\right\}\right.$ (PMes) , retaining two Lu-P bonds with an order greater than 1. Quite interestingly, two out of the three $\mathrm{Nd}$ phosphinidene complexes also displayed slightly asymmetric $\mathrm{Nd}_{2} \mathrm{P}_{2}$ cores $(\Delta d \approx 0.04 \AA)$ [28, 27]. Finally, an unusual structure was found for the thorium phosphinidene complex $\mathbf{4 3}$, with a T-shaped rather than trigonal planar geometry around $\mathrm{P}$ (Scheme 24), with a nearly linear Th-P-Th bond angle of 173.99(3) ${ }^{\circ}$ [49]. The Th-P bonds in this complex (av. $2.80 \AA$ ) are only slightly shorter than those in the mononuclear phosphanyl complex [ThCp* ${ }_{2}$ (PHTrip) ${ }_{2}$ (av. $2.88 \AA$ ). However, the linearity of the Th-P-Th group is likely enforced by the $\mathrm{Th}-\mathrm{CH}_{2}$ linkages, while a Natural Bond Orbital (NBO) analysis indicated that there is no multiple character in the corresponding Th- $\mathrm{P}$ bonds.

\subsection{Asymmetric trigonal planar phosphinidene complexes}

Only nine crystal structures containing a phosphinidene ligand bridging two transition metal fragments with different electron counts have been reported, and in all these examples the PR group bridges 17- and 15-electron metal fragments.

The first reported example of this family of compounds was the ditungsten complex 64 [66]. This compound displays a short $\mathrm{W}-\mathrm{P}$ bond length of $2.28 \AA$ with the 15 -electron fragment, a figure which is almost identical to that measured for the complex [ $\left.\mathrm{WCp}\left(\mathrm{P}^{t} \mathrm{Bu}_{2}\right)(\mathrm{CO})_{2}\right]$, a molecule with a three-electron donor phosphanyl ligand. On the other hand, the $\mathrm{W}-\mathrm{P}$ bond with the 17-electron fragment is significantly longer $(2.55 \AA)$, a value which can be taken as reference for a single-bond interaction and which expectedly is longer than the single dative bond with the terminal phosphine ligand in the same complex $(2.44 \AA)$. The related complex 11 displays slightly longer bond lengths of 2.30 and $2.61 \AA$, perhaps reflecting the higher steric demands of the phosphinidene substituent in this case (Mes*vs. Mes) [23]. 
The third reported example was the heterometallic complex 66 [67]. The Fe-P bond length in this complex $(2.26 \AA)$ approaches the values in the related $\mu_{3}$-phosphinidene complex $\left[\mathrm{Fe}_{2} \mathrm{MnCp} *\left(\mu_{3}\right.\right.$-POMes*)(CO) $]$ (av. $\left.2.24 \AA\right)$, and therefore is consistent with the singlebond formulation required to attain an 18 -electron configuration at the $\mathrm{FeCp}(\mathrm{CO})_{2}$ fragment. In contrast, the Mn-P distance of $2.13 \AA$ is much shorter than the single-bond length measured for the latter trimetallic complex (2.24 $\AA$ ) and approaches the figure measured for the $\mathrm{Mn}=\mathrm{P}$ bond in the phosphanyl complex $\left[\mathrm{Mn}\left\{\mathrm{P}\left(\mathrm{OMes}^{*}\right)\left(\mathrm{C}_{5} \mathrm{Me}_{5}\right)\right\}(\mathrm{CO})_{4}\right](2.08 \AA)$, thus indicating the presence of significant multiplicity in this bond [67].

The remaining six complexes contain bifunctional phosphinidene ligands where the phosphorus atom bridges asymmetrically two metal centres while binding one of them in a $\eta^{\mathrm{n}}$-fashion through its aryl or cyclopentadienylidene ring, a circumstance imposing some geometrical constraints. The dimolybdenum complexes 48 [52], 49b [52a] and 51 [84] display long Mo-P bonds of ca. $2.36 \AA$, some $0.2 \AA$ below the reference figure for a single bond (i.e. $2.55 \AA$ in 64) [66], thus suggesting the presence of some multiplicity in these bonds. On the other hand, the short Mo-P bond in these compounds ( $c a .2 .25 \AA$ ) is even marginally shorter than that measured in $\mathbf{6 4}$, therefore indicative of the presence of an important $\pi$-component in this bond.
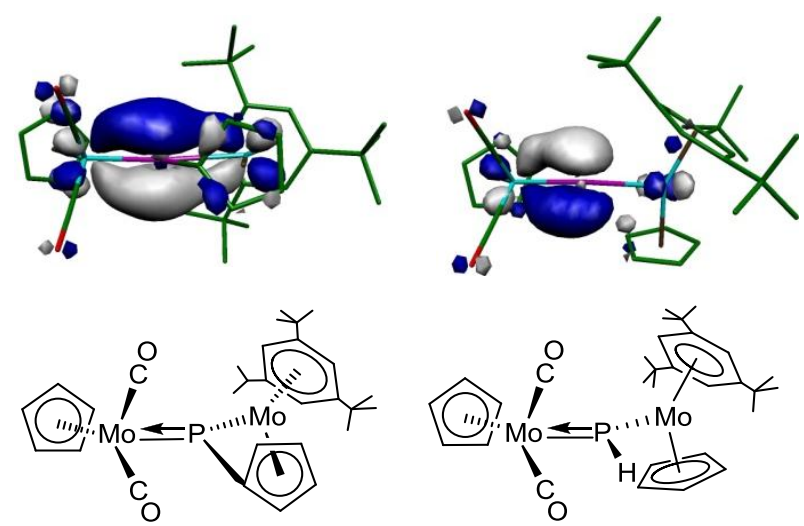

Figure 1

DFT calculations on $\mathbf{4 8}$ and $\mathbf{5 1}$ indeed revealed the presence of a $\pi$-bonding interaction significantly (but not fully) delocalised over the Mo-P-Mo skeleton in the above complexes (Figure 1, left) [83]. Interestingly, analogous calculations on the related PH-bridged complex 62 revealed that the metallocene fragment in this molecule is rotated by $90^{\circ}$ with respect to the bifunctional phosphinidenes, and the $\pi$-bonding interaction of the $\mathrm{P}$ atom is fully localised on the short Mo-P 
bond (Figure 1, right). Then it can be concluded that the geometrical constrains imposed by the bifunctional $\mathrm{PMes}^{*}$ and $\mathrm{PC}_{5} \mathrm{H}_{4}$ phosphinidenes are a critical element enabling partial delocalisation of the $\pi$-bonding interaction over the $\mathrm{M}-\mathrm{P}-\mathrm{M}$ skeleton in these complexes. Indeed, the same structural effect was later observed for the $\mathrm{M}-\mathrm{P}-\mathrm{M}^{\prime}$ skeletons in the heterometallic complexes 71, 72 and 73, with long P-Mo bonds of only $2.33 \AA$ [74]. 
Table 2. Structural and ${ }^{31} \mathrm{P}$ NMR parameters for crystallographically-characterized complexes containing $\mu_{2^{-}}$ phosphinidene ligands. ${ }^{a}$

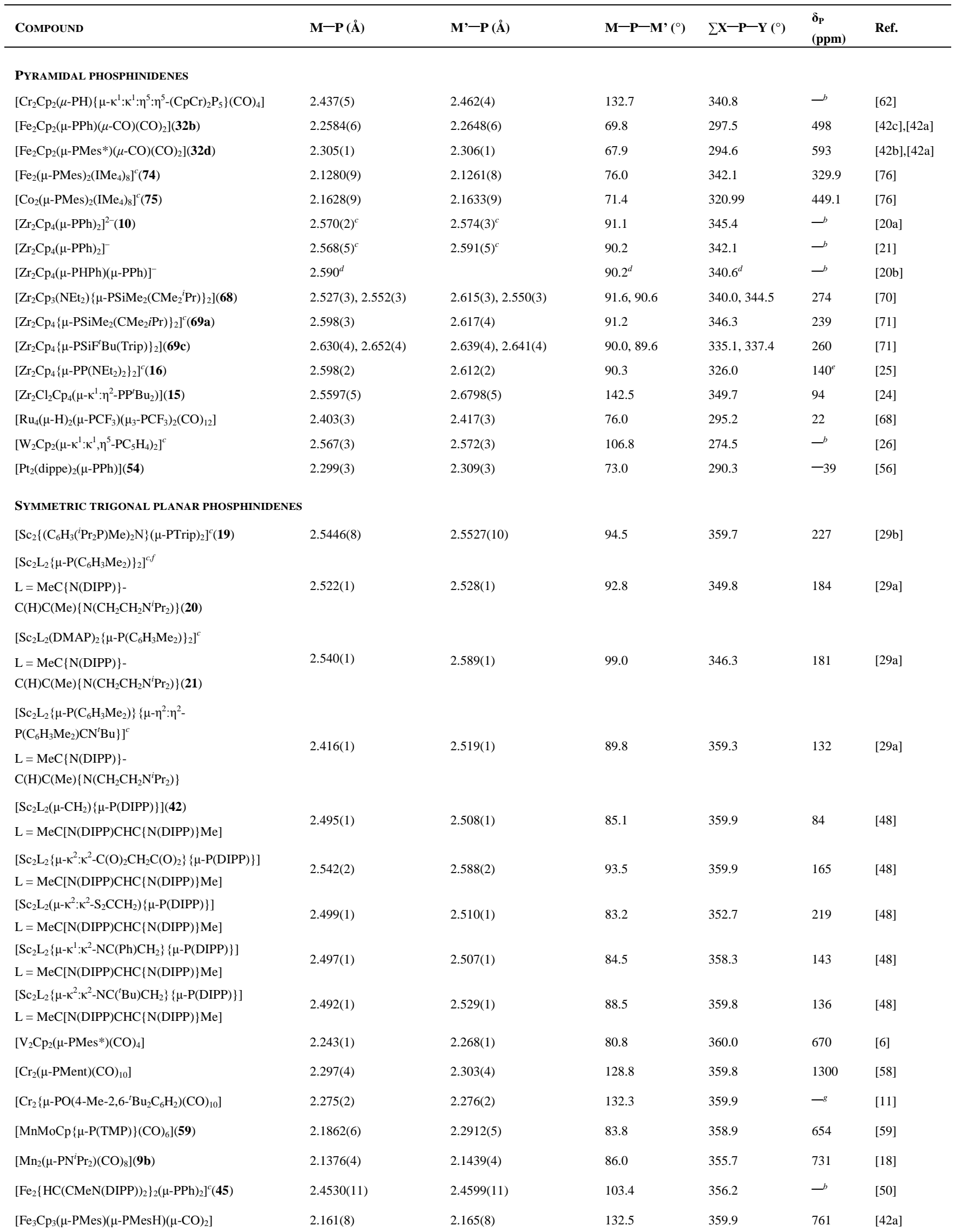




\begin{tabular}{|c|c|c|c|c|c|c|}
\hline$\left[\mathrm{Co}_{2} \mathrm{Cp}_{2}\left(\mu-\mathrm{PMes}^{*}\right)(\mathrm{CO})_{2}\right](2)$ & $2.105(3)$ & $2.115(4)$ & 134.0 & 359.9 & 612 & [7a] \\
\hline$\left[\mathrm{Co}_{2}\left(\mu-\mathrm{PMes}^{*}\right)(\mathrm{CO})_{6}\right]^{c}$ & $2.047(6)$ & & 82.0 & 359.8 & 664 & [7b] \\
\hline$\left[\mathrm{CoMoCp}\{\mu-\mathrm{P}(\mathrm{TMP})\}(\mathrm{CO})_{5}\right](\mathbf{5 7} \mathbf{a})$ & $2.0801(5)$ & $2.2821(5)$ & 85.3 & 360.0 & 587 & [59] \\
\hline$\left[\mathrm{CoMoCp} *\left(\mu-\mathrm{PN}^{i} \mathrm{Pr}_{2}\right)(\mathrm{CO})_{5}\right](\mathbf{5 7 b})$ & $2.067(1)$ & $2.268(1)$ & 87.1 & 359.5 & 588 & [59] \\
\hline$\left[\mathrm{Zr}_{2} \mathrm{Cl}_{2} \mathrm{Cp}_{4}(\mu-\mathrm{PMes})\right](\mathbf{3 6})$ & $2.597(6)$ & $2.637(6)$ & 134.7 & 359.4 & 326 & [22] \\
\hline$\left[\mathrm{Zr}_{2} \mathrm{Cp}_{2}(\mathrm{Ful})\left(\mu-\mathrm{PHSiPh}_{3}\right)\left(\mu-\mathrm{PSiPh}_{3}\right)\right](\mathbf{4 4})$ & $2.579(5)$ & $2.583(5)$ & 87.49 & 352.2 & $-^{g}$ & [20b] \\
\hline$\left[\mathrm{Zr}_{2} \mathrm{ClCp}_{3}\left(\mu-\kappa^{1}: \eta^{5}-\mathrm{C}_{5} \mathrm{H}_{4}\right)\left(\mu-\mathrm{PSiPh}_{3}\right)\right](\mathbf{3 5})$ & $2.549(6)$ & $2.559(6)$ & 95.2 & 359.8 & 244 & {$[2 \mathrm{j}]$} \\
\hline$\left[\mathrm{Zr}_{2} \mathrm{Cp}_{4} \mathrm{Me}_{2}(\mu-\mathrm{PMes})\right](\mathbf{3 8})$ & $2.606(3)$ & $2.646(3)$ & 136.6 & 359.5 & 303 & [45] \\
\hline$\left[\mathrm{Zr}_{2} \mathrm{Cp}_{3}\left(\mu-\kappa^{1}: \eta^{5}-\mathrm{C}_{5} \mathrm{H}_{4}\right)(\mu-\mathrm{PMes})(\mathrm{PHMes})\right](37)$ & $2.576(7)$ & $2.586(7)$ & 93.3 & 354.3 & 395 & [45] \\
\hline$\left[\mathrm{Mo}_{2} \mathrm{Cp}_{2}(\mu \text {-PMes*)(CO) })_{4}\right](\mathbf{1})$ & $2.297(8)$ & $2.315(8)$ & 88.4 & 359.4 & 687 & [7b] \\
\hline$\left[\mathrm{Mo}_{2} \mathrm{Cp}_{2} \mathrm{I}_{2}(\mu-\mathrm{PMes})(\mathrm{CO})_{2}\right]^{c}$ & $2.294(2)$ & & 80.3 & 360.0 & 596 & [51] \\
\hline$\left[\mathrm{Mo}_{2} \mathrm{Cp}_{2}\{\mu-\mathrm{P}(\mathrm{TMP})\}(\mathrm{CO})_{4}\right](\mathbf{5 8})$ & $2.2826(5)$ & $2.2876(5)$ & 92.1 & 360.0 & 647 & [59] \\
\hline$\left[\mathrm{Mo}_{2} \mathrm{Cp}_{2}(\mu-\mathrm{PMes})(\mu-\mathrm{CO})_{2}\right](\mathbf{4 7})$ & $2.2970(6)$ & $2.3028(5)$ & 66.8 & 359.8 & 532 & [52a] \\
\hline$\left[\mathrm{Mo}_{2} \mathrm{Cp}_{2}(\mu\right.$-PMes $*)(\mathrm{CO})_{2}(\mu$-dmpm $\left.)\right]$ & $2.272(2)$ & $2.332(2)$ & 93.1 & 359.8 & 590 & [77] \\
\hline$\left[\mathrm{Mo}_{2} \mathrm{Cp}_{2}\left(\mu-\mathrm{PMes}^{*}\right)(\mathrm{CO})_{2}\left(\kappa^{2}-\mathrm{dmpm}\right)\right]$ & $2.278(2)$ & $2.362(2)$ & 86.4 & 359.8 & 656 & [77] \\
\hline trans-[$\left[\mathrm{Mo}_{2} \mathrm{Cp}_{2}\left(\mu-\mathrm{PMes}^{*}\right)\left(\mu-\kappa^{1}: \eta^{2}-\mathrm{CN}^{t} \mathrm{Bu}\right)(\mathrm{CO})_{2}\right]$ & $2.2915(8)$ & $2.3334(8)$ & 85.7 & 359.4 & 688 & [77] \\
\hline cis-[Mo $\left.\mathrm{Mp}_{2}\left(\mu-\mathrm{PMes}^{*}\right)\left(\mu-\kappa^{1}: \eta^{2}-\mathrm{CN}^{t} \mathrm{Bu}\right)(\mathrm{CO})_{2}\right]$ & $2.3012(6)$ & $2.3766(6)$ & 82.4 & 359.7 & 656 & [77] \\
\hline$\left[\mathrm{Nd}_{2} \mathrm{I}_{2}\{\mu-\mathrm{P}(\mathrm{DIPP})\}_{2}(\mathrm{THF})_{6}\right]^{c}(\mathbf{1 7})$ & $2.7314(15)$ & $2.7769(16)$ & $95.4,95.4$ & 359.0 & $-^{b}$ & [27] \\
\hline$\left[\mathrm{Nd}_{2} \mathrm{Cp}_{2}{ }_{2}\{\mu-\mathrm{P}(\mathrm{DIPP})\}_{2}(\mathrm{THF})_{2}\right]^{c}(\mathbf{1 8 a})$ & $2.7456(11)$ & $2.7827(10)$ & 96.2 & 349.2 & $-^{b}$ & [28] \\
\hline$\left[\mathrm{Nd}_{2}{ }^{\mathrm{Ph}} \mathrm{Tp}_{2}\{\mu-\mathrm{P}(\mathrm{DIPP})\}_{2}(\mathrm{THF})_{2}\right]^{\mathrm{ch} h}(\mathbf{1 8 b})$ & $2.7808(16)$ & $2.7911(15)$ & 103.2 & 358.9 & $-^{i}$ & [28] \\
\hline$\left[\mathrm{Lu}_{2}\left\{\left(\mathrm{C}_{6} \mathrm{H}_{3}\left({ }^{i} \mathrm{Pr}_{2} \mathrm{P}\right) \mathrm{Me}\right)_{2} \mathrm{~N}\right\}_{2}(\mu-\mathrm{PMes})_{2}\right](\mathbf{4 1})$ & $\begin{array}{l}2.6031(16) \\
2.6724(14)\end{array}$ & $2.6527(16), 2.6724(14)$ & $\begin{array}{l}96.96(5), \\
96.61(5)\end{array}$ & $358.9,356.5$ & 187 & [47] \\
\hline$\left[\mathrm{Ta}_{2} \mathrm{Cl}_{2} \mathrm{Cp}_{2}{ }_{2}(\mu-\mathrm{PTrip})_{2}\right]^{c}(\mathbf{3 4})$ & $2.317(6)$ & $2.338(2)$ & 83.5 & 360.0 & 392 & [44] \\
\hline trans $-\left[\mathrm{Ta}_{2} \mathrm{Cl}_{2} \mathrm{Cp}_{2}{ }_{2}(\mu-\mathrm{PCy})_{2}\right]^{c}(\mathbf{2 2 a})$ & $2.334(2)$ & $2.336(2)$ & 84.3 & 360.0 & 438 & [30] \\
\hline trans $-\left[\mathrm{Ta}_{2} \mathrm{Cl}_{2} \mathrm{Cp}_{2}{ }_{2}\left(\mu-\mathrm{P}^{t} \mathrm{Bu}\right)_{2}\right]^{c}(\mathbf{2 2} \mathbf{b})$ & $2.354(1)$ & $2.357(1)$ & 84.8 & 359.8 & 482 & [30] \\
\hline trans- $\left[\mathrm{Ta}_{2} \mathrm{Cl}_{2} \mathrm{Cp}_{2}(\mu-\mathrm{PPh})_{2}\right]^{c}(\mathbf{2 2 c})$ & $2.344(1)$ & $2.345(1)$ & 85.9 & 359.7 & 404 & [30] \\
\hline trans- $\left[\mathrm{Ta}_{2} \mathrm{Cl}_{2} \mathrm{Cp}_{2}{ }_{2}(\mu-\mathrm{PMes})_{2}\right]^{c}(\mathbf{2 2 d})$ & $2.328(2)$ & $2.331(2)$ & 82.7 & 360.0 & 390 & [30] \\
\hline cis- $\left[\mathrm{Ta}_{2} \mathrm{Cl}_{2} \mathrm{Cp}_{2}{ }_{2}(\mu-\mathrm{PMes})_{2}\right]$ & $2.344(2), 2.344(2)$ & $2.344(2), 2.349(1)$ & $82.3,82.4$ & $358.0,357.8$ & 399 & [30] \\
\hline cis- $\left[\mathrm{Ta}_{2} \mathrm{Cl}_{2} \mathrm{Cp}_{2}{ }_{2}(\mu-\mathrm{PMes})_{2}\right]$ & $2.348(3), 2.358(3)$ & $2.336(3), 2.357(3)$ & $83.0,83.7$ & $356.8,358.8$ & 396 & [30] \\
\hline$\left[\mathrm{Ta}_{2}\left\{\mathrm{CyP}\left(\mathrm{CH}_{2} \mathrm{SiMe}_{2} \mathrm{NPh}\right)_{2}\right\}_{2}(\mu-\mathrm{H})_{2}(\mu-\mathrm{PAd})\right](\mathbf{4 0 a})$ & $2.3394(9)$ & $2.4030(9)$ & 71.0 & 359.58 & 468 & [46] \\
\hline$\left[\mathrm{W}_{2} \mathrm{Cp}_{2}\{\mu-\mathrm{P}(\mathrm{TMP})\}(\mathrm{CO})_{4}\right]$ & $2.278(7)$ & $2.290(7)$ & 90.8 & 360 & 593 & [7b] \\
\hline$\left[\mathrm{W}_{2} \mathrm{Cp}_{2}\left(\mu-\mathrm{PMes}^{*}\right)(\mathrm{CO})_{4}\right](\mathbf{1 2})$ & $2.2999(11)$ & $2.3178(10)$ & 87.9 & 359.8 & 601 & [23] \\
\hline$\left[\mathrm{W}_{2}\left(\mu-\mathrm{PCp}^{*}\right)(\mathrm{CO})_{10}\right](\mathbf{5})$ & $2.428(2)$ & $2.445(2)$ & 124.6 & 360.0 & 1077 & [10] \\
\hline$\left[\mathrm{W}_{2}\{\mu-\mathrm{P}(\mathrm{TMP})\}(\mathrm{CO})_{10}\right]$ & $2.440(4)$ & $2.449(4)$ & 123.3 & 359.7 & 959 & [78] \\
\hline$\left[\mathrm{W}_{2}\{\mu-\mathrm{PN}(\mathrm{H}) \mathrm{Ph}\}(\mathrm{CO})_{10}\right](\mathbf{5 5})$ & $2.4219(10)$ & $2.4333(10)$ & 131.2 & 359.7 & 728.5 & [57] \\
\hline$\left[\mathrm{W}_{4}\left\{\mu-\mathrm{PNC}\left(\mathrm{Cp}^{*}\right)-\mathrm{C}_{6} \mathrm{H}_{4}-\mathrm{C}(\mathrm{Cp} *) \mathrm{NP}\right\}(\mathrm{CO})_{20}\right](\mathbf{5 6})$ & $2.4249(9), 2.4265(8)$ & 2.4472(9), 2.4454(8) & $131.6,131.8$ & $359.6,359.7$ & 541.8 & [57] \\
\hline$\left[\operatorname{Re}_{2} \mathrm{Cp}_{2}(\mu-\mathrm{POH})(\mathrm{CO})_{4}\right](\mathbf{6 0})$ & $2.254(2)$ & $2.277(2)$ & 137.6 & 359.9 & 595 & [61] \\
\hline$\left[\mathrm{Th}_{2} \mathrm{Cp}_{4}^{*}\left\{\mu-\mathrm{P}\left(\mathrm{CH}_{2} \mathrm{CHMe}\right)_{2} \mathrm{C}_{6} \mathrm{H}_{2}^{i} \mathrm{Pr}\right\}\right]^{c}(\mathbf{4 3})$ & $2.8083(9)$ & $2.8186(9)$ & 174.0 & 359.9 & 162 & [49] \\
\hline \multicolumn{7}{|l|}{ ASYMMETRIC TRIGONAL PLANAR PHOSPHINIDENES } \\
\hline$\left[\mathrm{FeMnCp}^{*}\left(\mu-\mathrm{POMes} *(\mathrm{CO})_{6}\right](\mathbf{6 6})\right.$ & $2.126(2)$ & $2.258(2)$ & 133.1 & 359.9 & $-g$ & [67] \\
\hline$\left[\mathrm{Mo}_{2} \mathrm{Cp}_{2}\left(\mu-\kappa^{1}: \kappa^{1}, \eta^{6}-\mathrm{PMes} *\right)(\mathrm{CO})_{2}\right](\mathbf{4 8})$ & $2.2480(6)$ & $2.3630(6)$ & $156.54(2)$ & 359.9 & 510 & [52b] \\
\hline$\left[\mathrm{Mo}_{2} \mathrm{Cp}_{2}\left(\mu-\kappa^{1}: \kappa^{1}, \eta^{4}-\mathrm{PMes}^{*}\right)\left(\mathrm{CN}^{t} \mathrm{Bu}\right)(\mathrm{CO})_{2}\right](\mathbf{4 9 b})$ & $2.256(1)$ & $2.355(2)$ & 152.3 & 360.2 & 525 & [52a] \\
\hline$\left[\mathrm{Mo}_{2} \mathrm{Cp}\left(\mu-\kappa^{1}: \kappa^{1}, \eta^{5}-\mathrm{PC}_{5} \mathrm{H}_{4}\right)(\mathrm{CO})_{2}\left(\mathrm{HMes}^{*}\right)\right](\mathbf{5 1})$ & $2.252(2)$ & $2.403(1)$ & $163.7(1)$ & 359.9 & 519 & [84] \\
\hline$\left[\mathrm{CoMoCp}\left(\mu-\kappa^{1}: \kappa^{1}, \eta^{6}-\mathrm{PMes} *\right)(\mathrm{CO})_{3}\right](\mathbf{7 1})$ & $2.054(2)$ & $2.326(1)$ & 151.1 & 358.1 & 628 & [74] \\
\hline$\left[\mathrm{Fe}_{2} \mathrm{Mo}_{2} \mathrm{Cp}_{2}\left(\mu-\kappa^{1}: \kappa^{1}, \eta^{6}-\mathrm{PMes} *\right)\left(\mu_{3}-\mathrm{S}\right)(\mathrm{CO})_{7}\right](\mathbf{7 3})$ & $2.087(1)$ & $2.325(1)$ & 150.8 & 359.9 & 614 & [74] \\
\hline
\end{tabular}




\begin{tabular}{|c|c|c|c|c|c|c|}
\hline$\left[\mathrm{Mo}_{2} \mathrm{~W}_{2} \mathrm{Cp}_{2}\left(\mu-\kappa^{1}: \kappa^{1}, \eta^{6}-\mathrm{PMes}^{*}\right)\left(\mu_{3}-\mathrm{S}\right)(\mathrm{CO})_{9}\right](\mathbf{7 2})$ & $2.343(1)$ & $2.284(1)$ & 158.3 & 359.9 & 469 & [74] \\
\hline$\left[\mathrm{W}_{2} \mathrm{Cp}_{2}(\mu\right.$-PMes $\left.)(\mathrm{CO})_{4}\left(\mathrm{PH}_{2} \mathrm{Mes}\right)\right](\mathbf{6 4})$ & $2.281(3)$ & $2.550(3)$ & 136.7 & 360 & 314 & [66] \\
\hline$\left[\mathrm{W}_{2} \mathrm{Cp}_{2}\left(\mu\right.\right.$-PMes $\left.*(\mathrm{CO})_{5}\right](\mathbf{1 1})$ & $2.2976(16)$ & $2.6064(15)$ & 127.6 & 359.9 & 255.2 & [23] \\
\hline
\end{tabular}

${ }^{a}$ For complexes of formula $\left[\mathrm{MM}^{\prime}(\mu-\mathrm{PR}) \mathrm{L}_{\mathrm{n}}\right] \mathrm{M}$ has been assigned to the metal atom with lower atomic number, while for complexes of formula $\left[\mathrm{M}_{2}(\mu-\mathrm{PR}) \mathrm{L}_{\mathrm{n}}\right] \mathrm{M}$ has been arbitrarily taken as the metal centre with the shortest bond to P. ${ }^{b}$ Paramagnetic compound. ${ }^{c}$ Centrosymmetric compound. ${ }^{d}$ The P-bound hydrogen atom could not be located and therefore average values between the phosphanyl and phosphinidene ligand are provided. ${ }^{e}$ Broad signal, possibly average resonance. ${ }^{f}$ Two independent molecules present in the asymmetric unit. ${ }^{\mathrm{g}}$ Not reported. ${ }^{h}$ Modified Tp ligand, see Scheme $9 .{ }^{i}$ The NMR signals of the complex are very broad and not informative. ${ }^{i}$ Not reported. ${ }^{j}$ P-bound hydrogen atom not located.

\section{Reactivity}

In this section we will review the extensive literature dealing with reactions of $\mu_{2}$-phosphinidene complexes, excluding those of synthetic use, already discussed in Section 3. For clarity purposes, the contents of this epigraph is distributed into three main sections, each of them dealing with the reactivity of the three main types of $\mu_{2}$-phosphinidene complexes under discussion, namely pyramidal, symmetric trigonal planar, and asymmetric trigonal planar (types $\mathbf{D}, \mathbf{E}$ and $\mathbf{F}$ in Chart 1). Within each section, distinct subsections are provided according to the different types of reactions being discussed.

\subsection{Pyramidal phosphinidene complexes}

As noticed in Section 2, the chemical behaviour of this sort of complexes is dominated by the high nucleophilicity of the $\mathrm{P}$ atom, which in turn is derived from the presence of a lone electron pair at this site. In the next subsections we will discuss different reactions of these complexes, ranging from addition of simple electrophiles at the $\mathrm{P}$ site to more complex rearrangements or couplings following from this first elemental step. Some of these reactions have been mentioned already in Section 3, and therefore will not be discussed in detail (or not at all) here.

\subsubsection{Reactions with simple electrophiles}

The protonation reaction of the lithium salt of the dianionic bis(phosphinidene) complex $\left[\mathrm{Zr}_{2} \mathrm{Cp}_{4}(\mu-\mathrm{PPh})_{2}\right]^{2-}(\mathbf{1 0})$ with one equivalent of $\mathrm{NR}_{3} \mathrm{H}^{+}$, or in the presence of TMEDA-HCl $($ TMEDA $=$ tetramethylethylenediamine $)$, gives the phosphanyl complex $\left[\mathrm{Zr}_{2} \mathrm{Cp}_{2}(\mu-\right.$ 
$\mathrm{PHPh})(\mu-\mathrm{PPh})]\left[(\mathrm{THF})_{2} \mathrm{Li}(\mathrm{TMEDA})\right][20 \mathrm{~b}]$. The paramagnetic nature of this compound, having two $\mathrm{Zr}$ (III) centres, was confirmed through an EPR study. Similarly, methylation of the above dianion with $\mathrm{Me}_{3} \mathrm{O}\left[\mathrm{BF}_{4}\right]$ gave the corresponding methylphosphanyl derivative $\left[\mathrm{Zr}_{2} \mathrm{Cp}_{2}(\mu-\mathrm{PMePh})(\mu-\mathrm{PPh})\right]^{-}$, also detected by EPR, which, as opposed to the protonation product, could not be isolated. The heterobimetallic phosphinidene complex $\mathrm{K}[\mathrm{MoZrCp}(\mu-$ $\left.\mathrm{PCy})\left(\mu-\kappa^{1}: \eta^{2}-\mathrm{CO}\right)(\mathrm{CO})\right]$ reacted similarly with $\mathrm{NH}_{4} \mathrm{Cl}$ or $\mathrm{ND}_{4} \mathrm{Cl}$, the latter yielding the deuterated phosphanyl complex $\left[\operatorname{MoZrCp}(\mu-\mathrm{PDCy})\left(\mu-\kappa^{1}: \eta^{2}-\mathrm{CO}\right)(\mathrm{CO})\right]$.

As stated in Section 3.2, the phosphinidene complexes $\left[\mathrm{Ni}_{2} \mathrm{Cp}_{2}(\mu \text {-PRMes })(\mu-\mathrm{PMes})\right]^{-}(\mathrm{R}=\mathrm{H}, \mathrm{Me})$ and $\left[\mathrm{Ni}_{2} \mathrm{Cp}_{2}(\mu-\mathrm{PMes})\right]^{2-}$, prepared in situ, could be trapped by reacting them with MeI to give the corresponding neutral phosphanyl complexes $\left[\mathrm{Ni}_{2} \mathrm{Cp}_{2}(\mu\right.$-PRMes)( $\mu$-PMeMes)], as mixtures of syn and anti isomers $(\mathrm{R}=\mathrm{H})$, or only as the syn isomer $(\mathrm{R}=\mathrm{Me})$ [36]. Likewise, the diplatinum phosphinidene complex 30, also generated in situ, reacted with excess MeI to form the phosphanyl dication 76, whereas the addition of excess $\mathrm{BH}_{3}$. THF led to the borane adduct 77 (Scheme 41) [41]. In both cases, only one species was formed, as judged from the NMR spectra, although the authors could not identify the actual isomer (syn or anti), as crystalline structures were not obtained for any of these compounds.

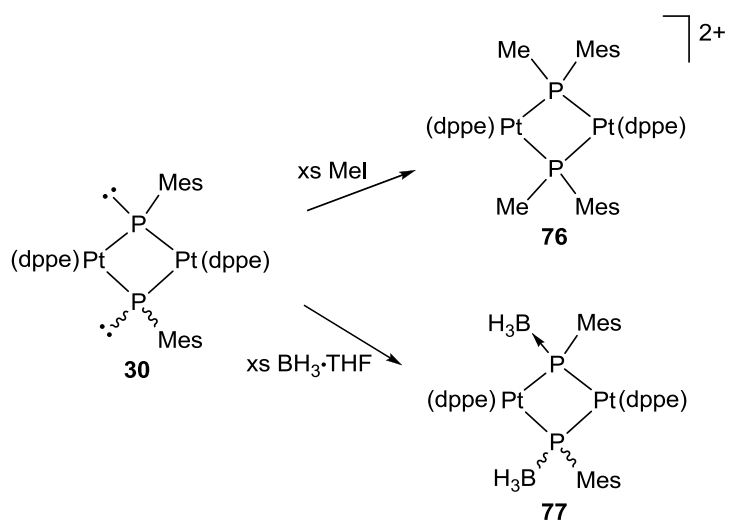

\section{Scheme 41}

Some subtle effects occur in the reactions of the diiron complexes 32a,b towards methylating agents such as $\mathrm{MeI}$ or $\mathrm{CF}_{3} \mathrm{SO}_{3} \mathrm{Me}[85,42 \mathrm{c}]$. As it turned out, the phosphinidene complexes were nucleophilic enough to react with MeI under mild reaction conditions (room temperature or below) to give the iodide salts of the phosphanyl complexes 78. The phenyl compound, however, was only stable at temperatures below $273 \mathrm{~K}$, giving rise to the neutral iodo complex 79 at higher temperatures, as a result of nucleophilic attack of the $\mathrm{I}^{-}$anion to one of the iron atoms of the cation, 
this in turn inducing the cleavage of the $\mathrm{Fe}-\mathrm{Fe}$ bond (Scheme 42). This reaction was reversible, as partial regeneration of the cationic species was observed after removal of solvent under vacuum. Apparently, the above nucleophilic attack is facilitated by the lower size and donor ability of the PPh ligand, when compared to the PCy one, since no iodide attack was observed in the latter case. In any event, to prevent this anion-cation reaction, methylation of the phenyl derivative was also performed with $\mathrm{CF}_{3} \mathrm{SO}_{3} \mathrm{Me}$ to give the stable triflate salt of $\mathbf{7 8 b}$. A similar reaction had been observed between the unstable tetracarbonyl complex $\left[\mathrm{Fe}_{2} \mathrm{Cp}_{2}(\mu-\mathrm{PPh})(\mathrm{CO})_{4}\right]$ and several alkyl halides RX, although in this case no subsequent halide coordination was reported [40].

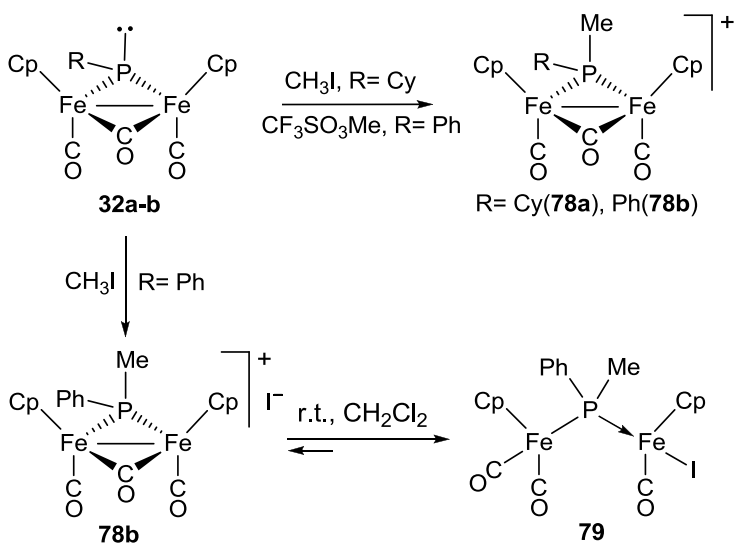

\section{Scheme 42}

The diiron complexes 32 also react with several borane adducts $\mathrm{BH}_{3} \cdot \mathrm{L}\left(\mathrm{L}=\mathrm{THF}, \mathrm{PPh}_{3}, \mathrm{~N}^{t} \mathrm{Bu}_{3}\right)$ to give the expected acid-base adducts 80 (Scheme 43) [85]. It should be mentioned that only the more labile THF adduct reacted readily with these complexes, whereas the more robust ones did only so with the more basic PCy complex and under thermal activation (343 K).

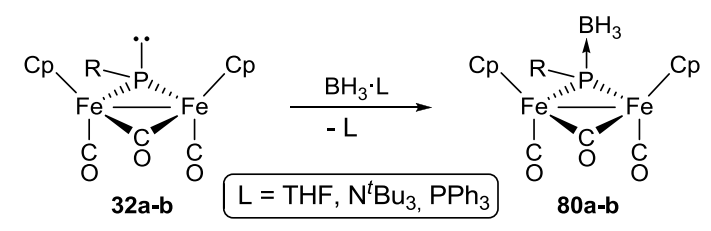

\section{Scheme 43}

The dimolybdenum complex 52 also reacts with $\mathrm{BH}_{3}$. THF to form the expected adduct $\mathbf{8 1}$ (Scheme 44) $[53,86]$, and with some other simple electrophiles such as $\mathrm{H}^{+}$and $\mathrm{Me}^{+}$[53]. Protonation with one equivalent of $\left[\mathrm{H}\left(\mathrm{OEt}_{2}\right)_{2}\right]\left(\mathrm{BAr}_{4}^{\prime}\right)\left[\mathrm{Ar}^{\prime}=3,5-\mathrm{C}_{6} \mathrm{H}_{3}\left(\mathrm{CF}_{3}\right)_{2}\right]$, a strong acid with a poorly coordinating anion, led to the stable salt of the phosphanyl-bridged cation 82a, whereas a second 
equivalent of acid caused protonation at the metallocene site to give the dipositive hydrido complex 83, a strongly acidic species which is deprotonated by addition of weak bases such as THF. Methylation of $\mathbf{5 2}$ was achieved by reaction with $\mathrm{MeI}$ at room temperature, and the stable borate salt of the cation 82b was isolated in good yield after anion exchange (Scheme 44). X-ray quality crystals of the related $\mathrm{PMe}_{2} \mathrm{Ph}$ complex could be grown to confirm the corresponding structure.

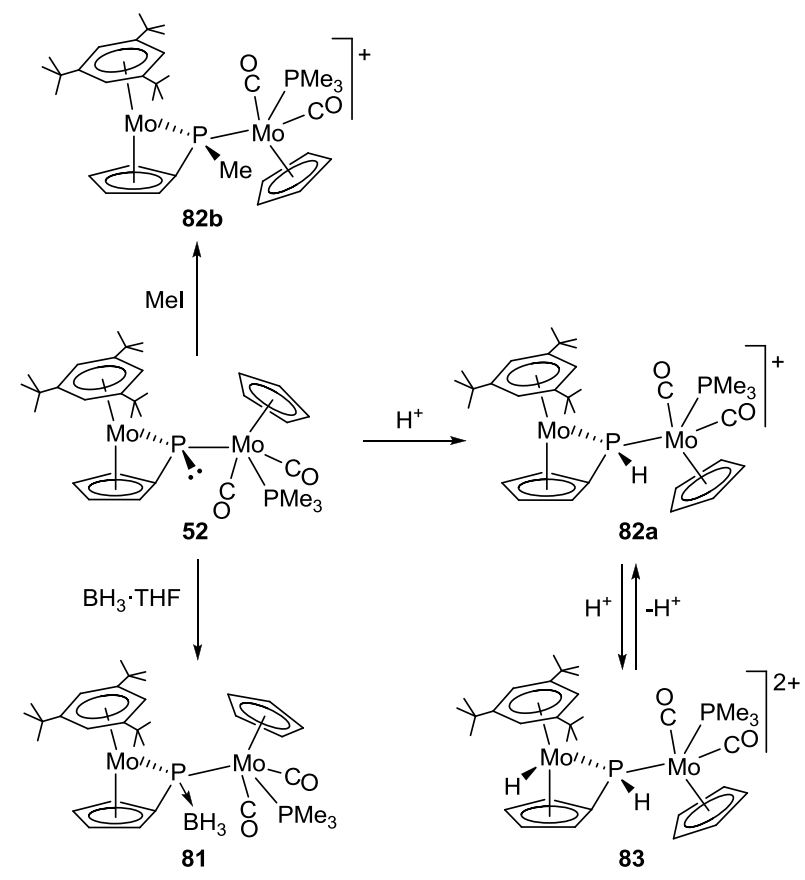

\section{Scheme 44}

In all the above dimolybdenum derivatives, the added electrophile is placed in the $\mathrm{Mo}_{2} \mathrm{P}$ plane, which renders an unusual trigonal pyramidal-like environment around the $\mathrm{P}$ atom, rather than the more common tetrahedral geometry. This could be satisfactorily explained with the aid of DFT calculations on the parent phosphinidene complex, which revealed that the lone electron pair at the $\mathrm{P}$ atom (actually the HOMO-2 of the molecule) has the required directionality. The latter in turn can be understood in qualitative terms by assuming an $s p^{2}$ hybridisation at the $\mathrm{P}$ atom to account for the Mo-P bonds and lone electron pair, while the remaining $p$ orbital is used for bonding to the carbon atom of the $\mathrm{C}_{5} \mathrm{H}_{4}$ ring (Figure 2) [53].
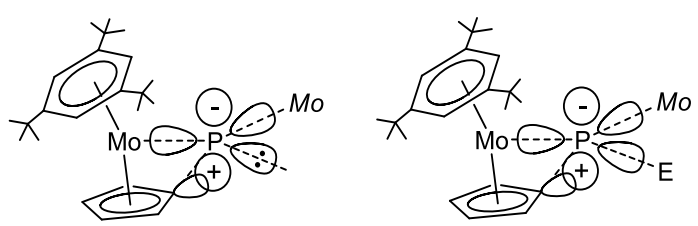

Figure 2 
A related, but less expected reaction was observed between $\mathbf{5 2}$ and ethylene sulphide. Instead of the corresponding SPR derivative, the cyclic phosphanyl-thiolato complex 84 was obtained in 55\% yield (Scheme 45). The latter product likely follows from initial nucleophilic attack of the phosphinidene $\mathrm{P}$ atom to one of the $\mathrm{C}$ atoms of the $\mathrm{C}_{2} \mathrm{~S}$ ring, with concomitant ring opening to afford a zwitterionic intermediate with a negative charge at the $\mathrm{S}$ atom, which enables the latter to displace the $\mathrm{PMe}_{3}$ ligand, thus yielding the final cyclic product [53].
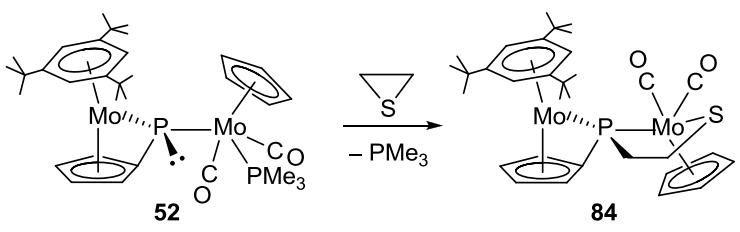

\section{Scheme 45}

\subsubsection{Reactions with molecules containing $\mathbf{E}-\mathbf{H}$ bonds}

There are only a few examples of this type of reactivity involving pyramidal phosphinidenes. The most remarkable example doubtless corresponds to the diiron complex 32d, which is able to react with dihydrogen under mild conditions $\left(295 \mathrm{~K}, P_{\mathrm{H} 2} c a .4 \mathrm{~atm}\right)$ to give the phosphine derivative 85 as the major product $[87,42 \mathrm{~b}]$. This reaction provided the first reported example of mild activation of $\mathrm{H}_{2}$ at the $\mathrm{P}$ atom of any phosphorus-containing molecule (Scheme 46). DFT calculations indicated that the actual $\mathrm{H}_{2}$ activation was likely to be accomplished by an isomer of the main substrate bearing a terminal phosphinidene ligand. Such an isomer would be present in solution in small amounts, since it was computed to be only $1.4 \mathrm{Kcal} \cdot \mathrm{mol}^{-1}$ less stable than the PMes*-bridged isomer in toluene solution, but it would display frontier orbitals with the right shapes to interact with the $\mathrm{H}_{2}$ molecule. The presence of this isomer, undetected by NMR, would be favoured by the large steric demands of the Mes* group, which is consistent with the fact that neither the PPh- nor the PCy-bridged complexes are able to perform $\mathrm{H}_{2}$ activation. Instead, complex 32a slowly reacted with $\mathrm{H}_{2} \mathrm{O}$ or EtOH to give the corresponding phosphinous acid (or ethyl phosphinite) derivatives 86, a behaviour not observed for the PMes* complex (Scheme 44). The rate of the latter reaction increased on addition of $\mathrm{BEt}_{3}$, which suggests that it takes place in two steps: (i) deprotonation of a $\mathrm{O}-\mathrm{H}$ bond, followed by (ii) nucleophilic attack of the $\mathrm{OR}^{-}$anion to the transient phosphanyl cations. 


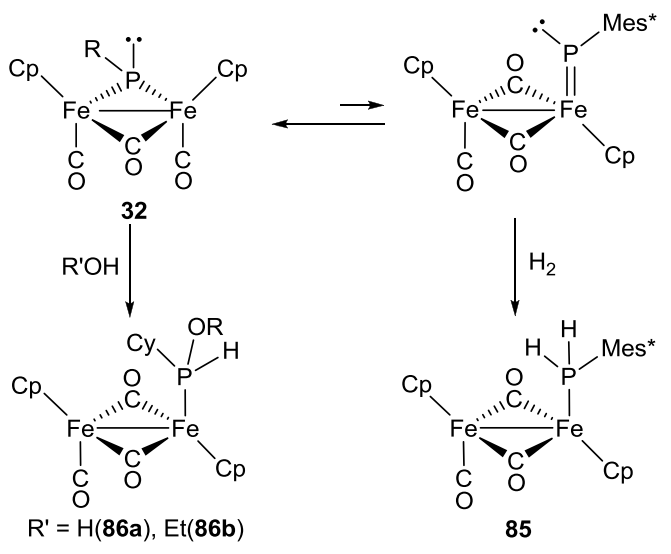

Scheme 46

\subsubsection{Reactions with unsaturated organic molecules}

In this section we will review the reactivity of pyramidal phosphinidene complexes towards unsaturated organic molecules, containing multiple $\mathrm{C}-\mathrm{C}$ and $\mathrm{N}-\mathrm{N}$ multiple bonds. Most of these reactions involve again the diiron complexes 32, thus illustrating the potential of this type of phosphinidene complexes in the generation of novel organophosphorus ligands.

\subsubsection{Reactions with molecules containing $\mathrm{C}-\mathrm{C}$ multiple bonds}

The diiron complexes 32 react with alkenes and alkynes under mild conditions. Reaction of $\mathbf{3 2 a}$ with methyl acrylate at $293 \mathrm{~K}$ led to 87 , a complex bearing a phosphanyl-acyl ligand resulting from coupling of the added alkene, the phosphinidene group, and a carbonyl ligand (Scheme 47) [42c].

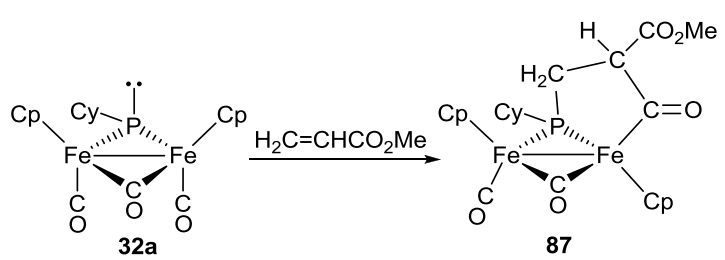

\section{Scheme 47}

In contrast, reactions of 32a with alkynes turned out to be complex and strongly dependent on both the alkyne and experimental conditions [88]. Thus, reaction with excess $p$-tolylacetylene at $293 \mathrm{~K}$ yielded 88, a molecule following from unprecedented coupling of the phosphinidene ligand both to the alkyne and one of the Cp groups. However, a mixture of the latter complex and two isomers of the phosphanyl-acyl complex 89 was obtained at 348 K (Scheme 48). 


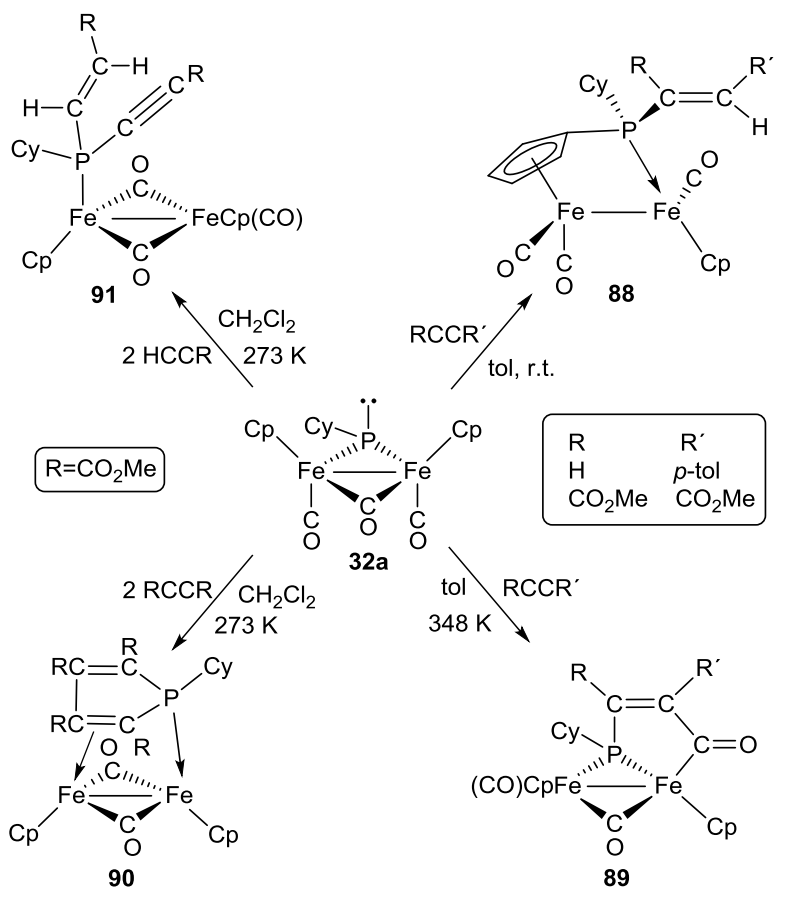

Scheme 48

The stoichiometric reaction with dimethyl acetylenedicarboxylate proceeded analogously to yield complexes of type $\mathbf{8 8}$ and $\mathbf{8 9}$. However, the reaction with 2 equiv of alkyne at $273 \mathrm{~K}$ gave selectively the dicarbonyl complex $\mathbf{9 0}$, a molecule with a four-electron-donor bridging phosphole ligand derived from coupling of the phosphinidene with two alkyne molecules (Scheme 48) [88a].

The reactions of 32a with methyl propiolate still were more complex, and several compounds were formed in significant amounts, depending on reaction conditions. Notably, the slow addition of a dichloromethane solution of the phosphinidene complex to a solution of 2 equiv of alkyne in the same solvent at $273 \mathrm{~K}$ led to the exclusive formation of the (alkenyl)(alkynyl)phosphine complex 91 [88]. It is interesting to note that, in spite of the great diversity of products formed in the above reactions with alkynes, all of them seem to follow from a common zwitterionic intermediate that would result from the initial nucleophilic attack of the pyramidal phosphinidene ligand to the sterically less protected $\alpha$ carbon of the alkyne.

An unprecedented dimerisation of maleic anhydride (MA) involving olefinic to carbonyl $\mathrm{C}-\mathrm{C}$ coupling and an $[1,7]-\mathrm{H}$ shift, was promoted by reaction of MA with the 
dimolybdenum complex 52. This multistep reaction takes place even at $193 \mathrm{~K}$, to yield the unprecedented phosphinidenium-ylide complex 92 (Scheme 49) [86]. The new carbene moiety undergoes dramatic structural changes when going from solution to the solid state, involving a keto to enol tautomerisation and a strong pyramidalization of the ylidic carbon atom, possibly induced by the intermolecular $\pi \cdot \pi$ stacking interactions that are established in the crystal lattice.

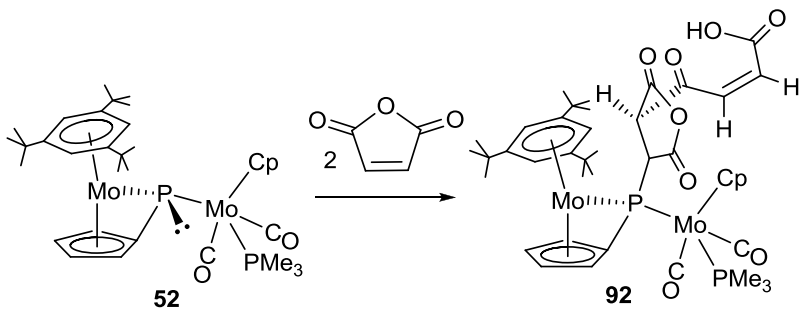

Scheme 49

\subsubsection{Reactions with molecules containing $\mathrm{N}-\mathrm{N}$ multiple bonds}

Diazoalkanes $[89,88 \mathrm{~b}]$ and azides $[85,88 \mathrm{~b}]$ were quite reactive towards the diiron complexes 32 . The latter actually reacted with a variety of diazoalkanes under mild conditions ( $293 \mathrm{~K}$ or below) to give the corresponding $P: P$-bound phosphadiazadiene derivatives 93 in high yields (Scheme 50).

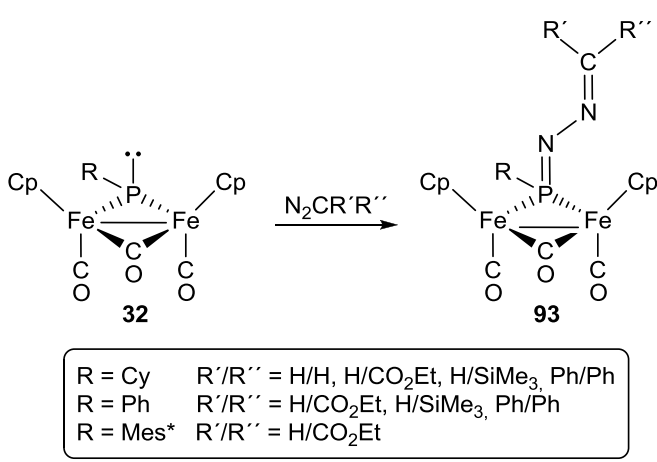

Scheme 50

On the other hand, when benzyl azide was added to solutions of 32a (at $293 \mathrm{~K}$ ) or 32b (at $203 \mathrm{~K}$ ) the related compounds 94 were obtained, these being the first reported examples containing a $\mu-$ $P: P$-bound phosphatriazadiene ligand (Scheme 51). These products displayed low thermal stability, and 94a undergoes clean denitrogenation upon heating in toluene solution at $268 \mathrm{~K}$, to give the corresponding iminophosphinidene derivative $\left[\mathrm{Fe}_{2} \mathrm{Cp}_{2}\left\{\mu-\mathrm{P}\left(\mathrm{NCH}_{2} \mathrm{Ph}\right) \mathrm{Cy}\right\}(\mu-\mathrm{CO})(\mathrm{CO})_{2}\right][85]$. 


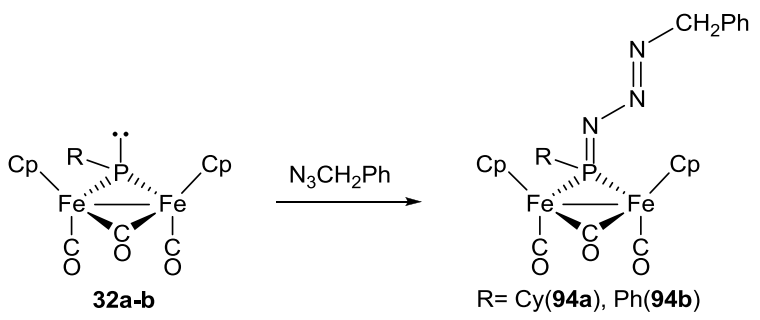

\section{Scheme 51}

\subsubsection{Oxidation reactions with group 16 elements and related processes}

In this section we will survey the reactions of pyramidal $\mu$-phosphinidenes mostly towards chalcogens $\left(\mathrm{O}_{2}, \mathrm{~S}_{8}\right)$, leading to the formal oxidation of the $\mathrm{P}$ atom of the phosphinidene group, from $\mathrm{P}(\mathrm{I})$ to $\mathrm{P}(\mathrm{III})$.

Oxidation of the diplatinum complex $\mathbf{3 0}$ with air or $\mathrm{O}_{2}$ gives one of the possible isomers of the bis(phosphinidene oxide) complex 95, which could be only characterised by NMR, since attempts to crystallise it led to its decomposition (Scheme 52) [41]. A related sulphide analogue was expected in the reaction with sulphur, but instead the trithiophosphorane complex 96 was obtained. The authors assumed that the expected phosphinidene sulphide ligand was formed first, but reaction of the latter with excess $\mathrm{S}_{8}$ degraded the binuclear product. A complex mixture of uncharacterised products was obtained in the related reaction with elemental selenium.

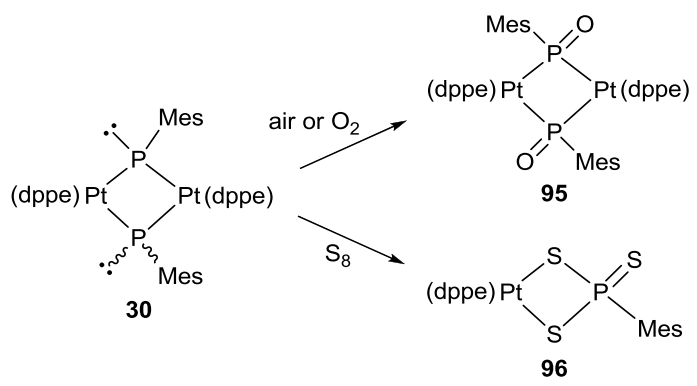

\section{Scheme 52}

A stable sulphide derivative, however, was obtained upon reaction of sulphur with the tetracarbonyl diiron complex $\left[\mathrm{Fe}_{2} \mathrm{Cp}_{2}(\mu-\mathrm{PPh})(\mathrm{CO})_{4}\right]$ [90]. In a more systematic study, Ruiz and co-workers explored the reactivity of the diiron tricarbonyls $32(\mathrm{R}=\mathrm{Cy}[85,42 \mathrm{c}], \mathrm{Ph}$ [42c], Mes* [42b]) with different sources of oxygen atoms and sulphur to give the 
corresponding complexes 97 and 98 bearing $P$ :P-bridging phosphinidene chalcogenide ligands (Scheme 53). It should be noted that the highest yields of the complex 97b were obtained with $m$-chloroperbenzoic acid (MCPBA) as the oxygen source, since air gave intractable mixtures of compounds [85]. An steric effect was clearly observed in the oxidation of the complex 32d, which gave first the expected $\mathrm{P}(\mathrm{O}) \mathrm{R}$-bridged complex, the latter slowly rearranging in solution at $293 \mathrm{~K}$ to reach an equilibrium with a more stable isomer 99 having a terminal phosphinidene oxide ligand [42b].

Complexes 32 also reacted readily with 3,5-di-tert-butyl-o-benzoquinone to give complexes of type 100, with a terminal phosphonite ligand formally derived from the oxidative addition of the quinone to the $\mathrm{P}$ atom, a process similar to that described for phosphines with these quinones (Scheme 54) [85].

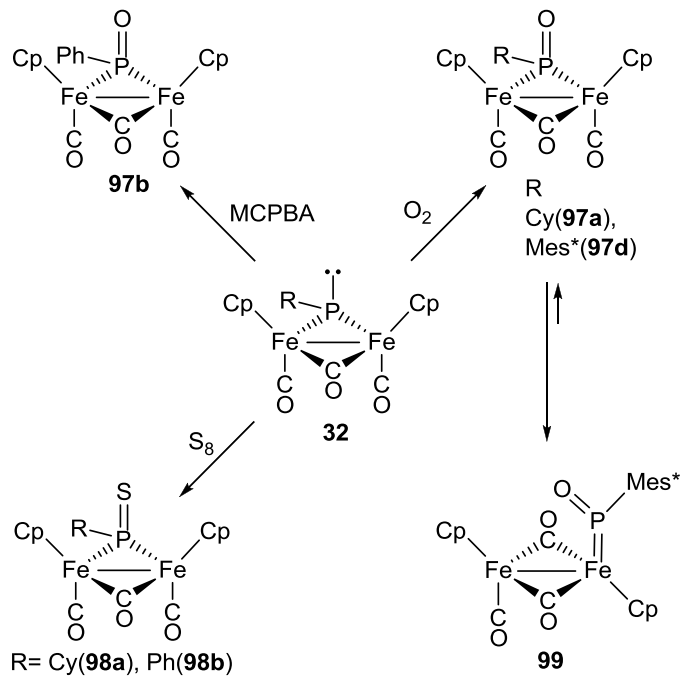

\section{Scheme 53}
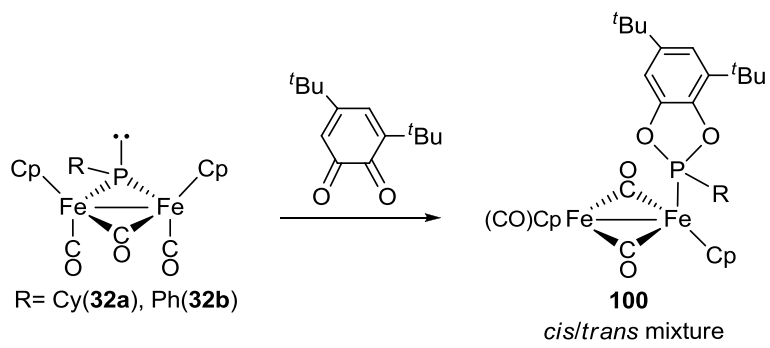

\section{Scheme 54}

The dimolybdenum complex 52 reacted with $\mathrm{S}_{8}$ at $223 \mathrm{~K}$ to give the unstable $\mathrm{P}(\mathrm{S}) \mathrm{R}$-bridged complex 101 (Scheme 55) [53], which reacted with MeI to give, after ion exchange with $\mathrm{Na}\left(\mathrm{BAr}_{4}{ }_{4}\right.$ ), 
the more stable phosphanyl complex 102. The structure of the latter was determined through an Xray analysis, which confirmed the unusual trigonal pyramidal-like geometry around the $\mathrm{P}$ atom already observed in the alkylated derivatives of this phosphinidene complex (see Section 5.1.1).

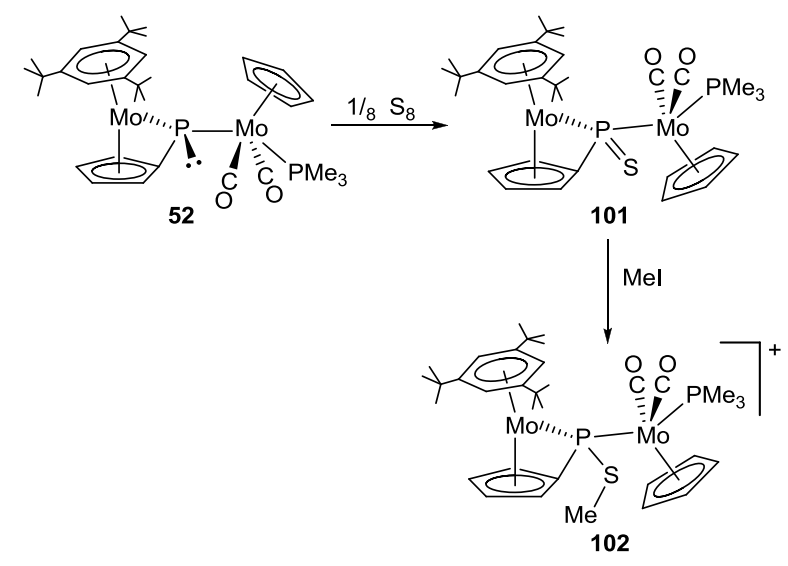

\section{Scheme 55}

\subsubsection{Addition of metal fragments}

The high nucleophilicity of pyramidal $\mu_{2}$-phosphinidene complexes, with a lone pair of electrons at phosphorus, can be also exploited to form new $\mathrm{P}-\mathrm{M}$ bonds through reactions with suitable electrophilic complexes.

The monoaurated complexes $104\left(\mathrm{R}=\mathrm{Cy}, \mathrm{Ph}, p-\mathrm{C}_{6} \mathrm{H}_{4} \mathrm{OMe}, p-\mathrm{C}_{6} \mathrm{H}_{4} \mathrm{CF}_{3}\right)$ were prepared by reacting the in situ generated phosphinidene $[\mathrm{HDBU}]\left[\mathrm{Mn}_{2}(\mu-\mathrm{H})(\mu-\mathrm{PCy})(\mathrm{CO})_{8}\right](\mathbf{1 0 3})$ with $\left[\mathrm{AuCl}\left(\mathrm{PR}_{3}\right)\right]$ (Scheme 56) [33b]. Interestingly, this product is in equilibrium with its isomeric trinuclear cluster $\left[\mathrm{Mn}_{2}\left(\mu-\mathrm{AuPR}_{3}\right)(\mu-\mathrm{PHCy})(\mathrm{CO})_{8}\right]$, which is the kinetic product according to NMR measurements. On this basis it was proposed that, although the phosphinidene complex 103 was the only product detected by NMR during deprotonation of the phosphanyl precursor $\left[\mathrm{Mn}_{2}(\mu-\mathrm{H})(\mu-\mathrm{PHCy})(\mathrm{CO})_{8}\right]$ with DBU, it must be also in equilibrium with an undetected phosphanyl-bridged anion $\left[\mathrm{Mn}_{2}(\mu-\right.$ $\left.\mathrm{PHCy})(\mathrm{CO})_{8}\right]^{-}$.

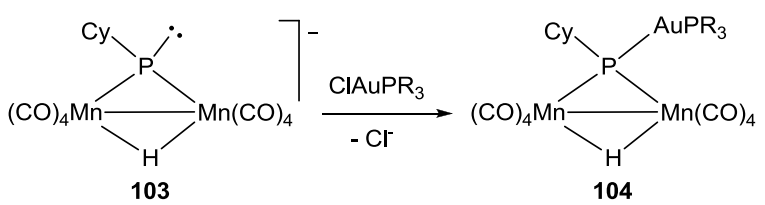

\section{Scheme 56}


An analogous rhenium complex $\left[\mathrm{Re}_{2}(\mu-\mathrm{H})\left\{\mu-\mathrm{PCy}\left(\mathrm{AuPPh}_{3}\right)\right\}(\mathrm{CO})_{8}\right]$ could be prepared from the corresponding anionic phosphinidene complex, also generated in situ. In this case, there was no evidence for equilibrium with the $\mathrm{Re}_{2} \mathrm{Au}$ cluster, which was prepared independently. The latter was possible since the phosphinidene anion following deprotonation of the hydrido-phosphanyl precursor $\left[\operatorname{Re}_{2}(\mu-\mathrm{H})(\mu-\mathrm{PHCy})(\mathrm{CO})_{8}\right]$ underwent full tautomerisation to the more stable phosphanyl-bridged isomer $\left[\operatorname{Re}_{2}(\mu-\mathrm{PHCy})(\mathrm{CO})_{8}\right]^{-}[33 \mathrm{~d}]$.

Related phosphinidene-bridged heterometallic complexes $\mathbf{1 0 6}$ were reported as the main products in the reactions of the anionic phosphanyl complexes $\mathbf{1 0 5}$ (prepared in situ by deprotonating the corresponding neutral hydrido complexes) with different halide complexes $\left[\mathrm{M}^{\prime} \mathrm{XL}_{\mathrm{n}}\right]\left(\mathrm{M}=\mathrm{Mo}, \mathrm{W} ; \mathrm{M}^{\prime} \mathrm{L}_{\mathrm{n}}=\mathrm{MCp}(\mathrm{CO})_{3}, \mathrm{FeCp}(\mathrm{CO})_{2}, \mathrm{Mn}(\mathrm{CO})_{5}\right)($ Scheme 57) [37]. To explain the formation of these products, the authors proposed the presence of small amounts of the dianionic phosphinidene complexes $\left[\mathrm{M}_{2} \mathrm{Cp}_{2}(\mu-\mathrm{PH})(\mathrm{CO})_{4}\right]^{2-}$ in the solutions of the $\mathrm{PH}_{2}$-bridged anions. An alternative explanation, of course, would be the operation of a phosphanyl/phosphinidene equilibrium analogous to that proposed for the above mentioned dimanganese complexes.

More recently, related heterometallic complexes 108 were upon reaction of the FeMn phosphinidene complex 107, generated in situ, with different halide complexes [MXL $\left.{ }_{n}\right]$ (Scheme 57) [35]. In contrast, the more unstable complex $\left[\mathrm{FeMn}(\mathrm{CO})_{8}(\mu-\mathrm{PH})\right]^{-}$, generated upon deprotonation of the corresponding $\mu_{2}-\mathrm{PH}_{2}$ complex, gave a rapid coupling reaction with the latter phosphanyl complex to give the anionic tetranuclear phosphinidenephosphanyl complex $\left[\mathrm{FeMn}(\mathrm{CO})_{8}\left(\mu_{3}-\mathrm{PH}\right) \mathrm{Mn}(\mathrm{CO})_{4}\left(\mu-\mathrm{PH}_{2}\right) \mathrm{Fe}(\mathrm{CO})_{4}\right]^{-}$, which decomposed upon removal of solvent.
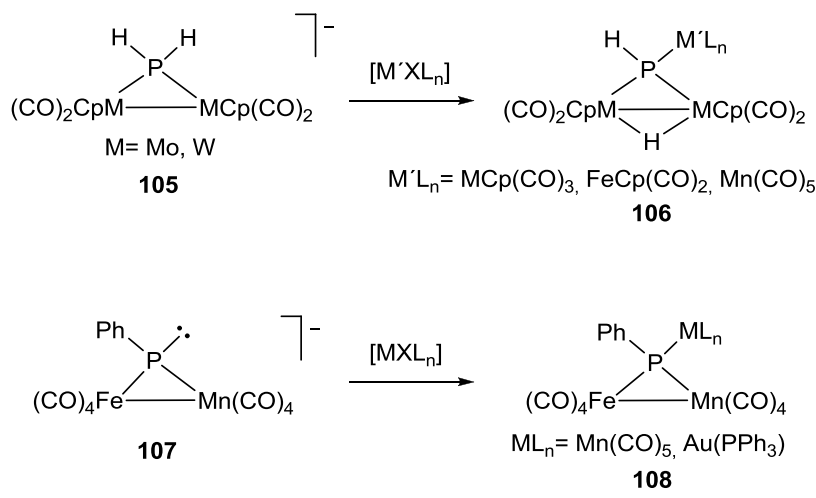


\section{Scheme 57}

The diiron complex 32a also reacts with different metal fragments, thus providing a rational synthetic procedure to heterometallic phosphinidene-bridged complexes (Scheme 58) [91]. Reactions with precursors of 16-electron metal fragments, such as $\left[\mathrm{M}(\mathrm{CO})_{5}(\mathrm{THF})\right](\mathrm{M}=\mathrm{Cr}, \mathrm{Mo}$, $\mathrm{W}),\left[\mathrm{MnCp}(\mathrm{CO})_{2}(\mathrm{THF})\right]$ or $\left[\mathrm{Fe}_{2}(\mathrm{CO})_{9}\right]$, as well as group 11 metal halides, such as $\mathrm{CuCl}$ or $[\mathrm{AuCl}(\mathrm{THT})](\mathrm{THT}=$ tetrahydrothiophene $)$, proceeded under mild conditions to yield the corresponding trinuclear complexes 109-112, with a $\mu_{3}$-bridging phosphinidene ligand. The reaction with iron carbonyl also yielded small amounts of the pentanuclear complex 113, a product of uncertain origin, since it could not be selectively synthesised from the same reagents under different experimental conditions. Another unusual reaction outcome was observed in the reaction with $\left[\mathrm{Co}_{2}(\mathrm{CO})_{8}\right]$, which gave the pentanuclear compound $\left[\left\{\mathrm{Co}(\mathrm{CO})_{3}\right\}\left\{\left(\mu_{3}-\mathrm{PCy}\right) \mathrm{Fe}_{2} \mathrm{Cp}_{2}(\mu-\right.\right.$ $\left.\left.\mathrm{CO})(\mathrm{CO})_{2}\right\}_{2}\right]\left[\mathrm{Co}(\mathrm{CO})_{4}\right]$, a product following from disproportionation of the $\mathrm{Co}(0)$ precursor, as observed in some reactions of $\left[\mathrm{Co}_{2}(\mathrm{CO})_{8}\right]$ with phosphines.

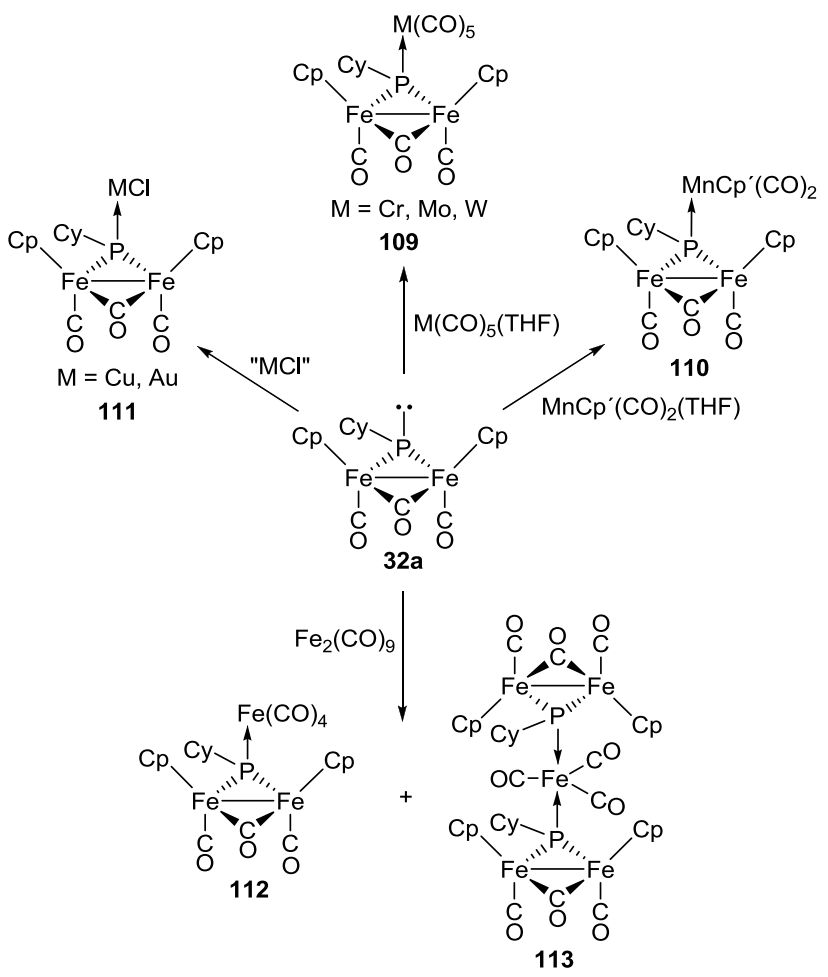

\section{Scheme 58}

\subsubsection{Thermolysis and photolysis}


The stability of the diiron complexes 32 was tested under thermal and photochemical conditions, and the products obtained turned to be strongly dependent on the nature of the $\mathrm{R}$ group at phosphorus (Scheme 59) [42a]. The phenylphosphinidene complex only gave decomposition products, with the dimer $\left[\mathrm{Fe}_{2} \mathrm{Cp}_{2}(\mathrm{CO})_{4}\right]$ being the major organometallic species detected after heating in toluene at $333 \mathrm{~K}$ or upon irradiation with visible-UV light. In contrast, the cyclohexylphosphinidene complex was thermally more robust, as prolonged times in refluxing toluene were required to achieve total degradation, which in any case gave again the mentioned iron dimer as major product. However, upon irradiation with visible-UV, two decarbonylation products could be isolated, the tetranuclear cluster 114 and the trinuclear isomers syn-and anti-115. The mesitylphosphinidene complex only reacted under refluxing toluene to give the trimetallic complex 116 in moderate yields, as a mixture of syn and anti isomers in solution. The structure of the syn isomer was established through X-ray diffraction, which revealed the presence of a trigonal planar phosphinidene ligand in the molecule $\left(\delta_{\mathrm{P}} 761 \mathrm{ppm}\right)$. In contrast, the supermesitylphosphinidene complex displayed a reduced thermal stability in toluene, it actually rearranging slowly at $293 \mathrm{~K}$ ( $80 \%$ conversion in 4 days) to give the phosphine derivative $\mathbf{1 1 7}$, as a result of intramolecular insertion of the $\mathrm{P}$ atom into a $\mathrm{C}-\mathrm{H}$ bond of one of the $o-{ }^{t} \mathrm{Bu}$ groups. This is likely due to the presence in solution of small amounts of the isomer with a terminal phosphinidene ligand mentioned in section 5.1.2, thought to be also responsible for the reaction of this complex with $\mathrm{H}_{2}$ (Scheme 46).

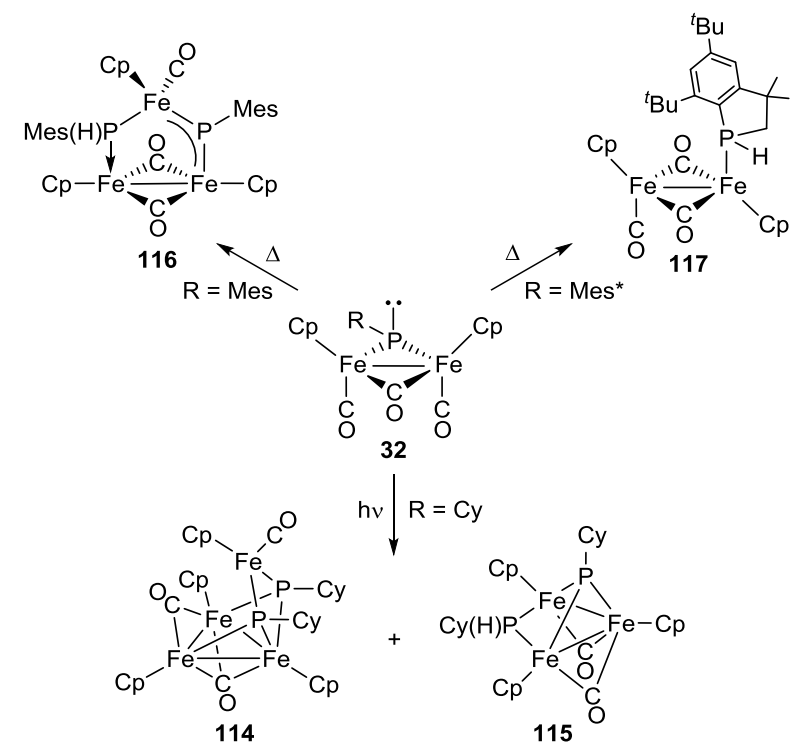

\section{Scheme 59}

\subsubsection{Reactivity of the transient diradical $\left[\mathrm{Fe}_{2}\left(\mu-\mathrm{PN}^{i} \operatorname{Pr}_{2}\right)_{2}(\mathrm{CO})_{6}\right]$}


An interesting subclass of pyramidal phosphinidene complexes which deserves a section on its own is that of the aminophosphinidene complex 118. This diradical is generated in situ upon heating solutions of the diamagnetic complex 119 at $c a .373 \mathrm{~K}$, and its reactivity was thoroughly studied by King and co-workers [92], and reviewed specifically [4e, 93] (Scheme 60). This transient species displays two main reactivity patterns: (a) addition of hydrogen active $\mathrm{H}-\mathrm{X}$ compounds (alcohols, amines, hydrogen chloride), to give usually the less hindered anti phosphanyl derivative 120, or (b) addition across multiple $\mathrm{Y}=\mathrm{Z}$ bonds $(\mathrm{C}=\mathrm{O}$ of aldehydes, ketones or anhydrides; $\mathrm{C} \equiv \mathrm{N}$ bonds of nitriles; or $\mathrm{C}=\mathrm{C}$ bond of acrylonitrile but not maleic anhydride). An exception to these general reactivity patterns was observed in the reaction with norbornadiene, which gave the nortricyclane derivative $\left[\mathrm{Fe}_{2}\left\{\mu-\mathrm{PH}\left(\mathrm{N}^{i} \mathrm{Pr}_{2}\right)\right\}\left\{\mu-\mathrm{P}\left(\right.\right.\right.$ nor $\left.\left.\left.-\mathrm{C}_{7} \mathrm{H}_{8}\right)\right\}(\mathrm{CO})_{6}\right]$ through elimination of one of the diisopropylamino groups as the imine $\left(\mathrm{CH}_{3}\right)_{2} \mathrm{CHN}=\mathrm{C}\left(\mathrm{CH}_{3}\right)_{2}$, which probably involves a phosphinidene-phosphanyl intermediate [92a].

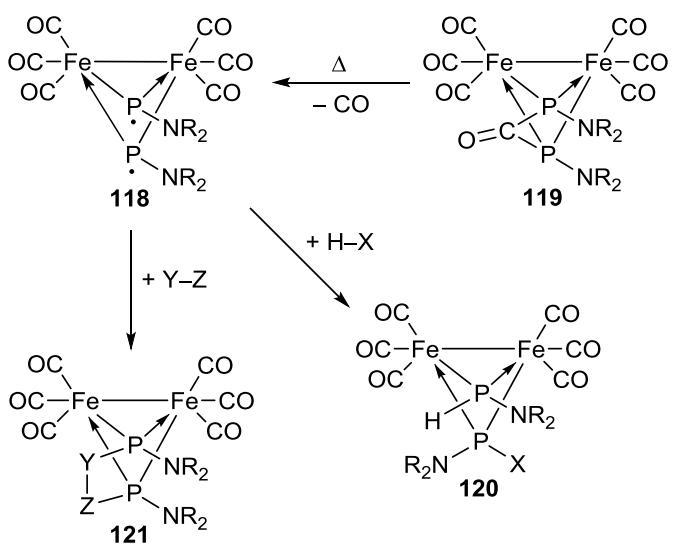

Scheme 60

\subsection{Symmetric trigonal planar phosphinidene complexes}

\subsubsection{Reactions with simple nucleophiles}

The reaction of the aminophosphinidene complexes $\mathbf{9 b}$ and $\mathbf{8 b}$ with 1,3-bis(R)imidazol-2-ylidene ( $\mathrm{R}={ }^{t} \mathrm{Bu}$ and adamantly), results in the formation of abnormal N-heterocyclic carbene adducts $\mathbf{1 2 2}$ and the related $\left[\mathrm{Co}_{2}(\mathrm{CO})_{4}(\mu-\mathrm{dppm})\left\{\mu-\mathrm{P}\left(\mathrm{N}^{i} \mathrm{Pr}_{2}\right)\left(4-\right.\right.\right.$ cyclo- $\left.\left.\left.\mathrm{C}_{3} \mathrm{H}_{2}-1,3-(\mathrm{NR})_{2}\right)\right\}\right]$, in which the 'ylidene' moiety of the NCN carbene has migrated to position 4 of the carbene precursor (Scheme 61) [94]. The structures of these compounds were confirmed through X-ray analyses showing $\mathrm{P}-\mathrm{C}$ distances 
consistent with only $\sigma(\mathrm{C}-\mathrm{P})$ interactions. The rearrangement in the carbene fragment is thought to be induced by unfavourable steric interactions of either the $\mathrm{N}^{i} \mathrm{Pr}_{2}$ group or the metal-carbonyl moieties with the N-bound R groups of the carbene, which would destabilise an interaction between the $\mathrm{P}$ atom and the $\mathrm{C}-2$ atom of the carbene.

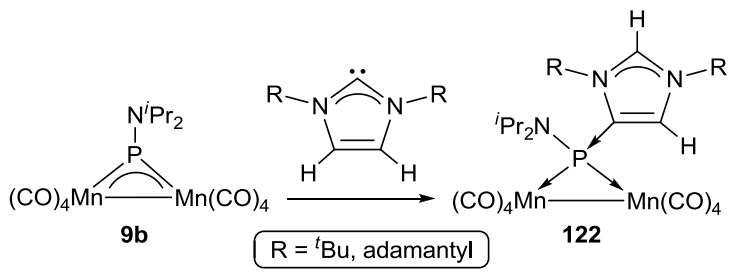

\section{Scheme 61}

The interaction of the scandium dimer $\mathbf{2 0}$ with apparently simple donors such as 2,2'-bipyridine (bpy) and CO gave unexpected results. In the first case, the complex underwent a redox reaction upon addition of 3 equiv of bpy to give two mononuclear species: the diphosphene complex $\mathbf{1 2 3}$ and a complex with two bpy radical anions 124 (Scheme 62) [29a]. In order to account for the formation of the diphosphene complex, two dianionic phosphinidene ligands [PAr] ${ }^{2-}$ must be oxidatively coupled in the parent bis(phosphinidene) complex, which concomitantly reduce two bpy ligands to afford the radical anions present in the second complex. However, upon exposure to CO (1 atm, $15 \mathrm{~min}$ ) a novel Sc oxocomplex containing a 3-oxo-4-ylidene-1,2-diphosphetene ligand was obtained, whose formation can be accounted for through a complex sequence of steps involving $\mathrm{C}-\mathrm{P}$ bond formation, $\mathrm{C}-\mathrm{C}$ coupling, $\mathrm{C}-\mathrm{O}$ bond cleavage of $\mathrm{CO}$, and $\mathrm{P}-\mathrm{P}$ coupling (see Section 5.2.3.4).

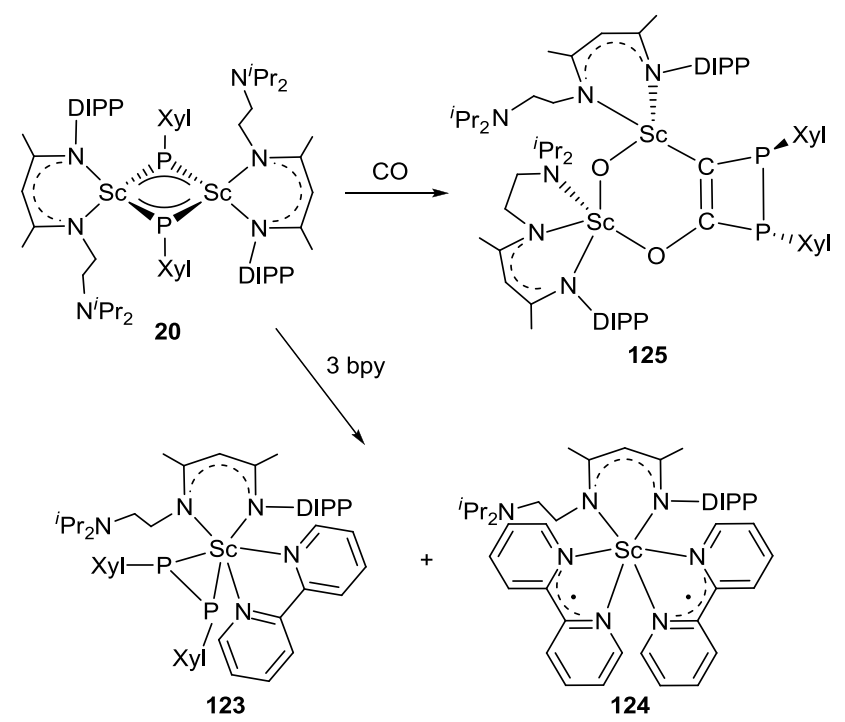




\section{Scheme 62}

As stated in Section 3.1.1., the reactivity of the ditungsten phosphinidene complex 5 towards a great variety of molecules has been explored in detail. Reactions with simple donors as tertiary phosphines led to mixtures of two types of complexes having coordinated phosphine-phosphinidene adducts: the mononuclear complexes 126, following from elimination of a $\mathrm{W}(\mathrm{CO})_{5}$ moiety, and the binuclear complexes 127, obtained after elimination of tetramethylfulvene (Scheme 63) [95].

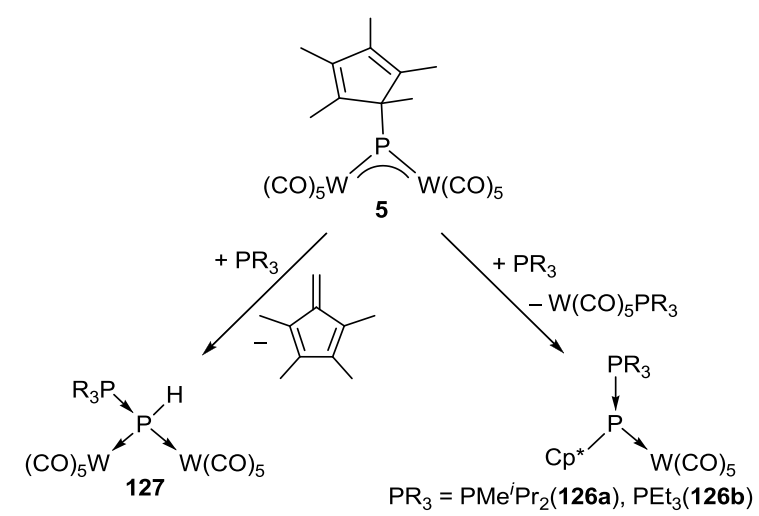

\section{Scheme 63}

\subsubsection{Reactions with molecules containing $E-H$ bonds $(E=B, P)$}

The reactivity of the ditungsten complex 5 towards a variety of primary and secondary phosphines and diphosphines containing $\mathrm{P}-\mathrm{H}$ bonds was also examined systematically. When reacted with 1,2-diphosphinobenzene in toluene at $333 \mathrm{~K}$, a novel polycyclic phosphorus-containing cage compound 128 was obtained (Scheme 64), whose formation involves the dimerisation of 1,2,3-triphosphole intermediates through a hetero-Diels-Alder cycloaddition [96]. To prove this hypothesis, the authors were able to trap such an intermediate in the presence of 2,3-dimethylbuta-1,3-diene to give the expected product.

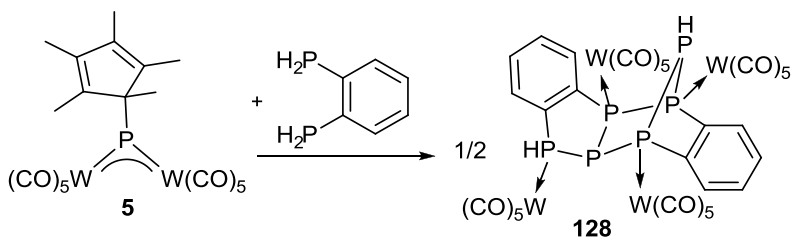

\section{Scheme 64}


Complex 5 reacts with simple primary phosphines $\left(\mathrm{PH}_{2} \mathrm{R} ; \mathrm{R}=\mathrm{BH}_{2} \mathrm{NMe}_{3}, \mathrm{Ph}\right)$ to give stable adducts 129 which at room temperature undergo a novel intramolecular hydrophosphination reaction of a $\sigma$ bound $\mathrm{Cp}^{*}$ group when $\mathrm{R}=\mathrm{Ph}$, to give a diphospha-norbornene derivative with two $\mathrm{W}(\mathrm{CO})_{5}$ groups located at one of the phosphorus atom, which at $383 \mathrm{~K}$ rearranges to yield the diphosphanorbornene complex 130 (Scheme 65). In contrast, reaction with $\mathrm{PH}_{2}{ }^{t} \mathrm{Bu}$ proceeded at $363 \mathrm{~K}$ through elimination of $\mathrm{HCp}^{*}$ to give a novel 1,2,3-trihydrotriphosphine 131a stabilised by two $\mathrm{W}(\mathrm{CO})_{5}$ fragments [97].

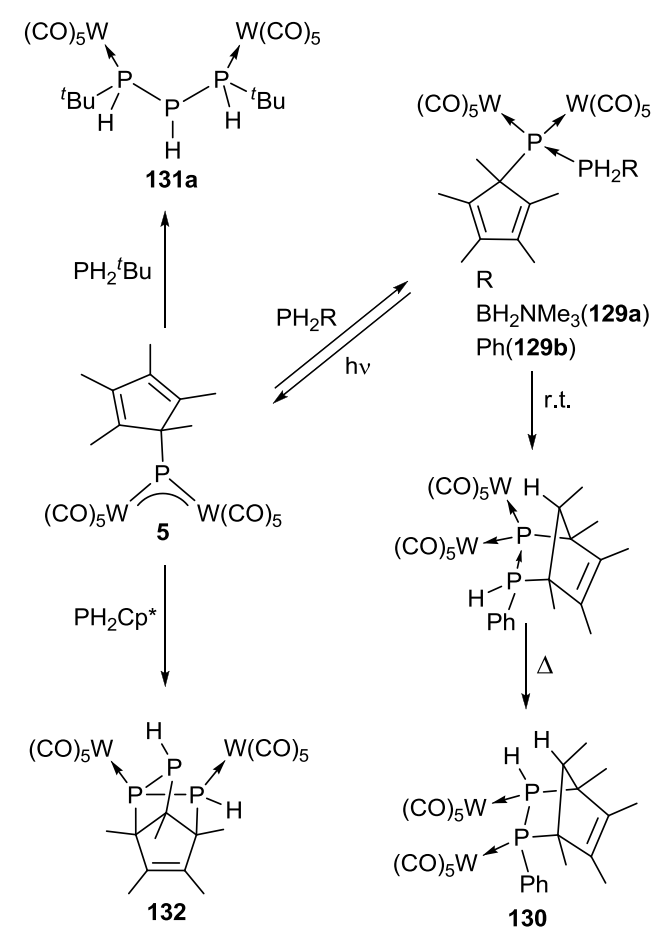

\section{Scheme 65}

When $\mathrm{PH}_{2} \mathrm{Cp}^{*}$ was used, an even more complex reaction took place at room temperature to yield a ditungsten complex 132 with a [1,2,3,4,5]-pentamethyl-6,7,8-triphospha-tricyclo$\left[3,3,0,0^{2,7}\right]-3$-octene ligand as the only isolable product (Scheme 65) [98]. The formation of this cage compound, which may be regarded as a heteronorbornene with an additional PH fragment linking a W-bound phosphorus atom and the $\mathrm{C}$ atom of the $\mathrm{C}(\mathrm{Me})$ bridge, can be accounted for by a hydrophosphination reaction, followed by a retro [2+4]-cycloaddition. Then, $\mathrm{HCp}^{*}$ is eliminated and a subsequent intramolecular [2+4]-cycloaddition reaction takes place, this being followed by a tungsten pentacarbonyl shift to give the final triphosphine derivative. 
The reaction of complex 5 with the secondary phosphine $\mathrm{PH}^{i} \mathrm{Pr}_{2}$ at $195 \mathrm{~K}$ generated a mononuclear phosphine adduct 126c comparable to those formed with tertiary phosphines (Scheme 66). Additionally, a $\mathrm{W}(\mathrm{CO})_{5}$-stabilised triphosphine complex $\mathbf{1 3 1 b}$ was formed as a minor product, reminiscent of that obtained with $\mathrm{PH}_{2}{ }^{t} \mathrm{Bu}$ [95].

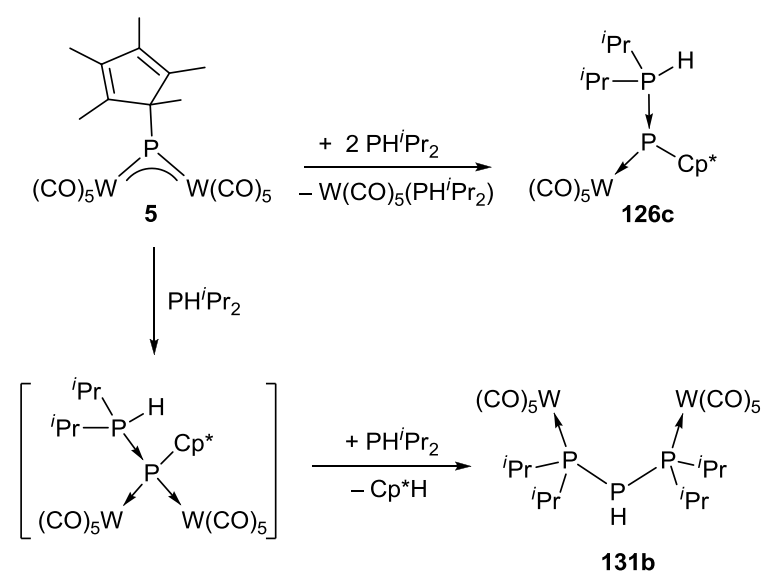

\section{Scheme 66}

The scandium complex 20 reacted with catecholborane, pinacolborane and 9borabicyclo[3.3.1]nonane (9-BBN) showing different reactivity patterns (Scheme 67) [99]. The reaction with the first two boranes, containing B-O bonds, gave the corresponding cathecol- and pinacol-bridged complexes 133, with an unusual $[\mathrm{P}(\mathrm{Xyl}) \mathrm{B}(\mathrm{H}) \mathrm{P}(\mathrm{Xyl})]^{2-}$ diphosphanyl ligand in a $\mu-$ $\kappa^{2}: \kappa^{2}$ coordination mode, which follows from unexpected B-O bond cleavages, most likely triggered by the strong oxophilicity of the Sc(III) ion. In contrast, reaction with 9-BBN, a reagent having no $\mathrm{B}-\mathrm{O}$ bonds, afforded the $\mathrm{B}-\mathrm{H}$ bond cleavage product 1,3-diphospha-2,4diboracyclobutane $\mathbf{1 3 4}$ and a complex mixture of other uncharacterised products. 


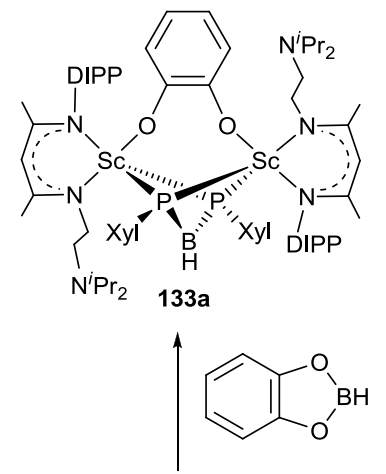

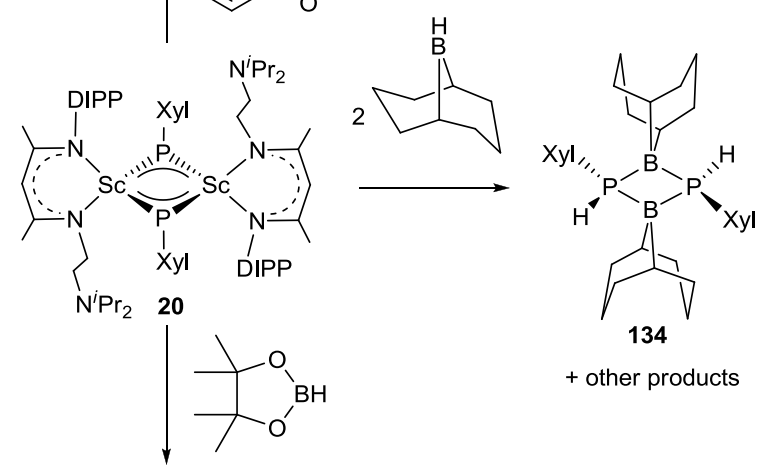

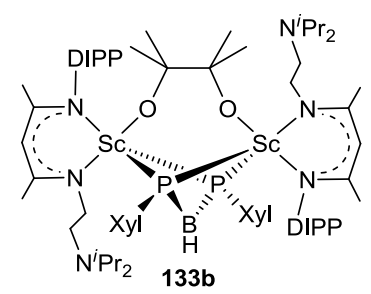

Scheme 67

The triply bonded dimolybdenum complex 47 reacts with the primary phosphine $\mathrm{PH}_{2} \mathrm{Cy}$ to give selectively the 32-electron bis(phosphanyl)-bridged derivative 135 (Scheme 68). This product follows from a H-transfer reaction from a phosphine molecule to the phosphinidene ligand to yield a mixture of the corresponding syn and anti isomers, which differ in the relative orientations of the $\mathrm{P}-\mathrm{H}$ bonds at the bridging ligands [77].

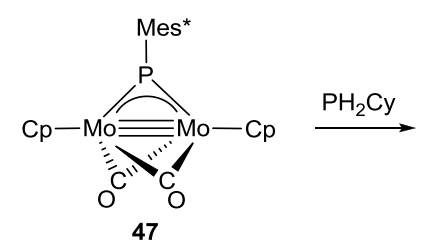

Scheme 68

\subsubsection{Reactions with unsaturated organic molecules}

\subsubsection{Reactions with molecules containing $\mathrm{C}-\mathrm{C}$ multiple bonds}


The reactions of the ditungsten complex $\mathbf{5}$ with alkynes are strongly dependent on reagents and experimental conditions. Its reactions with $\mathrm{MeC} \equiv \mathrm{CMe}$ under thermal or photochemical conditions give the three-membered heterocycle 136 (Scheme 69) [100]. The structure of the latter, confirmed through an X-ray analysis, suggest the operation of a reaction pathway involving CO loss from a $\mathrm{W}(\mathrm{CO})_{5}$ moiety under thermal or photochemical conditions, followed by side-on coordination of the alkyne at the $\mathrm{W}(\mathrm{CO})_{4}$ unit. Then, $\mathrm{P}-\mathrm{C}$ and $\mathrm{W}-\mathrm{C}$ bond formation would lead to migration of a $\mathrm{H}$ atom from a methyl group of the $\mathrm{Cp}$ * fragment to the alkyne ligand, rendering a $\eta^{2}$-coordination mode of the $\mathrm{CH}_{2} \mathrm{C}_{5} \mathrm{Me}_{4}$ moiety to the $\mathrm{W}(\mathrm{CO})_{4}$ fragment.

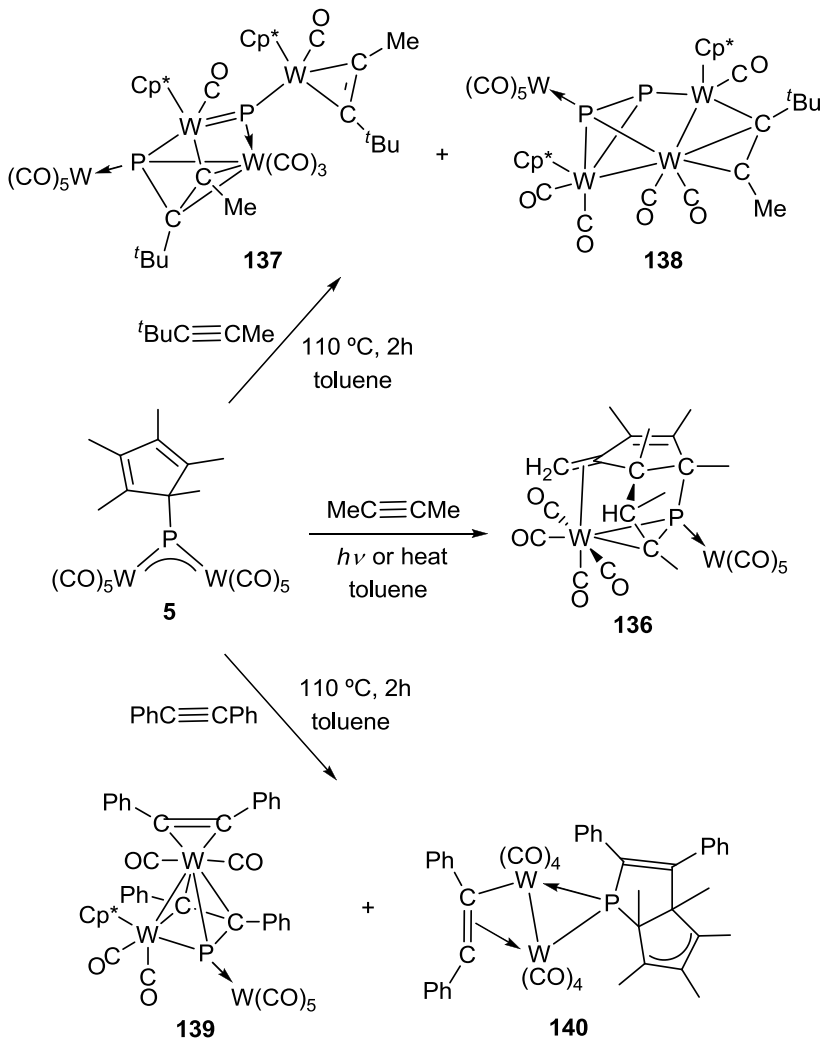

\section{Scheme 69}

However, different results were obtained when the thermolysis of the phosphinidene complex was carried out in the presence of other internal alkynes. Thus, reaction with ${ }^{t} \mathrm{BuC} \equiv \mathrm{CMe}$ gave two four-membered ring complexes: the phosphido complex 137 (major product), and the diphosphorus complex 138 (Scheme 69) [101], while the reaction with $\mathrm{PhC} \equiv \mathrm{CPh}$ led to the phosphaallyl-like complex 139 (major product) and the phosphanyl complex 140. Products 137 and 139 can be regarded as formal cycloaddition products of the intermediate phosphido complex $\left[\mathrm{Cp} *(\mathrm{CO})_{2} \mathrm{~W} \equiv \mathrm{P} \rightarrow \mathrm{W}(\mathrm{CO})_{5}\right]$, formed under thermal 
conditions by $\mathrm{Cp}^{*}$ migration within the parent phosphinidene complex (see Section 5.2.6). Moreover, compound 140 can be viewed as the result of a 1,3-dipolar cycloaddition of the alkyne to a phosphaallylic subunit of the PCp* fragment of the parent phosphinidene complex.

The dimolybdenum complex 1 reacted under photochemical conditions with $\mathrm{HC} \equiv \mathrm{C}(p$-tol) to give the phosphaallyl complex 141 (Scheme 70) [51]. The structure of this compound confirmed the insertion of the alkyne into a Mo-P bond to give a ligand unexpectedly having a pyramidal environment around the $\mathrm{P}$ atom. A non-dissociative 32-electron photoexcited state of the parent phosphinidene complex, bearing a pyramidal $\mu_{2}$-phosphinidene ligand, was proposed to account for the formation of the above product.
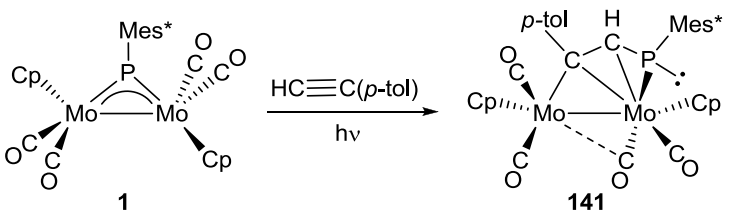

\section{Scheme 70}

The scandium dimer 20 reacted with a variety of unsaturated organic molecules to give different addition products always involving formation of new $\mathrm{P}-\mathrm{C}$ bonds (Scheme 71). Reaction with a twofold excess of benzylallene yielded the bis(allylphosphanyl) complex 142, whose structure was confirmed through an X-ray diffraction analysis [29a]. Other related reactions are discussed in the next subsection. 

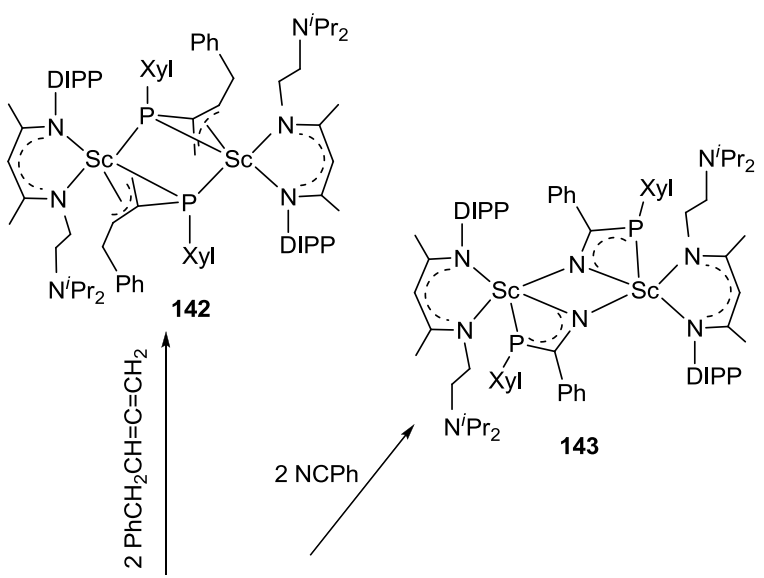

$\begin{array}{ll}\mathrm{N}^{\prime} \mathrm{Pr}_{2} & 143\end{array}$
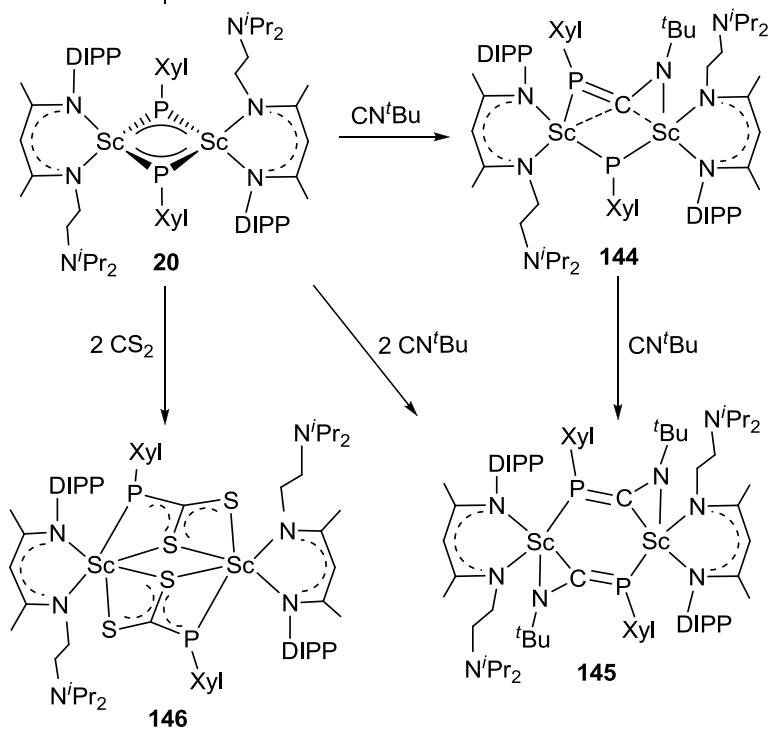

\section{Scheme 71}

\subsubsection{Reactions with molecules containing $\mathrm{C}-\mathrm{N}$ multiple bonds}

Complex 20 also reacts with nitriles $(\mathrm{N} \equiv \mathrm{CPh})$ and isocyanides $\left(\mathrm{C} \equiv \mathrm{N}^{t} \mathrm{Bu}\right)$ to give cycloaddition products (Scheme 71) [29a]. Reaction with a two-fold excess of the nitrile yielded 143, with new dianionic $N, P$-donor ligands bridging both metal centres through the $\mathrm{N}$ atom, whereas the $\mathrm{P}$ atom binds the Sc atom in a terminal fashion. On the other hand, reaction with the isocyanide allowed the isolation of the monoaddition product 144 , bearing a 1-aza-3-phosphaallyl dianionic ligand. Addition of a second equivalent of isocyanide yielded the diaddition product 145 which, expectedly, can also be obtained directly by the reaction with a two-fold excess of the isocyanide to $\mathbf{2 0}$. Complex 145 also bears 1-aza-3phosphaallyl dianionic ligands but, unlike the monoaddition product, the central $\mathrm{C}$ atom is 
just bound to one of the metal centres in each case, as proved by the corresponding X-ray structural analysis.

The reactivity of the ditungsten complex 5 towards molecules containing multiple C-N bonds such as nitriles [57, 102], isocyanides [103], carbodiimides [104] and carboimidophosphenes [105] has been examined in detail (Schemes 72 and 73). Reaction with acetonitrile proceeded at $293 \mathrm{~K}$ to give a 1,2-dihydro-1,3,2-diazaphosphinine derivative 147a following from double NCMe insertion into the $\mathrm{P}-\mathrm{C}$ bond of the phosphinidene ligand, with $\mathrm{C}-\mathrm{C}$ bond formation and subsequent migration of $\beta-\mathrm{H}$ atoms of one acetonitrile to the $\mathrm{N}$ atoms. $\mathrm{NC}^{t} \mathrm{Bu}$, with no $\beta-\mathrm{H}$ atoms, did not react with the phosphinidene even in refluxing toluene for 2 days. However, benzonitrile reacted at ambient temperature to give a 3,4-benzo-1H-1,2-azaphosphole derivative 148a, which proves that after insertion of the nitrile into the $\mathrm{P}-\mathrm{C}$ bond, an additional $\mathrm{C}-\mathrm{H}$ bond activation occurs [102]. Aminobenzonitriles also react with 5 to give single-insertion products, with structures depending on the relative positions of the $\mathrm{CN}$ and $\mathrm{NH}_{2}$ groups: of type 147 for the orthosubstituted reagent, and of type 148 for the rest. Reactions with dinitriles were also sensitive to the particular reagent used. As discussed in section 3.6, a tetranuclear phosphinidene complex 56 was obtained when reacting 5 with 1,4-benzodinitrile (scheme 29). In contrast, reaction with malononitrile in refluxing toluene led to a derivative of type $\mathbf{1 4 7}$ now bearing two $\mathrm{Cp}^{*}$ substituents, along with other thermolysis products (Scheme 72). The reactions of 5 with malononitrile and acetonitrile represent the first examples in which two nitriles form a $\beta$-diketiminate assisted by a phosphinidene complex [57]. 


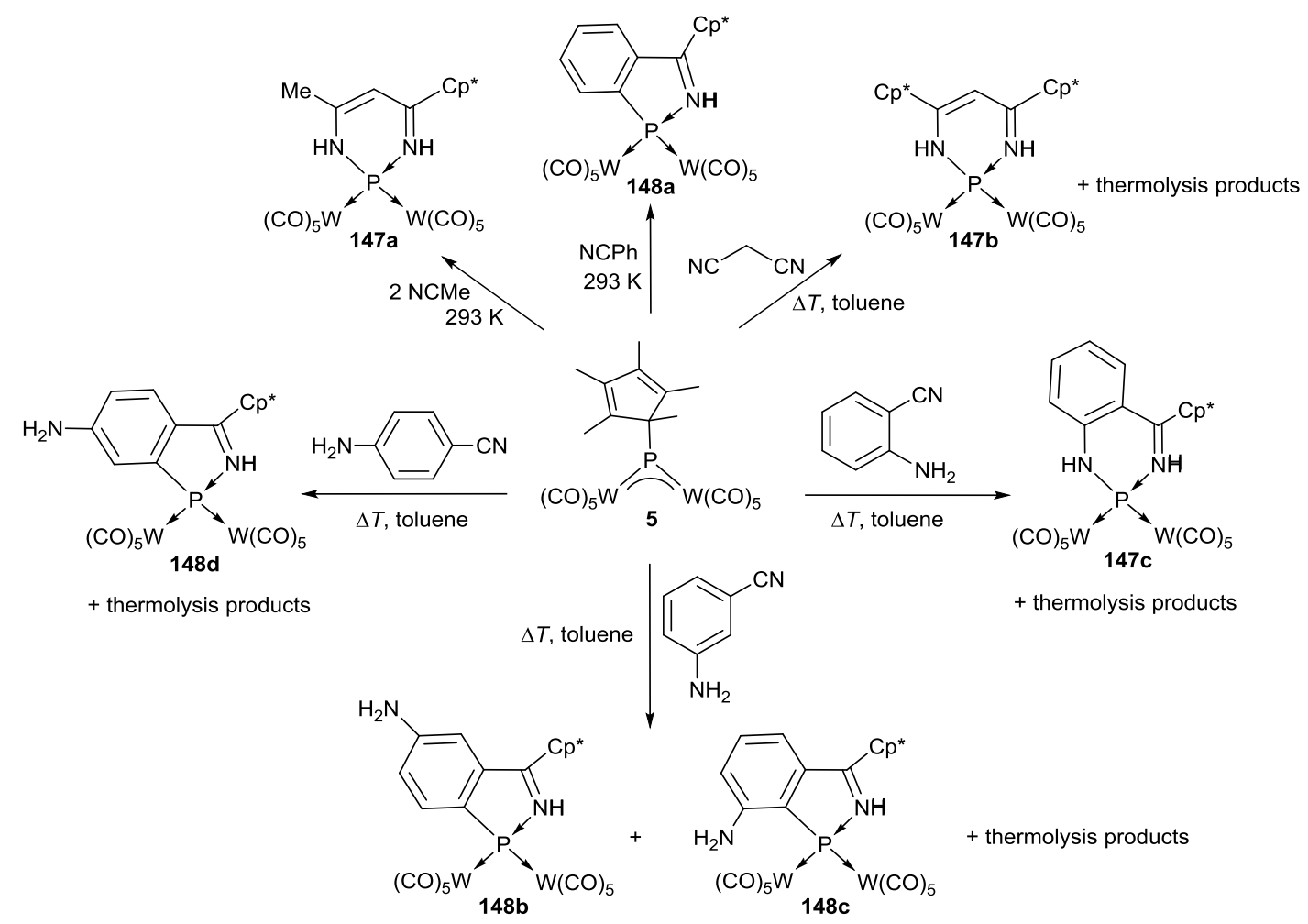

\section{Scheme 72}

The reaction of $\mathbf{5}$ with isocyanides turned out to be strongly dependent on the steric demands of the substituent at the reagent (Scheme 73). When $\mathrm{CN}^{t} \mathrm{Bu}$ was used, only the acid-base adduct 149 was obtained. However, a rearrangement took place at room temperature in reactions with less sterically demanding isocyanides $\mathrm{CNCy}$ and $\mathrm{CN}^{n} \mathrm{Bu}$ to give bicyclo[3.2.0]heptane derivatives of type 150. Addition of another equivalent of isocyanide still revealed two new structural motifs, these being the four-membered ring derivative of type 151 and the bicyclic complex 152. The reaction pathways in the formation of the latter products involve nucleophilic attack of the isocyanides at the electrophilic $\mathrm{P}$ atom, rearrangements with $\mathrm{Cp}^{*}$ migration, and the formation of condensed heterocycles [103].

Finally, the reactions with carbodiimides $\mathrm{C}(\mathrm{NR})_{2}\left(\mathrm{R}={ }^{i} \mathrm{Pr}, \mathrm{Cy}\right)$ led to new four-membered heterocycles of the type $\mathbf{1 5 3}$, these being rare examples of insertion of carbodiimides into $\mathrm{P}-\mathrm{C}$ bonds, uncommon in the literature [104]. More recently, the same group has reported that, if two equivalents of the phosphinidene complex and one carboimidophosphene are reacted, then equimolar amounts of 154, a complex bearing a $\mathrm{P}-\mathrm{C}$ cage formed after a unique elimination of $\mathrm{CN}^{t} \mathrm{Bu}$ followed by a cycloaddition, and the acid-base adduct 149 are obtained [105]. 


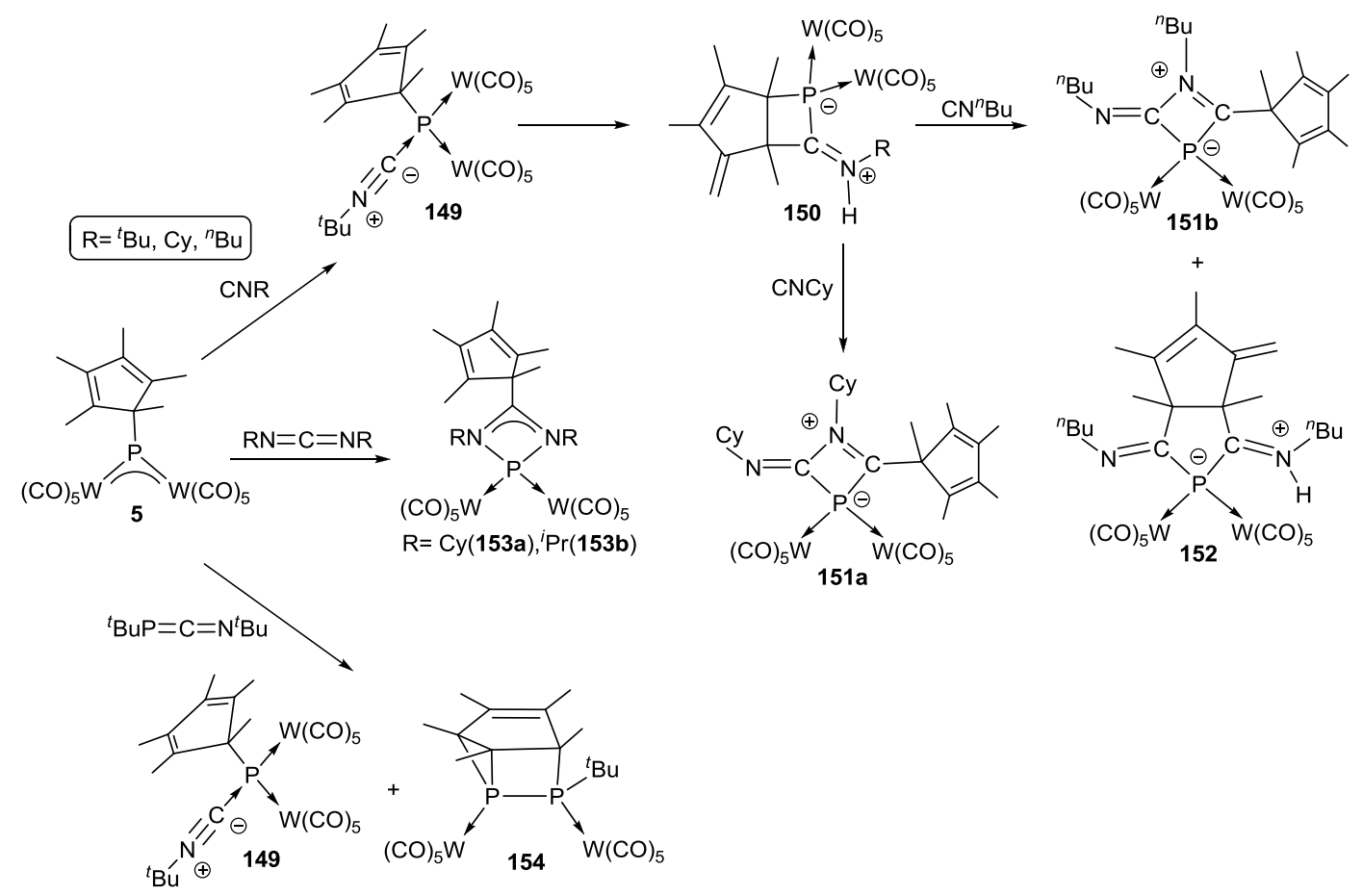

Scheme 73

Reactions of the triply-bonded dimolybdenum complex 47 with isocyanides were also dependent on the substituent at the reagent and reaction conditions, although the phosphinidene ligand seemed to be a spectator, since the reactivity was centred at the unsaturated dimetal centre [77]. By choosing the right conditions, products of the type cis- or trans-[Mo $\left.\mathrm{Cp}_{2}(\mu-\mathrm{PMes} *)\left(\mu-\kappa^{1}: \eta^{2}-\mathrm{CNR}\right)(\mathrm{CO})_{2}\right]$, and $\left[\mathrm{Mo}_{2} \mathrm{Cp}_{2}(\mu\right.$-PMes $\left.*)(\mathrm{CO})_{2}(\mathrm{CNR})_{2}\right]$ could be obtained.

\subsubsection{Reactions with molecules containing $\mathrm{N}-\mathrm{N}$ multiple bonds}

The reactivity of the aminophosphinidene complexes $\mathbf{9 b}$ and $\mathbf{8 a}, \mathbf{b}$ towards diazoalkanes and azides has been investigated (Scheme 74) [18]. The manganese complex reacted readily with several azides $\mathrm{RN}_{3}\left(\mathrm{R}=\mathrm{Me}_{3} \mathrm{Si}, \mathrm{Me}_{3} \mathrm{Sn}\right.$, adamantyl, $\left.\mathrm{Ph}\right)$ to give the compounds of type 155 , with novel $\mu$ $\kappa^{1}: \eta^{2}$-aminophosphaimine ligands following from spontaneous denitrogenation. In contrast, no denitrogenation took place in the reaction with diphenyldiazomethane, which gave the phosphadiazadiene-bridged complex 156, as confirmed through an X-ray diffraction analysis. The reaction of the dicobalt complexes with diazomethane still provided a different output in these reactions, since it involved denitrogenation to give the complexes 157, bearing $\kappa^{1}: \eta^{2}$ aminophosphaalkene ligands formally derived from methylene insertion into one of the Co-P bonds. 

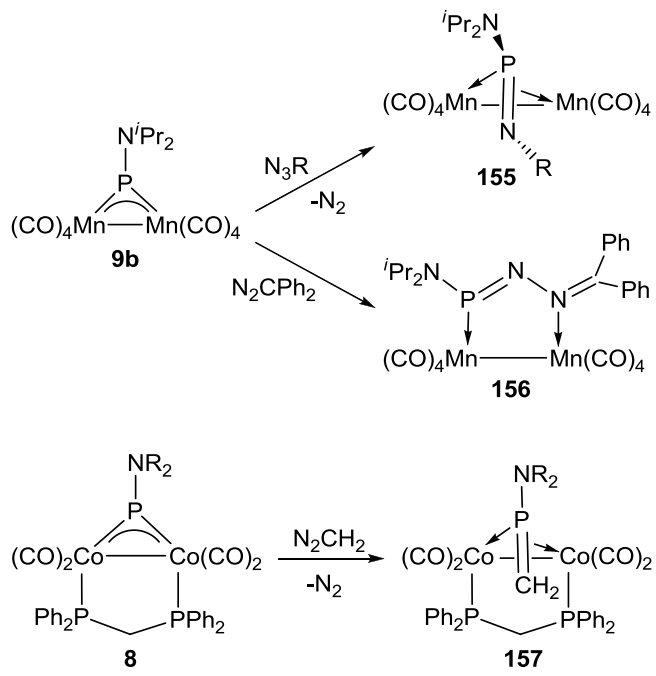

Scheme 74

The ditungsten complex $\mathbf{5}$ also reacted with alkyl azides, but no denitrogenation takes place here. In contrast, unprecedented triazaphosphete derivatives $\mathbf{1 5 8}$ are formed, with a $\mathrm{PN}_{3}$ four-membered ring (Scheme 75) [104]. These products may be regarded as stabilised intermediates of the Staudinger reaction never isolated before.

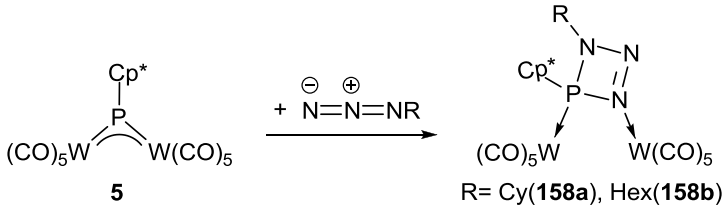

\section{Scheme 75}

\subsubsection{Reactions with molecules containing $C-E$ multiple bonds $(E=O, S, P)$}

The ditungsten complex 5 reacts with phosphaalkynes $(\mathrm{RC} \equiv \mathrm{P})$ under thermal activation (Scheme 76) [106]. The outcome of these reactions revealed that phosphalkynes, like alkynes, might act as trapping reagents of the phosphido intermediate $\left[\mathrm{Cp} *(\mathrm{CO})_{2} \mathrm{~W} \equiv \mathrm{P} \rightarrow \mathrm{W}(\mathrm{CO})_{5}\right]$ which is generated upon heating at $383 \mathrm{~K}$ (see Section 5.2.6). In the reaction with $\mathrm{P} \equiv \mathrm{C}^{t} \mathrm{Bu}$, the major product 159 follows from cycloaddition of the reagent with the mentioned intermediate. In contrast, in the reaction with $\mathrm{Mes} C \equiv \mathrm{P}$, this pathway was responsible of only one of the products (160), and a rare product 161 was obtained, with a 
diphosphacyclooctatetraene ring resulting from an unusual ring opening of the $\mathrm{Cp}^{*}$ ring following insertion of the phosphaalkyne into the $\mathrm{P}-\mathrm{Cp}$ * bond.

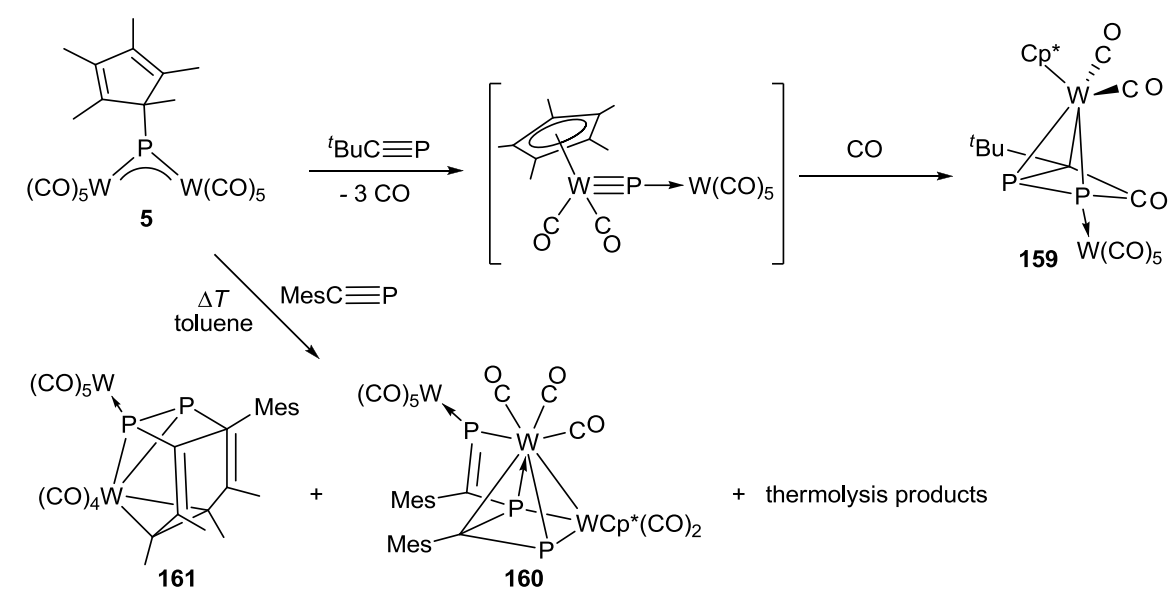

\section{Scheme 76}

The slightly asymmetric lutetium dimer $\mathbf{4 1}$ behaves as a nucleophilic phosphinidene transfer reagent in reactions with aldehydes and ketones, to give the corresponding phosphaalkenes in a phosphaWittig-type reaction (Scheme 77) [47].

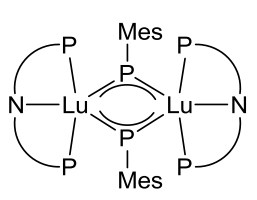

41

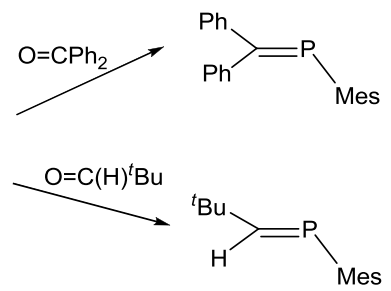

Scheme 77

Similarly, the neodymium complex $\mathbf{1 7}$ is able of transfer the phosphinidene group to benzophenone to give the corresponding phosphaalkene (Scheme 78) [27]. In all, the behaviour of these dimeric complexes is clearly reminiscent of that of nucleophilic mononuclear phosphinidene complexes [2b, $\mathrm{f}, 4 \mathrm{~d}]$, and it might be considered whether dissociation at some extent of these asymmetric dimers in solution (to give the corresponding monomers) would actually account for this chemistry. 


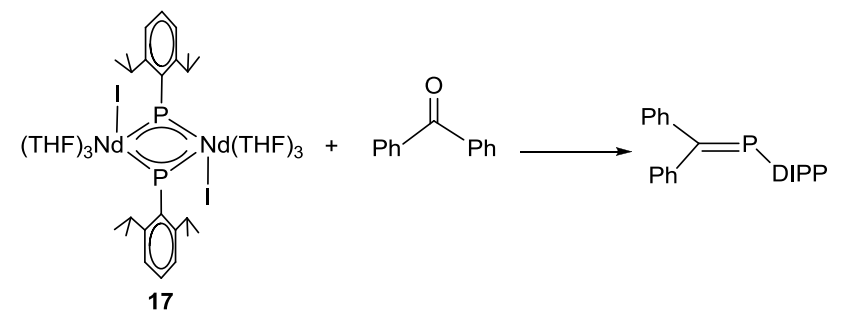

Scheme 78

In contrast, the scandium dimer $\mathbf{2 0}$ reacted readily with a two-fold excess of $\mathrm{CS}_{2}$ with retention of the overall nuclearity, to give the insertion product 146 (see Scheme 71), whose structure was confirmed by X-ray diffraction [29a].

\subsubsection{Reactions with other p-block elements and compounds}

The reaction of the ditantalum complex 22c with an excess (50-fold) of wet acetone gives the trinuclear oxo complex 162 in very low yield (Scheme 79) [30]. The presence of the phosphinidene-derived phenylphosphinate group in the latter compound was confirmed through a single-crystal X-ray diffraction analysis, although no signals were detected in the ${ }^{31} \mathrm{P}$ NMR spectrum to confirm the presence of the $\mathrm{PH}$ proton.

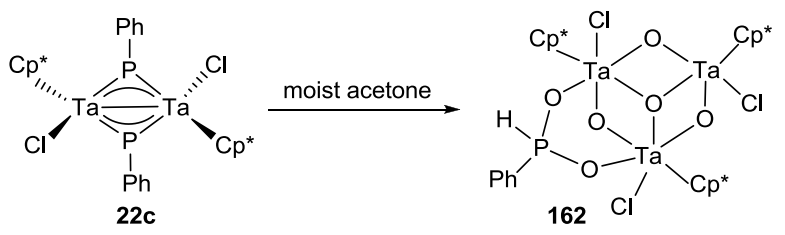

Scheme 79

The outcome of the reactions of the dimanganese complexes $\mathbf{9 a , b}$ with sulphur was dependent on the substituents at the nitrogen atom (Scheme 80) [19]. The P(TMP)-bridged complex 9a yielded the eneacarbonyl derivative 163 , with a phosphinidene sulphide ligand in an unusual $\mu-\kappa^{1}, \kappa^{2}$ coordination mode, as confirmed through an X-ray diffraction study, also revealing the absence of intermetallic bond as a result of the presence of an additional CO ligand. In contrast, the $\mathrm{P}\left(\mathrm{N}^{i} \mathrm{Pr}_{2}\right)$ bridged complex yielded the octocarbonyl complex 164, with a similar coordination of the phosphinidene sulphide ligand, but preserving the $\mathrm{Mn}-\mathrm{Mn}$ bond. Although no crystals suitable for an X-ray analysis could be grown for this compound, the spectroscopic similarity with the isoelectronic aminophosphaimine complexes 155 gave strong support to the proposed structure. 


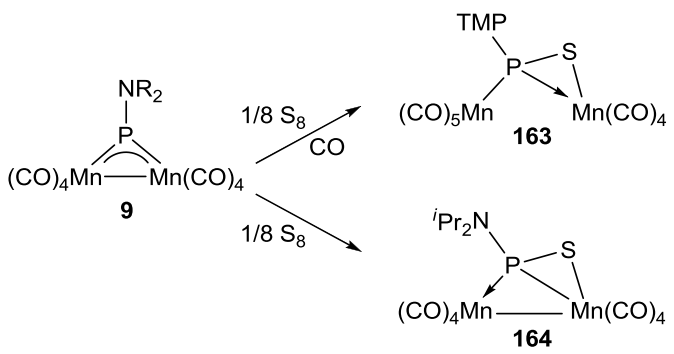

\section{Scheme 80}

The ditungsten complex 5 reacted with a diphosphene under photochemical conditions to give the air-stable phosphaallyl derivative 165 (Scheme 81), a compound with interesting redox chemistry [107]. The mechanistic proposal for this reaction assumes that the photochemical activation of the title phosphinidene generates a phosphido radical after losing a Cp* radical (see Section 5.2.6), which in this case is trapped by the diphosphene to give the final phosphaallyl product. Compound 165 abstracts readily an $\mathrm{H}$ atom upon chromatographic workup to give the diamagnetic derivative $\mathbf{1 6 6 .}$

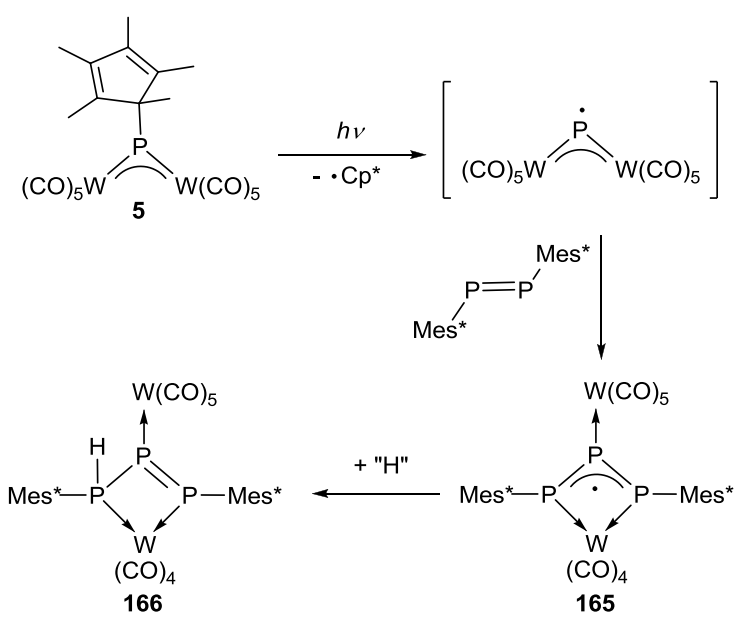

\section{Scheme 81}

The scandium complex 20 reacted with Se and Te at room temperature to give the corresponding chalcogenide- and diphosphene-bridged compounds 167 , following from a reductive coupling of the phosphinidene ligands (Scheme 82) [29a]. In contrast, reaction with $S_{8}$ gave a complex mixture of products. Fortunately, an analogous sulphide-bridged complex was obtained in the reactions with phosphine sulphides $\left(\mathrm{R}_{3} \mathrm{P}=\mathrm{S}, \mathrm{R}=\mathrm{Me}, \mathrm{Ph}\right)$, with concomitant elimination of the corresponding phosphine, as unambiguously determined by ${ }^{31} \mathrm{P}$ NMR spectroscopy. The synthesis of the selenide complex could be also achieved through this route, by using $\mathrm{Ph}_{3} \mathrm{P}=\mathrm{Se}$. 


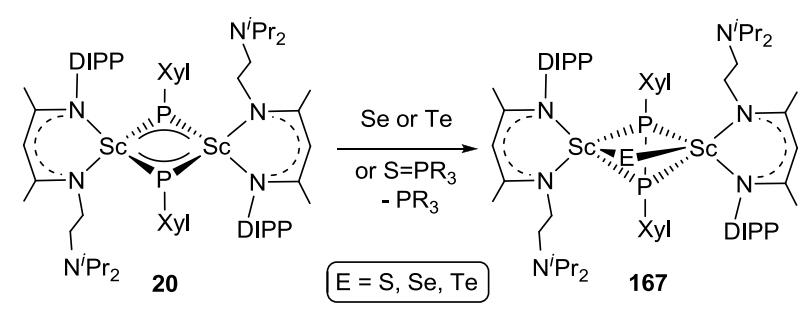

\section{Scheme 82}

\subsubsection{Addition of metal fragments}

The ditungsten complex 5 was reacted with $\left[\mathrm{Cr}(\mathrm{CO})_{3}(\mathrm{CNMe})_{3}\right]$ to give the trinuclear complex 168, a molecule bearing a planar $\mu_{3}$-phosphido ligand which follows from $\mathrm{Cp}^{*}$ transfer from $\mathrm{P}$ to $\mathrm{Cr}$ and decarbonylation (Scheme 83) [9]. Later on, the thermal and photochemical reactions of 5 in the presence of the triply-bonded dimolybdenum complex $\left[\mathrm{Mo}_{2} \mathrm{Cp}_{2}(\mathrm{CO})_{4}\right]$ were examined, these leading to complex reaction mixtures containing mainly trinuclear MoW clusters following from trapping of the phosphido intermediate $\left[\mathrm{Cp}^{*}(\mathrm{CO})_{2} \mathrm{~W} \equiv \mathrm{P} \rightarrow \mathrm{W}(\mathrm{CO})_{5}\right]$ generated under the above mentioned conditions (see also Section 5.2.6) [108].

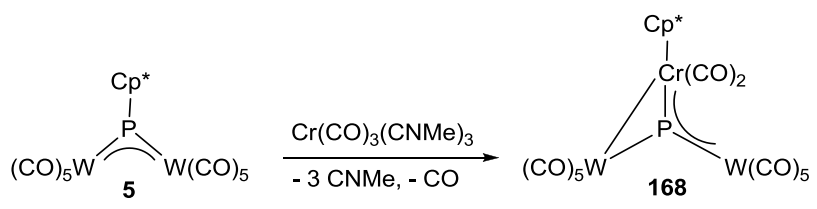

\section{Scheme 83}

Reaction of $\mathrm{K}\left[\mathrm{Co}(\mathrm{CO})_{4}\right]$ with $\mathrm{Cl}_{2} \mathrm{P}(\mathrm{TMP})$ in $\mathrm{THF}$ at $303 \mathrm{~K}$ yielded the phosphinidene-bridged tricobalt cluster 169. Formation of this cluster could be rationalised as resulting from addition of the transient chlorophosphanyl complex $\left[\mathrm{Co}\{\mathrm{PCl}(\mathrm{TMP})\}(\mathrm{CO})_{4}\right]$ to the phosphinidene-bridged dicobalt complex $\left[\mathrm{Co}_{2}\{\mu-\mathrm{P}(\mathrm{TMP})\}(\mathrm{CO})_{6}\right]$ (Scheme 84) [16]. Attempted generation of a second phosphinidene ligand upon addition of $\mathrm{AlCl}_{3}$ led instead to the cationic phosphinidene cluster $\mathbf{1 7 0}$. On the other hand, addition of one equivalent of $\left[\mathrm{Co}_{2}(\mathrm{CO})_{8}\right]$ to in situ prepared solutions of $\left[\mathrm{Co}_{2}\{\mu-\right.$ $\left.\mathrm{P}(\mathrm{TMP})\}(\mathrm{CO})_{6}\right]$ afforded the tetranuclear cluster 171. 


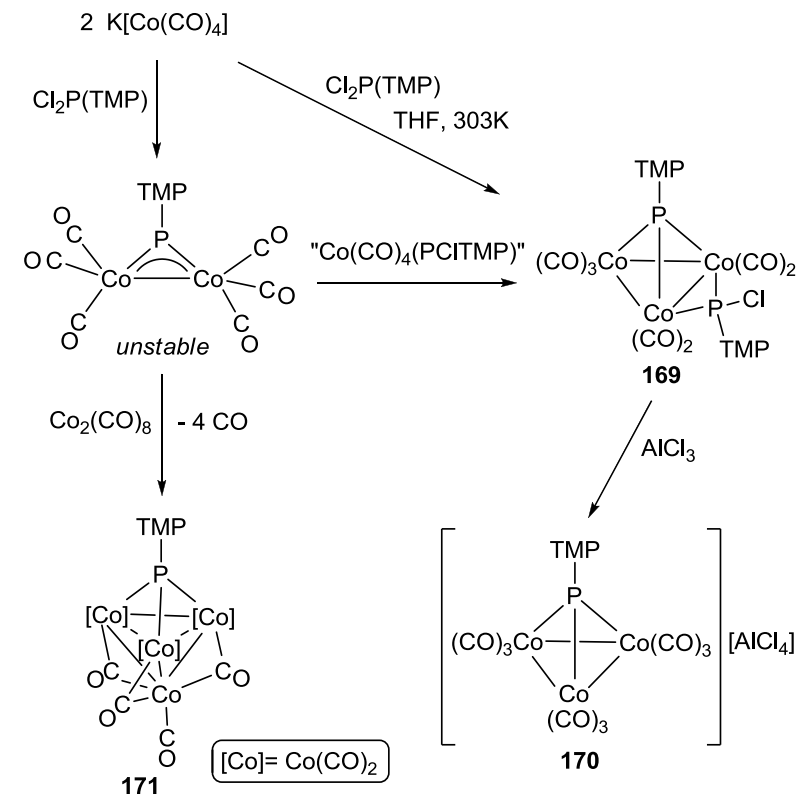

\section{Scheme 84}

The reaction of the scandium complex 20 with $\left[\mathrm{Mo}(\mathrm{CO})_{6}\right]$ at room temperature yielded a trinuclear oxocomplex 172 bearing a 1,4-diphospha-2-ylidene-3-oxo-buta-1,3-diene ligand (Scheme 85) [29a]. This product is reminiscent of that obtained in the reaction of $\mathbf{2 0}$ with CO (125 in Scheme 62), except for the additional insertion of a $\mathrm{Mo}(\mathrm{CO})_{4}$ fragment in the $\mathrm{P}-\mathrm{P}$ bond of $\mathbf{1 2 5}$.

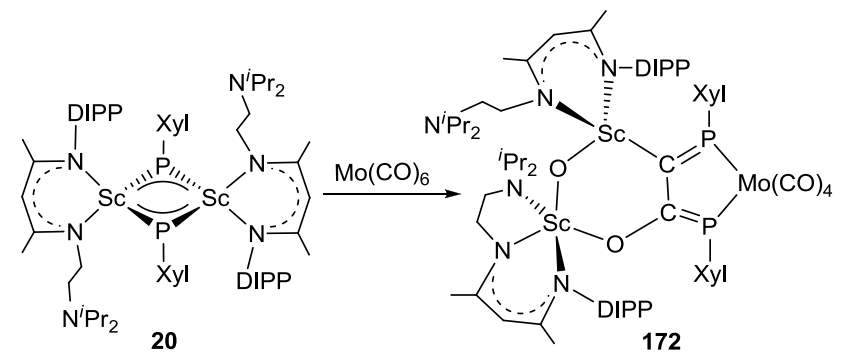

Scheme 85

\subsubsection{Thermolysis and photolysis}

The thermal [10] and photochemical [109] stability of the ditungsten complex $\mathbf{5}$ has been examined in detail (Scheme 86). Thermolysis in refluxing toluene induces, by the loss of two CO ligands, a $\mathrm{Cp} \mathrm{p}^{*}$ migration from $\mathrm{P}$ ( $\sigma$-bound) to $\mathrm{W}$ ( $\pi$-bound), presumably to yield the intermediate $\left[\left\{\mathrm{Cp} * \mathrm{~W}(\mathrm{CO})_{3}\right\} \mathrm{P}\left\{\mathrm{W}(\mathrm{CO})_{5}\right\}\right]$, which leads to the phosphanyl complex 173 after insertion of the unsaturated $\mathrm{P}$ atom into the $\mathrm{C}-\mathrm{H}$ bond of a methyl group. A further $\mathrm{CO}$ loss at the intermediate yields the phosphido intermediate $\left[\mathrm{Cp} *(\mathrm{CO})_{2} \mathrm{~W} \equiv \mathrm{P} \rightarrow \mathrm{W}(\mathrm{CO})_{5}\right]$, which in the absence of external 
reagents evolves in a number of ways to give different products: the diphosphorus complex 174, following from a P-P coupling reaction, and the hexanuclear complex 175. In contrast, photolysis of the phosphinidene complex turned out to be a much more selective process, yielding as major product the diphosphorus-bridged hydrido complex 176 [109]. In order to account for the formation of this compound, it has been proposed that, in addition to the $\mathrm{Cp}^{*}$ migration observed in the thermal reaction, $\mathrm{Cp} *$ elimination to form a phosphido-bridged radical intermediate $\left[\mathrm{W}_{2}(\mu-\right.$ $\left.\mathrm{P})(\mathrm{CO})_{10}\right]$ takes also place (see Scheme 81).

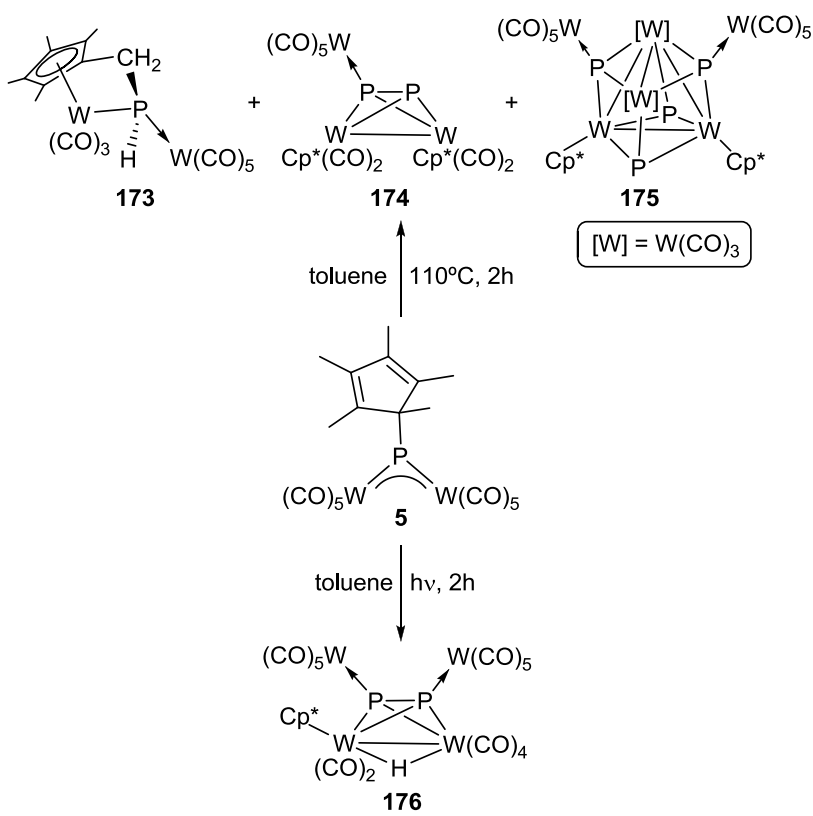

\section{Scheme 86}

As mentioned in Section 3.6, photolysis of the electron-precise dimolybdenum complex 1 can lead to three different products depending on reaction conditions: the phosphanyl complex 46, following from an intramolecular $\mathrm{C}-\mathrm{H}$ activation of a ${ }^{t} \mathrm{Bu}$ group, the triplybonded phosphinidene complex 47 , and its isomer 48 , with a ten-electron donor arylphosphinidene ligand (see Scheme 27) [52b, 51].

In the absence of an stabilising ligand (such as dppm), the dicobalt aminophosphinidene complex $\left[\mathrm{Co}_{2}(\mathrm{CO})_{6}\{\mu-\mathrm{P}(\mathrm{TMP})\}\right]$ loses $\mathrm{CO}$ in hexane solution to yield the tetracobalt cluster 177 (Scheme 87), whose formation can be rationalised as resulting from condensation of two $\left[\mathrm{Co}_{2}(\mathrm{CO})_{6}\{\mu-\right.$ $\mathrm{P}(\mathrm{TMP})\}$ ] molecules with loss of three CO ligands [17]. The structure of the latter was confirmed by an X-ray diffraction analysis, evidencing the presence of two $\mu_{3}$-phosphinidene ligands, in good 
agreement with the ${ }^{31} \mathrm{P}$ NMR spectrum of the complex, which displays two broad low-field resonances at 542 and $472 \mathrm{ppm}$, respectively.

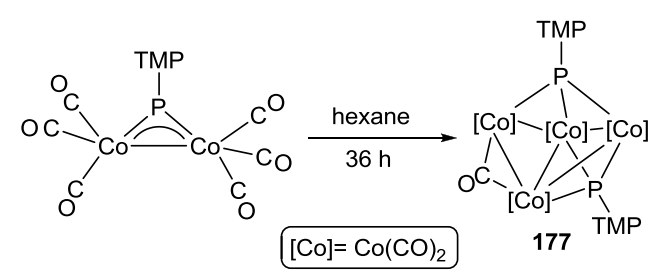

\section{Scheme 87}

\subsection{Asymmetric trigonal planar phosphinidene complexes}

\subsubsection{Reactions with simple neutral ligands}

As noted in Section 3.6, the asymmetric phosphinidene complex 48 could be generated selectively upon photolysis of the symmetric precursor 1 under the right reaction conditions. We should also add that this reaction is reversible, since the former complex adds $\mathrm{CO}$ stepwise to generate first the tricarbonyl 49a, with an asymmetric trigonal phosphinidene acting as an 8-electron donor, which subsequently adds another $\mathrm{CO}$ molecule to regenerate the parent tetracarbonyl complex (see Scheme 27) [52]. In a similar way, the reaction of the tricarbonyl 49a with $\mathrm{CN}^{t} \mathrm{Bu}$ caused full ring de-coordination of the arylphosphinidene ligand, although the product formed turned to be dependent on the solvent used: the metalmetal bonded $\left[\mathrm{Mo}_{2} \mathrm{Cp}_{2}(\mu\right.$-PMes $\left.*)(\mathrm{CO})_{3}\left(\mathrm{CN}^{t} \mathrm{Bu}\right)\right]$ when using tetrahydrofuran, and the bis(isocyanide) derivative $\mathbf{5 0}$ when using petroleum ether [52a]. Full ring de-coordination of the arylphosphinidene ligand was also observed upon carbonylation of the heterometallic complex 73 to give the symmetric trigonal planar phosphinidene complex 57c (see Section 3.9 and Scheme 39) [75].

The facile ring-slippage reactions of arylphosphinidene ligands taking place in the above reactions have never been observed for the related cyclopentadienylidene-phosphinidene complexes. Thus, reaction of complex $\mathbf{5 1}$ with $\mathrm{CO}$ proceeds in a completely different way, to give the diphosphanediyl complex 178 and the dimer $\left[\mathrm{Mo}_{2} \mathrm{Cp}_{2}(\mathrm{CO})_{6}\right]$, as a result of $\mathrm{P}-\mathrm{Mo}$ bond cleavage and P-P and Mo-Mo coupling processes (Scheme 88) [54]. The $\mu-\kappa^{1}: \kappa^{1}$ was apparently a novel coordination mode of the diphosphanediyl ligand, and it was shown to provide a strong 
communication between the metal centres derived from involvement of the lone electron pairs at phosphorus in a $\pi(\mathrm{PP})$-bonding interaction. On the other hand, reactions with $\mathrm{PMe}_{3}$ or $\mathrm{PMe}_{2} \mathrm{Ph}$ proceeded rapidly without degradation, to give novel pyramidal phosphinidene complexes $\mathbf{5 2}$ (see Scheme 27), which were stable enough so as to examine their chemical behaviour, as discussed in preceding sections $[53,86]$.

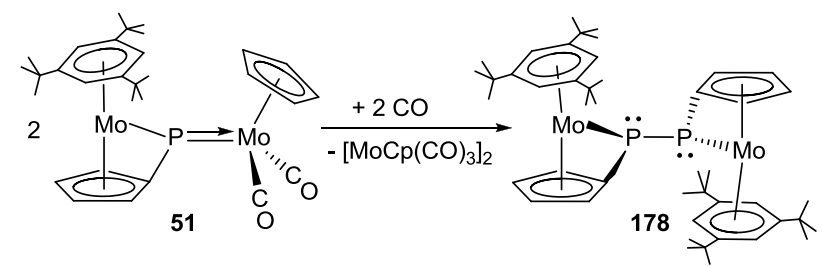

\section{Scheme 88}

\subsubsection{Reactions with electrophiles}

The arylphosphinidene complex $\mathbf{4 8}$ can be protonated stoichiometrically at $233 \mathrm{~K}$ with strong acids having non-coordinating anions, to give the cationic hydrido complex 179 as a mixture of $c i s$ and trans isomers in solution (Scheme 89) [52b]. The latter rearrange at room temperature to give the phosphido-bridged complex $\mathbf{6 1}$ after $\mathrm{P}-\mathrm{C}$ cleavage and $\mathrm{C}-\mathrm{H}$ bond formation steps. In contrast, addition of ethereal $\mathrm{HCl}$ to $\mathbf{5 1}$ afforded the chloride complex $\mathbf{1 8 0}$, after addition of $\mathrm{HCl}$ to the $\mathrm{Mo}-\mathrm{P}$ multiple bond with selective formation of $\mathrm{P}-\mathrm{H}$ bonds. The nucleophilic behaviour of the $\mathrm{P}$ atom in these asymmetric trigonal phosphinidene complexes is additionally illustrated through the reaction of 62 with $\mathrm{BH}_{3}$. THF, which proceeds readily at $243 \mathrm{~K}$ to give $\mathbf{1 8 1}$. The latter complex is the first reported complex with the phosphinidene-borane ligand $\left(\mathrm{PHBH}_{3}\right)$, which binds the metal atoms not only through $\mathrm{P}$ but also through one of the $\mathrm{B}-\mathrm{H}$ bonds, coordinated to the $\mathrm{MoCp}(\mathrm{CO})_{2}$ moiety in a side-on fashion, as revealed by an X-ray diffractometric analysis [63]. 


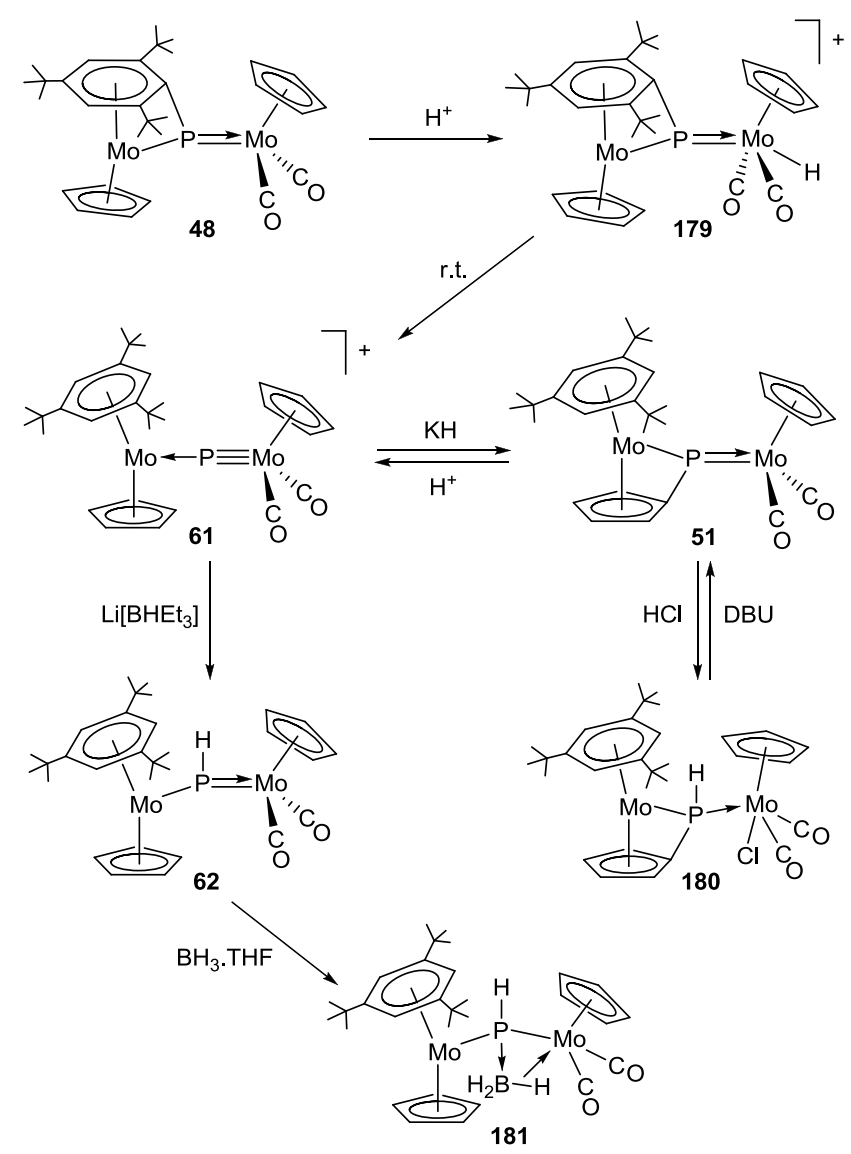

Scheme 89

\subsubsection{Reactions with unsaturated organic molecules}

The dimolybdenum complex $\mathbf{5 1}$ reacted with dimethyl acetylenedicarboxylate at $368 \mathrm{~K}$ in toluene to give the phosphanyl complex $182\left(\mathrm{R}=\mathrm{CO}_{2} \mathrm{Me}\right)$, apparently resulting from a $[2+2]$ cycloaddition process to the P-Mo multiple bond of 51 (Scheme 90) [84]. More interestingly, this phosphinidene complex was able to react with electron-poor alkenes and alkynes in the presence of $\mathrm{CO}$ or $\mathrm{CNXyl}$, in a multicomponent reaction that yielded cycloaddition products having novel five-membered phosphametallacycles (complexes 183-186) resulting from highly selective couplings between the alkyne/alkene, the added ligand, and the Mo-P multiple bond of 51 [55]. A detailed study on the reactions with alkynes suggested complex relationships between the different products observed, including the [2+2] cycloaddition products of type 182. The reactivity of the PH-bridged complex 62 towards alkynes was also studied, resulting somewhat reminiscent of that of the $\mathrm{PC}_{5} \mathrm{H}_{4}$ complex. However, the PH complex was more reactive and, for instance, addition of dimethyl acetylenedicarboxylate at $295 \mathrm{~K}$ afforded immediately the five-membered metallacyclic of type 183, which evolved progressively in solution to give the corresponding four-membered 
metallacyclic derivative of type $\mathbf{1 8 2}$ [55a]. From all the above experiments it could be concluded that all reactions of these trigonal complexes with alkynes are initiated by the coordination of a ligand (added $\mathrm{CO}, \mathrm{CNR}$ or the alkyne itself) to the $\mathrm{MoCp}(\mathrm{CO})_{2}$ fragment of the parent substrate, to yield intermediates having a pyramidal phosphinidene ligand that would rapidly attack an alkyne molecule, thus triggering the formation of five- and eventually four-membered phosphametallacycles [55a].
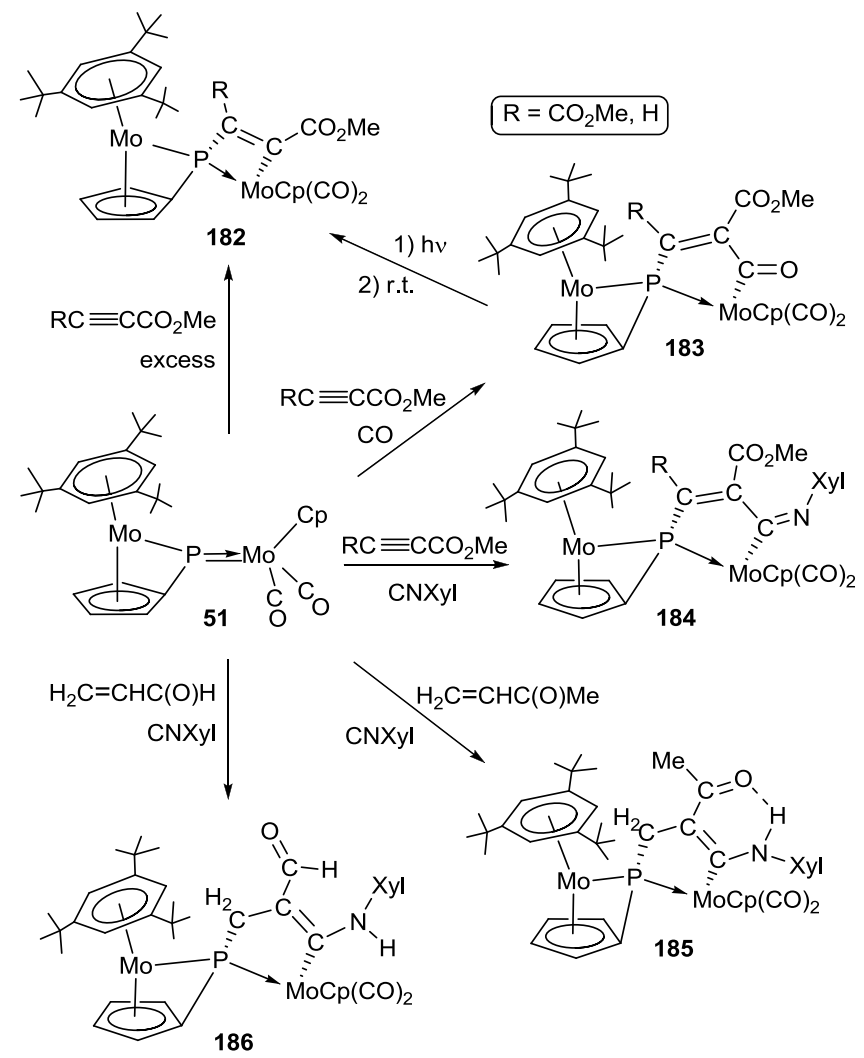

\section{Scheme 90}

\subsubsection{Reactions with other p-block elements and compounds}

The pentacarbonyl complexes $\left[\mathrm{MM}^{\prime} \mathrm{Cp}_{2}(\mu\right.$-PMes $\left.)(\mathrm{CO})_{5}\right]\left(\mathrm{M}, \mathrm{M}^{\prime}=\mathrm{Mo}, \mathrm{W}\right)$, analogous to complex 11, react with elemental sulphur and selenium to give the corresponding derivatives $\mathbf{1 8 7}$ displaying three-membered phospha-chalcogen-metallacycles resulting from formal addition of a chalcogen atom to the Mo=P double bond of the phosphinidene complex (Scheme 91) [110]. 


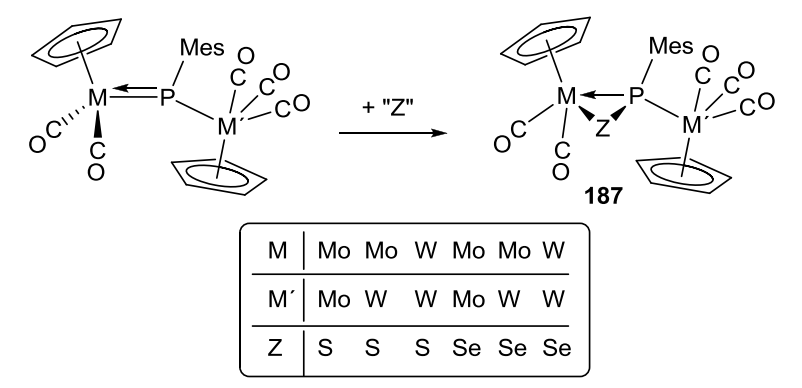

\section{Scheme 91}

The above reaction seems to be a characteristic feature of asymmetric trigonal planar phosphinidene ligands, as suggested by the results of the reactions of different asymmetric phosphinidene compounds such as 48, 49a, 49b, 51 and 62, with different sources of chalcogen atoms $(\mathrm{O}, \mathrm{S}, \mathrm{Se}$ and $\mathrm{Te})[111,74]$. The main products obtained in all reactions were complexes of type $\mathbf{1 8 8}$ displaying three-membered MoPZ cycles (Scheme 92). The $\mathrm{PC}_{5} \mathrm{H}_{4}$ complex proved to be very reactive in these reactions, and was able to add not just one, but up to two $\mathrm{S}$ atoms to give the dithiophosphorane complex 189, with full cleavage of one of the Mo-P bonds [111]. Interestingly, the last process could be reversed by just attempting chromatographic purification of this product on alumina at room temperature, which caused partial desulphurisation to regenerate the phosphinidene sulphide ligand.

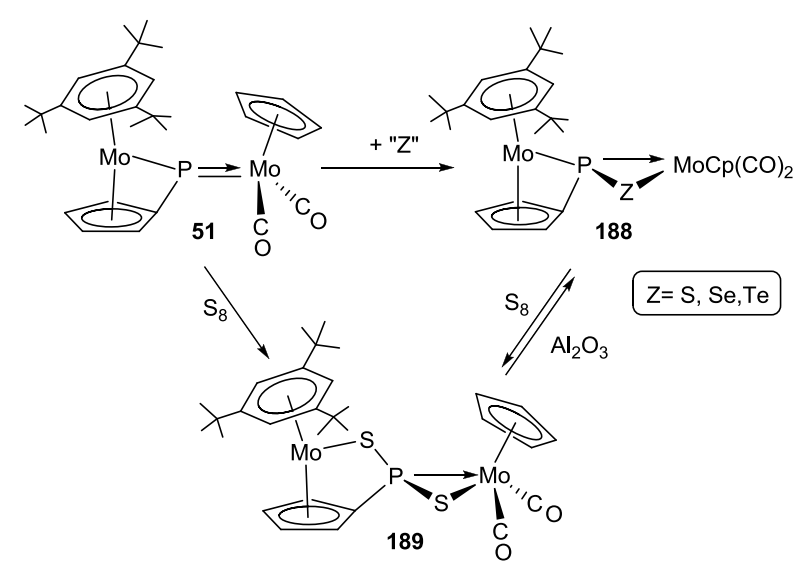

\section{Scheme 92}

\subsubsection{Addition of metal fragments}

The heteronuclear complex 66 reacts with $\left[\mathrm{Fe}_{2}(\mathrm{CO})_{9}\right]$ to give the trinuclear derivative 190, bearing a phosphinidene ligand bridging three metal centres, which follows from addition of a 16-electron " $\mathrm{Fe}(\mathrm{CO})_{4}$ " fragment to the $\mathrm{Mn}=\mathrm{P}$ double bond in the parent substrate (Scheme 93) [67]. 


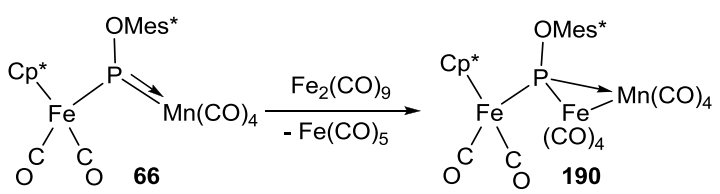

\section{Scheme 93}

The above reaction is reminiscent of the addition of chalcogen atoms to the $\mathrm{M}=\mathrm{P}$ double bond of asymmetric phosphinidenes discussed in the preceding section, and it would be the expected result of the addition of any 16-electron metal carbonyl fragment to a phosphinidene complex of this class. Indeed, a systematic analysis of the reactivity of the dimolybdenum complexes 51 [83-84], and 62 [83], towards different precursors of 16-electron metal carbonyl fragments such as $\left[\mathrm{Fe}_{2}(\mathrm{CO})_{9}\right]$ and $\left[\mathrm{M}(\mathrm{CO})_{5}(\mathrm{THF})\right](\mathrm{M}=\mathrm{Cr}, \mathrm{Mo}, \mathrm{W})$, indicated that the $\mathrm{Mo}=\mathrm{P}$ double bond in these asymmetric complexes was basic enough to act as a donor towards these metal fragments, to give the expected trinuclear derivatives 191 and 192 (Scheme 94$)$ and $\left[\mathrm{M}^{\prime} \mathrm{Mo}_{2} \mathrm{Cp}_{2}\left(\mu_{3}-\mathrm{PH}\right)\left(\eta^{6}-\right.\right.$ HMes*) $(\mathrm{CO})_{2} \mathrm{~L}_{\mathrm{n}}$ ] [83]. In a less expected way, the $\mathrm{PC}_{5} \mathrm{H}_{4}$ complex proved to be able to bind two new metal fragments, as found in its reaction with $\left[\mathrm{Co}_{2}(\mathrm{CO})_{8}\right]$ to give the tetranuclear cluster 193. The crystal structure of this new compound revealed an unusual geometry around the P atom, trigonally bound to three metal centres (Mo, Mo and Co) while the apical position of a virtual trigonal pyramid would be occupied by the midpoint of the $\mathrm{Co}-\mathrm{C}_{5} \mathrm{H}_{4}$ vector, the $\mathrm{C}_{5} \mathrm{H}_{4}$ group actually being located half its way from $\mathrm{P}$ to Co [83].

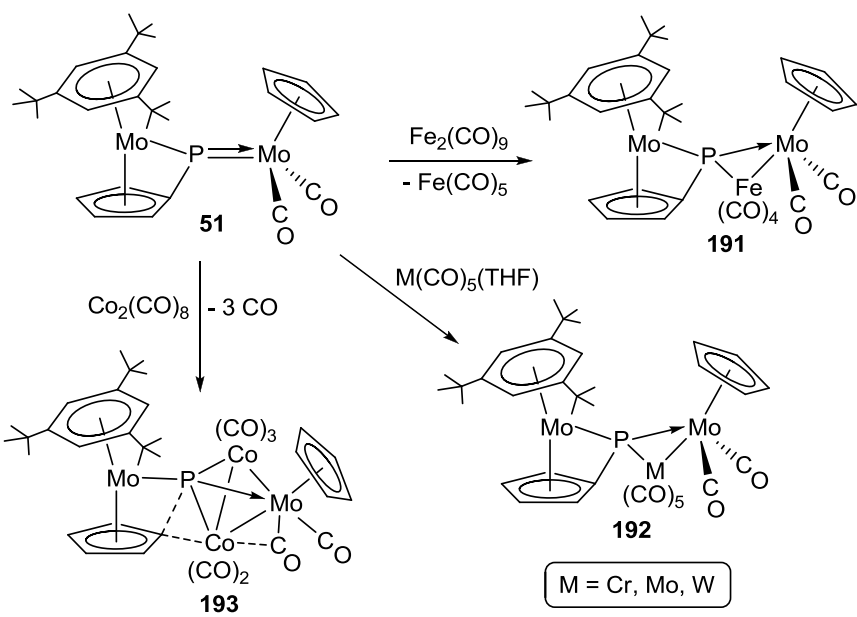

Scheme 94

The above asymmetric phosphinidene complexes were also confronted with suitable precursors of $\mathrm{Au}(\mathrm{I}), \mathrm{Ag}(\mathrm{I}), \mathrm{Cu}(\mathrm{I})$ and $\mathrm{Hg}(\mathrm{II})$ fragments [112, 52a]. A summary of this type 
of reactivity for complexes $\mathbf{4 8}$ and $\mathbf{5 1}$ is depicted in Scheme 95. The $\pi$-bonding electron density located at the short Mo-P bond in these compounds makes them good donors towards $\mathrm{Au}(\mathrm{I})$ centres, and their reactions with suitable gold complexes such as the neutral $[\mathrm{AuCl}(\mathrm{THT})]$ or the cations $\left[\mathrm{Au}\left(\mathrm{PR}_{3}\right)(\mathrm{THT})\right]^{+}$and $\left[\mathrm{Au}(\mathrm{THT})_{2}\right]^{+}$provide a rational route to heterometallic $\mathrm{Mo}_{2} \mathrm{Au}$ and $\mathrm{Mo}_{4} \mathrm{Au}$ clusters held by tricentric MoPAu bonds (complexes of types 194 to 197). Unfortunately, analogous examples involving $\mathrm{Ag}(\mathrm{I})$ or $\mathrm{Cu}(\mathrm{I})$ fragments were more limited due to undesired redox side-reactions. It should be noted that coordination of $\mathrm{Au}$ atoms to the arylphosphinidene complex promotes a complex sequence of $\mathrm{P}-\mathrm{C}$ and $\mathrm{C}-\mathrm{H}$ bond formation and cleavage steps in the aryl and cyclopentadienyl groups to form isomeric species having the bridging $\mathrm{PC}_{5} \mathrm{H}_{4}$ ligand. In addition, the $\mathrm{Au}(\mathrm{THT})$ derivatives proved to be unstable and evolved with loss of THT and dimerisation, to yield a dicationic cluster 198 with an unusual H-shaped geometry derived from the formation of two new intermetallic interactions: a dative $\mathrm{Mo} \rightarrow \mathrm{Au}$ one, via a non-bonding Mo-based electron pair of the metallocene fragment, and an aurophilic $\mathrm{Au}-\mathrm{Au}$ one.

In contrast, reactions of the above phosphinidene complexes with $\mathrm{HgI}_{2}$ took a different course: in the case of the $\mathrm{PC}_{5} \mathrm{H}_{4}$-bridged complex, oxidative addition of a $\mathrm{Hg}-\mathrm{I}$ bond to the $\mathrm{Mo}=\mathrm{P}$ double bond was observed, reminiscent of its reaction with $\mathrm{HCl}$ (see Section 5.3.2), to yield complex 199. For the more crowded PMes*-bridged complex, a dative $\mathrm{Mo} \rightarrow \mathrm{Hg}$ interaction was established via a non-bonding Mo-based electron pair of the $\mathrm{MoCp}(\mathrm{CO})_{2}$ fragment, again resembling the initial hydrido complex formed upon protonation of this substrate (see Scheme 89). This acid-base reaction is then followed by dimerization via halide-bridge formation, to eventually yield the hexanuclear complex 200. 


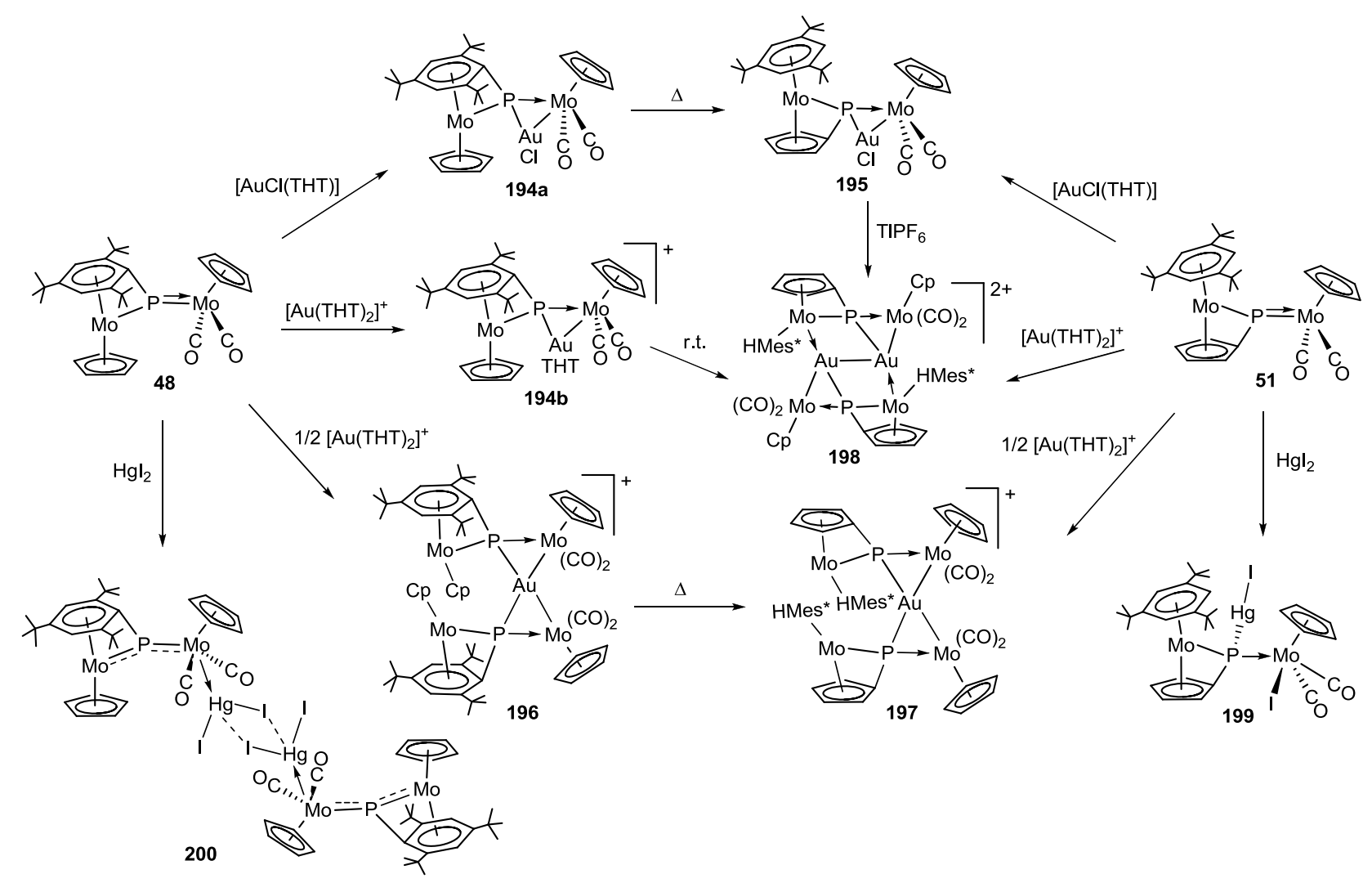

Scheme 95

\subsubsection{Thermolysis and photolysis}

Photochemical reactions of the 8-electron-donor phosphinidene complexes 49a $(\mathrm{L}=\mathrm{CO}$ [52b], ) and $49 \mathrm{~b}\left(\mathrm{~L}=\mathrm{CN}^{t} \mathrm{Bu}\right.$ [52]), directly obtained by addition of $\mathrm{L}$ to the dicarbonyl complex 48 (see Scheme 27), regenerates the latter species, thus proving that the ring slippage of the $\eta^{6}$-bound arylphosphinidene ligand to give the corresponding $\eta^{4}$-bound products is actually reversible.

Finally, as mentioned in Section 3.1.3, photolysis of homo- and heterometallic phosphinidene complexes 11 and 13, which have no metal-metal interactions, yielded the corresponding symmetric trigonal planar phosphinidene complexes 12 and 14, after loss of one molecule of CO in each case, with concomitant formation of a metal-metal bond (see Scheme 7) [23].

\section{Conclusions}

A large number of synthetic methods have been implemented over the years to build binuclear complexes bearing bridging phosphinidene ligands, most of them based on the 
cleavage of $\mathrm{P}-$ halogen or $\mathrm{P}-\mathrm{H}$ bonds of suitable phosphorus compounds or metal complexes. In this way, binuclear complexes of most transition metals (except for Ti, Hf, Tc, Pd and the group 11 metals) and five lanthanide elements have been prepared. Three different structural environments are possible for the $\mathrm{P}$ atom at the bridging phosphinidene ligand: pyramidal, symmetric trigonal planar (the most abundant to date) and asymmetric trigonal planar, depending on the electronic demands of the metal fragments involved. In the trigonal complexes there is a $\pi$ bonding interaction which increases the $\mathrm{M}-\mathrm{P}$ formal bond orders to 1.5 (symmetric) and up to 2 (asymmetric), and reduces the corresponding bond lengths, although the asymmetric ligands may actually display significant delocalization over the $\mathrm{M}-\mathrm{P}-\mathrm{M}$ skeleton. We note that a small number of symmetric complexes display relatively long, single bond-like, $\mathrm{M}-\mathrm{P}$ distances, yet to be seen whether they should be considered as a different class.

The reactivity of all these complexes relates strongly to the geometry of the phosphinidene ligand. The behaviour of complexes with pyramidal ligands is mainly dictated by the high basicity of the $\mathrm{P}$ atom in these molecules, somewhat reminiscent of the chemical behaviour of tertiary phosphines. This enables the formation of new bonds with many $p$-block elements and transition metals upon reaction with suitable electrophilic reagents and complexes, although further reactions and rearrangements frequently follow the initial nucleophilic attack of the phosphinidene complex. Binuclear complexes displaying trigonal planar ligands display an ambiphilic behaviour displaced to the electrophilic side. Their reactions often involve addition or even full insertion of the added reagent to the $\mathrm{M}-\mathrm{P}$ multiple bond of the phosphinidene ligand. In particular cases, a marked tendency to cleavage of the $\mathrm{P}-\mathrm{C}$ bond of the phosphinidene ( $\mathrm{PC} \mathrm{p}^{*}$ ligands), or full phosphinidene transfer (some lanthanide complexes) can be appreciated. Finally, the reactivity of complexes with asymmetric trigonal planar ligands is located at the corresponding short $\mathrm{P}-\mathrm{M}$ bonds, which behave as polar double bonds with nucleophilic $\mathrm{P}$ and electrophilic $\mathrm{M}$ sites easily involved in addition and cycloaddition reactions. Simple ligand addition to the $M$ site induces a rearrangement of the phosphinidene ligand, from trigonal to pyramidal, which notably increases its basicity, an elemental step that might be present in many multistep reactions of these binuclear species. In all, the phosphinidene-bridged binuclear complexes have proved so far to induce, in a stoichiometric way, a large number of novel transformations, rearrangements, bond activations, formation of heterometallic clusters and metal-bound organophosphorus ligands. Future investigations will establish whether these binuclear species can also display catalytic activity in processes of interest. 
As the chemical behaviour of these species is strongly influenced by the nature of the metal atoms and their chemical environments, it will be also of future interest to examine the chemistry of phosphinidene complexes of transition metals and lanthanide elements not explored to date.

\section{Acknowledgements}

We thank the Ministerio de Economía y Competividad of Spain and the Consejería de Educación de Asturias for continuous financial support over the years to our work on phosphinidene-bridged complexes. A. R. acknowledges a postdoctoral contract funded by the "Plan Propio de I+D+i" of the Universidad de Castilla-La Mancha, co-funded by the Social European Fund.

\section{References}

[1] a) F.E. Hahn, M.C. Jahnke, Angew. Chem. Int. Ed. 47 (2008) 3122; b) G. Bertrand, Carbene Chemistry, Marcel Dekker, New York, 2002; c) D. Bourissou, O. Guerret, F.P. Gabbai, G. Bertrand, Chem. Rev. 100 (2000) 39.

[2] a) F. Mathey, Z. Duan, Dalton Trans. 45 (2016) 1804; b) H. Aktas, J.C. Slootweg, K. Lammertsma, Angew. Chem. Int. Ed. Engl. 49 (2010) 2102; c) R. Waterman, Dalton Trans. (2009) 18; d) J.C. Slootweg, K. Lammertsma, Sci. Synth. 42 (2009) 15; e) F. Mathey, Dalton Trans. (2007) 1861; f) K. Lammertsma, Top. Curr. Chem. 229 (2003) 95; g) K. Lammertsma, M.J.M. Vlaar, Eur. J. Org. Chem. (2002) 1127; h) F. Mathey, N.H.T. Huy, A. Marinetti, Helv. Chim. Acta 84 (2001) 2938; i) A.H. Cowley, Acc. Chem. Res. 30 (1997) 445; j) J. Ho, R. Rousseau, D.W. Stephan, Organometallics 13 (1994) 1918; k) A.H. Cowley, A.R. Barron, Acc. Chem. Res. 21 (1988) 81; 1) F. Mathey, Angew. Chem. Int. Ed. Engl. 26 (1987) 275.

[3] G. Huttner, K. Evertz, Acc. Chem. Res. 19 (1986) 406.

[4] a) T. Li, S. Kaercher, P.W. Roesky, Chem. Soc. Rev. 43 (2014) 42; b) D. García-Vivó, A. Ramos, M.A. Ruiz, Coord. Chem. Rev. 257 (2013) 2143; c) S. Greenberg, D.W. Stephan, Chem. Soc. Rev. 37 (2008) 1482; d) D.W. Stephan, Angew. Chem. Int. Ed. 39 (2000) 314; e) R.B. King, T.E. Bitterwolf, Coord. Chem. Rev. 206-207 (2000) 563; f) L. Weber, Chem. Rev. 92 (1992) 1839. [5] a) G. Huttner, J. Organomet. Chem. 308 (1986) C11; b) G. Huttner, J. Borm, L. Zsolnai, J. Organomet. Chem. 263 (1984) C33.

[6] A.M. Arif, A.H. Cowley, M. Pakulski, N.C. Norman, A.G. Orpen, Organometallics 6 (1987) 189. 
[7] a) A.M. Arif, A.H. Cowley, M. Pakulski, M.-A. Pearsall, W. Clegg, N.C. Norman, A.G. Orpen, J. Chem. Soc., Dalton Trans. (1988) 2713; b) A.M. Arif, A.H. Cowley, N.C. Norman, A.G. Orpen, M. Pakulski, Organometallics 7 (1988) 309.

[8] A.H. Cowley, D.M. Giolando, C.M. Nunn, M. Pakulski, D. Westmoreland, N.C. Norman, J. Chem. Soc., Dalton Trans. (1988) 2127.

[9] P. Jutzi, R. Kroos, J. Organomet. Chem. 390 (1990) 317.

[10] M. Scheer, E. Leiner, P. Kramkowski, M. Schiffer, G. Baum, Chem. Eur. J. 4 (1998) 1917.

[11] R.A. Barlett, H.V.R. Dias, K.M. Flynn, H. Hope, B.D. Murray, M.M. Olmstead, P.P. Power, J. Am. Chem. Soc. 109 (1987) 5693.

[12] N.A. Pushkarevsky, S.N. Konchenko, A.V. Virovets, M. Scheer, Organometallics 32 (2013) 770.

[13] U. Vogel, G. Stößer, M. Scheer, Angew. Chem. Int. Ed. 40 (2001) 1443.

[14] H. Lang, L. Zsolnai, G. Huttner, Angew. Chem. Int. Ed. Engl. 22 (1983) 1463.

[15] M. Scheer, U. Vogel, U. Becker, G. Balazs, P. Scheer, W. Hönle, M. Becker, M. Jansen, Eur. J. Inorg. Chem. (2005) 135.

[16] J. Sánchez-Nieves, B.T. Sterenberg, K.A. Udachin, A.J. Carty, J. Cluster Sci. 15 (2004) 151.

[17] J. Sánchez-Nieves, B.T. Sterenberg, K.A. Udachin, A.J. Carty, Can. J. Chem. 82 (2004) 1507.

[18] T.W. Graham, K.A. Udachin, A.J. Carty, Chem. Commun. (2005) 4441.

[19] T.W. Graham, K.A. Udachin, A.J. Carty, Inorg. Chim. Acta 360 (2007) 1376.

[20] a) J. Ho, R.J. Drake, D.W. Stephan, J. Am. Chem. Soc. 115 (1993) 3792; b) J. Ho, Z. Hou, R.J. Drake, D.W. Stephan, Organometallics 12 (1993) 3145.

[21] T.A. Bazhenova, A.V. Kulikov, A.F. Shestakov, A.E. Shilov, M.Y. Antipin, K.A. Lyssenko, Y.T. Struchkov, V.D. Makhaev, J. Am. Chem. Soc. 117 (1995) 12176.

[22] J. Ho, D.W. Stephan, Organometallics 10 (1991) 3001.

[23] R. Schmitt, PhD Thesis, Julius Maximilian University of Würzburg, 2005.

[24] J. Pikies, E. Baum, E. Matern, J. Chojnacki, R. Grubba, A. Robaszkiewicz, Chem. Commun. (2004) 2478.

[25] R. Grubba, A. Wisniewska, K. Baranowska, E. Matern, J. Pikies, Dalton Trans. 40 (2011) 2017.

[26] R. Grubba, K. Baranowska, D. Gudat, J. Pikies, Organometallics 30 (2011) 6655.

[27] P. Cui, Y. Chen, X. Xu, J. Sun, Chem. Commun. (2008) 5547.

[28] P. Cui, Y. Chen, M.V. Borzov, Dalton Trans. 39 (2010) 6886. 
[29] a) Y. Lv, C.E. Kefalidis, J. Zhou, L. Maron, X. Leng, Y. Chen, J. Am. Chem. Soc. 135 (2013) 14784; b) B.F. Wicker, J. Scott, J.G. Andino, X. Gao, H. Park, M. Pink, D.J. Mindiola, J. Am. Chem. Soc. 132 (2010) 3691.

[30] S. Blaurock, E. Hey-Hawkins, Eur. J. Inorg. Chem. (2002) 2975.

[31] S.B. Colbran, B.F.G. Johnson, J. Lewis, R.M. Sorrell, J. Organomet. Chem. 296 (1985) C1. [32] A.J. Deeming, S. Doherty, M.W. Day, K.I. Hardcastle, H. Minassian, J. Chem. Soc., Dalton Trans. (1991) 1273.

[33] a) U. Flörke, H.-J. Haupt, Acta Crystallogr. Sect. C: Cryst. Struct. Commun. 51 (1995) 573; b) H.J. Haupt, M. Schwefer, H. Egold, U. Flörke, Inorg. Chem. 34 (1995) 5461; c) H.J. Haupt, M. Schwefer, U. Flörke, Inorg. Chem. 34 (1995) 292; d) H.J. Haupt, M. Schwefer, U. Flörke, Z. Anorg. Allg. Chem. 621 (1995) 1098.

[34] U. Vogel, P. Sekar, R. Ahlrichs, U. Huniar, M. Scheer, Eur. J. Inorg. Chem. (2003) 1518.

[35] A.C. Colson, K.H. Whitmire, Organometallics 29 (2010) 4611.

[36] S.V. Maslennikov, D.S. Glueck, G.P.A. Yap, A.L. Rheingold, Organometallics 15 (1996) 2483.

[37] J.E. Davies, M.J. Mays, E.J. Pook, P.R. Raithby, P.K. Tompkin, J. Chem. Soc., Dalton Trans. (1997) 3283.

[38] T. Pugh, F. Tuna, L. Ungur, D. Collison, E.J.L. McInnes, L.F. Chibotaru, R.A. Layfield, Nat. Commun. 6 (2015) Article number: 7492.

[39] U.-A. Hirth, W. Malisch, J. Organomet. Chem. 439 (1992) C16.

[40] a) I.-P. Lorenz, W. Pohl, H. Nöth, M. Schmidt, J. Organomet. Chem. 475 (1994) 211; b) C. Klasen, G. Effinger, S. Schmid, I.-P. Lorenz, Z. Naturforsch., B: Chem. Sci. 48 (1993) 705.

[41] I.V. Kourkine, D.S. Glueck, Inorg. Chem. 36 (1997) 5160.

[42] a) M.A. Alvarez, M.E. García, R. González, A. Ramos, M.A. Ruiz, Organometallics 30 (2011) 1102; b) M.A. Alvarez, M.E. García, R. González, A. Ramos, M.A. Ruiz, Organometallics 29 (2010) 1875; c) C.M. Alvarez, M.A. Alvarez, M.E. García, R. González, M.A. Ruiz, H. Hamidov, J.C. Jeffery, Organometallics 24 (2005) 5503.

[43] A.T. Termaten, T. Nijbacker, A.W. Ehlers, M. Schakel, M. Lutz, A.L. Spek, M.L. McKee, K. Lammertsma, Chem. Eur. J. 10 (2004) 4063.

[44] G.A. Abdul Hadi, K. Fromm, S. Blaurock, S. Jelonek, E. Hey-Hawkins, Polyhedron 16 (1997) 721.

[45] T.L. Breen, D.W. Stephan, Organometallics 15 (1996) 4509.

[46] M.P. Shaver, M.D. Fryzuk, Organometallics 24 (2005) 1419. 
[47] J.D. Masuda, K.C. Jantunen, O.V. Ozerov, K.J.T. Noonan, D.P. Gates, B.L. Scott, J.L. Kiplinger, J. Am. Chem. Soc. 130 (2008) 2408.

[48] J. Zhou, T. Li, L. Maron, X. Leng, Y. Chen, Organometallics 34 (2015) 470.

[49] A.C. Behrle, L. Castro, L. Maron, J.R. Walensky, J. Am. Chem. Soc. 137 (2015) 14846.

[50] G. Bai, P. Wei, A.K. Das, D.W. Stephan, Dalton Trans. (2006) 1141.

[51] M.E. García, V. Riera, M.A. Ruiz, D. Sáez, J. Vaissermann, J.C. Jeffery, J. Am. Chem. Soc. 124 (2002) 14304.

[52] a) I. Amor, M.E. García, M.A. Ruiz, D. Sáez, H. Hamidov, J.C. Jeffery, Organometallics 25 (2006) 4857; b) M.E. García, V. Riera, M.A. Ruiz, D. Sáez, H. Hamidov, J.C. Jeffery, T. RiisJohannessen, J. Am. Chem. Soc. 125 (2003) 13044.

[53] I.G. Albuerne, M.A. Alvarez, M.E. García, D. García-Vivó, M.A. Ruiz, Inorg. Chem. 54 (2015) 9810.

[54] M.A. Alvarez, M.E. García, D. García-Vivó, A. Ramos, M.A. Ruiz, J. Suárez, Inorg. Chem. 51 (2012) 34 .

[55] a) M.A. Alvarez, I. Amor, M.E. García, D. García-Vivó, M.A. Ruiz, J. Suárez, Organometallics 31 (2012) 2749; b) M.A. Alvarez, M.E. García, M.A. Ruiz, J. Suárez, Angew. Chem. Int. Ed. Engl. 50 (2011) 6383.

[56] R. Waterman, T.D. Tilley, Chem. Sci. 2 (2011) 1320.

[57] M. Seidl, R. Weinzierl, A.Y. Timoshkin, M. Scheer, Chem. Eur. J. 22 (2016) 5484.

[58] A.-M. Hinke, A. Hinke, W. Kuchen, W. Hönle, Z. Naturforsch., B: Chem. Sci. 41 (1986) 629.

[59] J. Sánchez-Nieves, B.T. Sterenberg, K.A. Udachin, A.J. Carty, Inorg. Chim. Acta 350 (2003) 486.

[60] M. Di Vaira, P. Stoppioni, M. Peruzzini, Polyhedron 6 (1987) 351.

[61] M. Ehses, G. Schmitt, G. Wolmershäuser, O.J. Scherer, Z. Anorg. Allg. Chem. 625 (1999) 382.

[62] P. Sekar, M. Scheer, A. Voigt, R. Kirmse, Organometallics 18 (1999) 2833.

[63] I. Amor, D. García-Vivó, M.E. García, M.A. Ruiz, D. Sáez, H. Hamidov, J.C. Jeffery, Organometallics 26 (2007) 466.

[64] W.A. Herrmann, B. Koumbouris, E. Herdtweck, M.L. Ziegler, P. Weber, Chem. Ber. 120 (1987) 931.

[65] G. Huttner, H.-D. Müller, A. Frank, H. Lorenz, Angew. Chem. Int. Ed. Engl. 14 (1975) 705. [66] W. Malisch, U.-A. Hirth, T.A. Bright, H. Käb, T.S. Ertel, S. Hückmann, H. Bertagnolli, Angew. Chem. Int. Ed. Engl. 31 (1992) 1525.

[67] H. Lang, M. Winter, M. Leise, O. Walter, L. Zsolnai, J. Chem. Soc., Chem. Commun. (1994) 595. 
[68] H.-G. Ang, K.-W. Ang, S.-G. Ang, A.L. Rheingold, J. Chem. Soc., Dalton Trans. (1996) 3131.

[69] C.M. Alvarez, M.A. Alvarez, D. Garcia-Vivo, M.E. Garcia, M.A. Ruiz, D. Saez, L.R. Falvello, T. Soler, P. Herson, Dalton Trans. (2004) 4168.

[70] M. Driess, J. Aust, K. Merz, Eur. J. Inorg. Chem. (2002) 2961.

[71] M. Driess, J. Aust, K. Merz, Eur. J. Inorg. Chem. (2005) 866.

[72] K.F. Hirsekorn, A.S. Veige, P.T. Wolczanski, J. Am. Chem. Soc. 128 (2006) 2192.

[73] S. Takemoto, Y. Kimura, K. Kamikawa, H. Matsuzaka, Organometallics 27 (2008) 1780.

[74] B. Alvarez, M.A. Alvarez, I. Amor, M.E. García, M.A. Ruiz, Inorg. Chem. 50 (2011) 10561.

[75] B. Alvarez, M.A. Alvarez, M.E. García, M.A. Ruiz, Dalton Trans. 45 (2016) 1937.

[76] K. Pal, O.B. Hemming, B.M. Day, T. Pugh, D.J. Evans, R.A. Layfield, Angew. Chem. Int. Ed. 55 (2016) 1690.

[77] M.A. Alvarez, I. Amor, M.E. García, D. García-Vivó, M.A. Ruiz, D. Sáez, H. Hamidov, J.C. Jeffery, Inorg. Chim. Acta 424 (2015) 103.

[78] J. Borm, G. Huttner, L. Zsolnai, K. Evertz, H. Berke, J. Organomet. Chem. 327 (1987) 223.

[79] M.S. Davies, M.J. Aroney, I.E. Buys, T.W. Hambley, J.L. Calvert, Inorg. Chem. 34 (1995) 330.

[80] F.A. Cotton, D.J. Darensbourg, B.W.S. Kolthammer, Inorg. Chem. 20 (1981) 4440.

[81] K.M. Flynn, R.A. Bartlett, M.M. Olmstead, P.P. Power, Organometallics 5 (1986) 813.

[82] a) O. Tardif, M. Nishiura, Z. Hou, Tetrahedron 59 (2003) 10525; b) H. Schumann, E.

Palamidis, G. Schmid, R. Boese, Angew. Chem. Int. Ed. Engl. 25 (1986) 718.

[83] M.A. Alvarez, I. Amor, M.E. García, D. García-Vivó, M.A. Ruiz, J. Suárez, Organometallics 29 (2010) 4384.

[84] M.A. Alvarez, I. Amor, M.E. García, D. García-Vivó, M.A. Ruiz, Inorg. Chem. 46 (2007) 6230.

[85] M.A. Alvarez, M.E. Garcia, R. Gonzalez, M.A. Ruiz, Dalton Trans. 41 (2012) 14498.

[86] I.G. Albuerne, M.A. Alvarez, M.E. García, D. García-Vivó, M.A. Ruiz, Organometallics 32 (2013) 6178.

[87] M.A. Alvarez, M.E. García, D. García-Vivó, A. Ramos, M.A. Ruiz, Inorg. Chem. 51 (2012) 3698.

[88] a) M.A. Alvarez, M.E. García, R. González, M.A. Ruiz, Organometallics 32 (2013) 4601; b)

M.A. Alvarez, M.E. García, R. González, M.A. Ruiz, Organometallics 27 (2008) 1037.

[89] M.A. Alvarez, M.E. García, R. González, M.A. Ruiz, Organometallics 29 (2010) 5140.

[90] I.-P. Lorenz, P. Mürschel, W. Pohl, K. Polborn, Chem. Ber. 128 (1995) 413.

[91] M.A. Alvarez, M.E. García, R. González, A. Ramos, M.A. Ruiz, Inorg. Chem. 50 (2011) 7894. 
[92] a) Y.W. Li, M.G. Newton, R.B. King, Inorg. Chem. 32 (1993) 5720; b) R.B. King, N.K. Bhattacharyya, E.M. Holt, J. Organomet. Chem. 421 (1991) 247; c) R.B. King, F.J. Wu, E.M. Holt, J. Am. Chem. Soc. 110 (1988) 2775.

[93] R.B. King, J. Organomet. Chem. 557 (1998) 29.

[94] T.W. Graham, K.A. Udachin, A.J. Carty, Chem. Commun. (2006) 2699.

[95] M. Stubenhofer, C. Kuntz, M. Bodensteiner, A.Y. Timoshkin, M. Scheer, Organometallics 32 (2013) 3521.

[96] M. Stubenhofer, C. Kuntz, G. Balazs, M. Zabel, M. Scheer, Chem. Commun. (2009) 1745.

[97] M. Scheer, C. Kuntz, M. Stubenhofer, M. Zabel, A.Y. Timoshkin, Angew. Chem. Int. Ed. Engl. 49 (2010) 188.

[98] M. Stubenhofer, G. Lassandro, G. Balazs, A.Y. Timoshkin, M. Scheer, Chem. Commun. 48 (2012) 7262.

[99] W. Wang, Y.D. Lv, X.F. Gou, X.B. Leng, Y.F. Chen, Chin. J. Chem. 32 (2014) 752.

[100] M. Schiffer, M. Scheer, J. Chem. Soc., Dalton Trans. (2000) 2493.

[101] M. Schiffer, M. Scheer, Chem. Eur. J. 7 (2001) 1855.

[102] M. Schiffer, M. Scheer, Angew. Chem. Int. Ed. 40 (2001) 3413.

[103] M. Seidl, M. Schiffer, M. Bodensteiner, A.Y. Timoshkin, M. Scheer, Chem. Eur. J. 19 (2013) 13783.

[104] M. Seidl, C. Kuntz, M. Bodensteiner, A.Y. Timoshkin, M. Scheer, Angew. Chem. Int. Ed. 54 (2015) 2771.

[105] M. Seidl, G. Balázs, A.Y. Timoshkin, M. Scheer, Angew. Chem. Int. Ed. 55 (2016) 431.

[106] M. Scheer, D. Himmel, B.P. Johnson, C. Kuntz, M. Schiffer, Angew. Chem. Int. Ed. Engl. 46 (2007) 3971.

[107] a) M. Stubenhofer, C. Kuntz, M. Bodensteiner, U. Zenneck, M. Sierka, M. Scheer, Chem. Eur. J. 16 (2010) 7488; b) M. Scheer, C. Kuntz, M. Stubenhofer, M. Linseis, R.F. Winter, M. Sierka, Angew. Chem. Int. Ed. 48 (2009) 2600.

[108] M. Scheer, D. Himmel, C. Kuntz, S. Zhan, E. Leiner, Chem. Eur. J. 14 (2008) 9020.

[109] M. Schiffer, E. Leiner, M. Scheer, Eur. J. Inorg. Chem. (2001) 1661.

[110] U.-A. Hirth, W. Malisch, H. Käb, J. Organomet. Chem. 439 (1992) C20.

[111] B. Alvarez, M.A. Alvarez, I. Amor, M.E. García, D. García-Vivó, J. Suárez, M.A. Ruiz, Inorg. Chem. 51 (2012) 7810.

[112] a) B. Alvarez, M.A. Alvarez, I. Amor, M.E. Garcia, M.A. Ruiz, J. Suarez, Inorg. Chem. 53 (2014) 10325; b) M.A. Alvarez, I. Amor, M.E. García, M.A. Ruiz, Inorg. Chem. 47 (2008) 7963. 